NBER WORKING PAPER SERIES

\title{
REAL-TIME PRICE DISCOVERY IN STOCK, BOND AND FOREIGN EXCHANGE MARKETS
}

\author{
Torben G. Andersen \\ Tim Bollerslev \\ Francis X. Diebold \\ Clara Vega \\ Working Paper 11312 \\ http://www.nber.org/papers/w11312
}

\section{NATIONAL BUREAU OF ECONOMIC RESEARCH \\ 1050 Massachusetts Avenue \\ Cambridge, MA 02138}

May 2005

This work was supported by the National Science Foundation, the Guggenheim Foundation, and the BSI Gamma Foundation. For useful comments we thank seminar participants at the Bank for International Settlements, the 2003 BSI Gamma Conference, the 2004 Symposium of the European Central Bank / Center for Financial Studies Research Network, the October 2004 meeting of the NBER International Finance and Macroeconomics program, and the 2005 American Economic Association Annual Meeting, as well as Rui Albuquerque, Annika Alexius, Boragan Aruoba, Anirvan Banerji, Ben Bernanke, Robert Connolly, Jeffrey Frankel, Lingfeng Li, Richard Lyons, Marco Pagano, Paolo Pasquariello, and Neng Wang. The views expressed herein are those of the author(s) and do not necessarily reflect the views of the National Bureau of Economic Research.

(C2005 by Torben G. Andersen, Tim Bollerslev, Francis X. Diebold, and Clara Vega. All rights reserved. Short sections of text, not to exceed two paragraphs, may be quoted without explicit permission provided that full credit, including () notice, is given to the source. 
Real-Time Price Discovery in Stock, Bond and Foreign Exchange Markets

Torben G. Andersen, Tim Bollerslev, Francis X. Diebold, and Clara Vega

NBER Working Paper No. 11312

May 2005

JEL No. F3, F4, G1, C5

\begin{abstract}
We characterize the response of U.S., German and British stock, bond and foreign exchange markets to real-time U.S. macroeconomic news. Our analysis is based on a unique data set of high-frequency futures returns for each of the markets. We find that news surprises produce conditional mean jumps; hence high-frequency stock, bond and exchange rate dynamics are linked to fundamentals. The details of the linkages are particularly intriguing as regards equity markets. We show that equity markets react differently to the same news depending on the state of the U.S. economy, with bad news having a positive impact during expansions and the traditionally-expected negative impact during recessions. We rationalize this by temporal variation in the competing "cash flow" and "discount rate" effects for equity valuation. This finding also helps explain the apparent time-varying correlation between stock and bond returns, and the relatively small equity market news announcement effect when averaged across expansions and recessions. Hence, while our results confirm previous unconditional rankings suggesting that bond markets almost uniformly react most strongly to macroeconomic news, followed by foreign exchange and then equity markets, importantly when conditioning on the state of the economy the foreign exchange and equity markets appear equally responsive. Lastly, relying on the pronounced heteroskedasticity in the new high-frequency data, we also document important contemporaneous linkages across all markets and countries overand-above the direct news announcement effects.
\end{abstract}

Torben G. Andersen

Kellogg School of Management

Northwestern University

2001 Sheridan Road

Evanston, IL 60208

and NBER

t-andersen@kellogg.nwu.edu

Tim Bollerslev

Department of Economics

Duke University

Box 90097

Durham, NC 27708-0097

and NBER

boller@econ.duke.edu
Francis X. Diebold

Department of Economics

University of Pennsylvania

3718 Locust Walk

Philadelphia, PA 19104-6297

and NBER

fdiebold@sas.upenn.edu

Clara Vega

Department of Finance

University of Rochester

Rochester, NY 14627

vega@simon.rochester.edu 


\section{Introduction}

How do markets arrive at prices? There is perhaps no question more central to economics. This paper focuses on price formation in financial markets, where the question looms especially large: How, if at all, is news about macroeconomic fundamentals incorporated into stock prices, bond prices and foreign exchange rates?

Unfortunately the process of price discovery in financial markets remains poorly understood. Traditional "efficient markets" thinking suggests that asset prices should completely and instantaneously reflect movements in underlying fundamentals. Conversely, several prominent authors have recently gone so far as to assert that asset prices and fundamentals may be largely and routinely disconnected. Experiences such as the late 1990s U.S. technology-driven market bubble would seem to support that view, yet simultaneously it seems clear that financial market participants pay a great deal of attention to data on underlying economic fundamentals. The notable difficulty of empirically mapping the links between economic fundamentals and asset prices is indeed striking.

The central price-discovery question has many dimensions and nuances, including but not limited to the following. How quickly, and with what patterns, do adjustments to news occur? Does announcement timing matter? Are the magnitudes of effects similar for "good news" and "bad news," or, for example, do markets react more vigorously to bad news than to good news? Quite apart from the direct effect of news on assets prices, what is its effect on financial market volatility? Do the effects of news on prices and volatility vary across assets and countries, and what are the links? Are there readily identifiable herd behavior and/or contagion effects? Do news effects vary over the business cycle?

Just as the central question of price discovery has many dimensions and nuances, so too does a full answer. In this paper we progress by characterizing the simultaneous response of foreign exchange markets as well as the domestic and foreign stock and bond markets to real-time U.S. macroeconomic news. More precisely, we seek to better understand the links between asset prices and fundamentals by simultaneously combining: (1) high-quality and ultra-high frequency asset price data across markets and countries, which allows us to study price movements in (near) continuous time; (2) synchronized survey data on market participants' expectations, which allow us to infer "surprises" or "innovations" when news is announced; and (3) advances in statistical modeling of volatility, which facilitate efficient inference. By so doing, we can probe the workings of the marketplace in new and powerful ways, focusing on episodes where the source of price movements is well identified, leading to a high signal-to-noise ratio.

We proceed as follows. In Section 2 we provide background by situating our paper in the existing literature. In Section 3 we describe our data, and in Section 4 we present our new empirical 
findings. We conclude in section 5. In the Appendix we sketch a stylized multi-country monetary model that provides a simple theoretical benchmark and useful guidance for interpreting our empirical results.

\section{Background and Related Literature}

Our work speaks to three related but distinct literatures. The first examines the links between asset prices and macroeconomic fundamentals as embodied in news announcement effects, the second examines the links among domestic asset markets, and the third examines the link among various domestic and foreign asset markets. We set the stage by discussing selected aspects of each.

\section{Asset Prices and Macroeconomic Announcement Effects}

The literature contains many empirical studies seeking to link the effects of macroeconomic announcements to movements in stock, bond and foreign exchange returns. While the first generation studies relied on daily, or even weekly or monthly data, the more recent literature has moved toward the use of more finely-sampled intraday data. ${ }^{1}$ Typically, however, each market is examined in isolation. Recent examples include Fleming and Remolona (1997, 1999), Balduzzi, Elton and Green (2001), Bollerslev, Cai and Song (2000), Green (2004), Hautsch and Hess (2002), Kuttner (2001), Li and Engle (1998) who study bond markets; Bernanke and Kuttner (2005) and Kuttner (2004), Bomfim (2003), Boyd, Jagannathan and $\mathrm{Hu}$ (2005), Goto and Valkanov (2002), and Flannery and Protopapadakis (2002) who study equity markets; and Andersen and Bollerslev (1998), Andersen, Bollerselev, Diebold and Vega (henceforth ABDV, 2003), Almeida, Goodhart and Payne (1998), Chaboud, Chernenko, Howorka, Iyer, Liu and Wright (2004), and Galati and Ho (2003) who study foreign exchange markets. ${ }^{2}$

Most theories predict an unambiguous link between macroeconomic fundamentals and the bond market, with unexpected increases in real activity and inflation raising bond yields (lowering prices).

\footnotetext{
1 The first generation of exchange rate "news" studies focused primarily on money supply announcements. For example, Engel and Frankel (1984), Cornell (1983), Frankel and Hardouvelis (1985) and Tandon and Urich (1987) all associate positive U.S. money surprises with appreciations of the dollar and increases in nominal interest rates. Also, Ito and Roley (1987) find that across a set of U.S. and Japanese macroeconomic announcements, U.S. money announcements have the greatest impact. For a fine survey of this literature, see Frankel and Rose (1995). Similarly, the first generation of bond market "news" studies was primarily concerned with money supply announcements; e.g., Grossman (1981), Urich and Wachtel (1981), and Roley and Walsh (1985). The first generation of equity market "news" studies, as exemplified by Schwert (1981), Pearce and Roley (1985), Hardouvelis (1987), and Cutler, Poterba and Summers (1989), also report that with the possible exception of money supply figures, macroeconomic news announcements generally do not affect stock prices.

2 Two recent notable exceptions to this single market approach are Fair (2003) who examines the joint movements in stock, bond and foreign exchange markets around big market moves, typically associated with macroeconomic announcements, and Faust, Rogers, Wang and Wright (2003) who estimate the response of different maturity interest rates, exchange rates, and deviations from uncovered interest rate parity (UIP) to macroeconomic news.
} 
This is also in line with the stylized model sketched in the Appendix. Empirical analyses generally confirm the theoretical predictions. For example, Balduzzi, Elton and Green (2001) using 1990s data find that both positive real shocks and positive inflation shocks affect bond prices negatively and, moreover, that the absolute size of news effects generally increases with the maturity of the instrument.

The nature of the link between macroeconomic fundamentals and the stock market is less clear. Stock prices depend on expected cash flows, the discount rate, and the risk premium. Holding the risk premium constant, a positive macroeconomic shock increases expected cash flows, which increases the stock price, ceteris paribus, but it also increases the discount rate, which decreases the stock price, ceteris paribus, so the end result depends on which effect dominates. ${ }^{3}$ Again, these separate channels are readily identified within the stylized model in the Appendix.

Theory concerning news effects on foreign exchange markets generally predicts that good domestic news (e.g., brisk real activity, low inflation) strengthens the domestic currency, although an expected deterioration in the future terms of trade could have an opposing effect. As discussed for example in ABDV (2003), most existing empirical studies support this good news hypothesis, subject to subtleties such as announcement timing, sign effects and/or asymmetries.

\section{$\underline{\text { Within-Country Asset Markets Links }}$}

An extensive empirical literature has explored the relationship between stock and bond returns, but little consensus has emerged. For example, using a dynamic present value model and a long sample of annual U.S. data, Shiller and Beltratti (1992) report a strong positive correlation between stock and long-term bond prices, while Campbell and Ammer (1993) on employing a similar variance decomposition framework document a relatively low average correlation with a shorter and more recent sample of monthly stock and bond returns.

While these and many other related studies implicitly assume constancy of the covariance structures, much of the subsequent literature seeks to relax that constraint. ${ }^{4}$ Barsky (1989) shows theoretically, for example, that stock and bond comovement is in general state-dependent. This idea is supported by further theoretical arguments and related empirical evidence in Connolly, Stivers and Sun (2005), David and Veronesi (2004), Fleming, Kirby and Ostdiek (1998), Guidolin and Timmermann (2004, 2005), Li (2002), Ribeiro and Veronesi (2002), Rigobon and Sack (2003b, 2004), and Scruggs and

\footnotetext{
${ }^{3}$ See also the recent paper by Bernanke and Kuttner (2005), which decomposes the movements in daily and monthly equity prices around the times of FOMC meetings into a cash flow and a discount rate effect.

${ }^{4}$ Many of the recent developments in the burgeoning ARCH/GARCH literature have been explicitly concerned with modeling temporal dependencies in the correlations of asset returns; see, e.g., the discussion in Engle (2002).
} 
Glabadanidis (2003), among others.

Perhaps most directly related to the empirical results presented below is the recent work of Boyd, Jagannathan and $\mathrm{Hu}$ (2005) who argue for a time-varying stock-market effect of the employment report, with surprise increases in unemployment serving as "good news" during expansions and "bad news" during recessions. As previously noted, one explanation, which we subsequently discuss in detail, is that the cash flow effect dominates during contractions, while the discount rate effect is more important during expansions, thus resulting in positively correlated stock and bond price changes in expansions and lower, perhaps even negative, correlations during recessions. ${ }^{5}$ There are a couple of noteworthy precedents in the literature. In particular, Orphanides (1992) finds that the stock price response to employment news depends on the average unemployment rate during the previous year, hinting that the stock market reaction to employment news is state dependent. In a similar vein, McQueen and Roley (1993) report that daily stock prices respond asymmetrically to macroeconomic news across the business cycle, with equities reacting negatively to positive real economic news in good times and not reacting in any systematic direction to news in bad times. Our work improves on these studies by considering a much broader set of announcements and many more markets and asset classes. Importantly, the use of highfrequency intraday data dramatically improves the signal-to-noise ratio, allowing for more powerful tests and detailed estimation of news reaction functions and their interactions across asset categories.

\section{Cross-Country Asset Market Links}

A number of studies have focused on the transmission of information across international equity markets. Early empirical papers include Hamao, Masulis and Ng (1990) who examine spillover effects in the returns and volatilities of daily price changes for the Japanese, U.K., and U.S. equity markets, along with Lin, Engle and Ito (1994) who employ a similar GARCH-based approach but finer sampled data. Generally, only weak evidence of transmission from the U.S. to other markets, and none the other way around, has been found, although "contagion" effects, or increased correlations, have been documented during periods of financial crises such as the 1987 crash; e.g., King and Wadhwani (1990). ${ }^{6}$

More specifically, using a sample of five-years of high-frequency data, Becker, Finnerty and Friedman (1995) relate the U.S. - U.K. equity market linkages to the reactions of foreign traders to public

\footnotetext{
5 In contrast to our state independent bond market reaction to news, Boyd, Jagannathan and Hu (2005) find that the U.S. bond market reacts significantly and positively to unemployment news during expansions, while the reaction appears insignificant during recessions.

6 A recent literature has argued for the existence of even more pronounced "contagion" effects in developed stock markets during periods of financial crises. However, as forcefully demonstrated by Forbes and Rigobon (2004), these results need to be carefully interpreted when the overall level of volatility is also changing through time.
} 
information originating from the U.S. ${ }^{7}$ In a related context, Connolly and Wang (2003) analyze U.S., U.K. and Japanese equity markets and separate the influence of the foreign markets on domestic markets into two components: one driven primarily by economic fundamentals and the other, a so-called contagion factor, by foreign market returns. They conclude that the macro news effect is statistically significant but too small to account for any sizeable part of the return comovement among these markets.

Less work has been done on cross-country bond market linkages. However, recent results by Ehrmann and Fratzscher (2003), who model the degree of interdependence between the U.S. and European bond markets, suggest that the linkage between the markets has gradually increased, with the spillover effects from the U.S. to the Euro area being somewhat stronger than in the opposite direction. In addition, Christie-David, Chaudhry and Khan (2002) and Goldberg and Leonard (2003) demonstrate significant international bond market movement in response to the release of U.S. macroeconomic news.

Different exchange rates for the same currency are, of course, naturally linked through their joint dependence on the same underlying fundamental economic influences. Several papers have studied the dynamic dependencies in the correlations among exchange rates as well as inter-market dependencies in the volatilities of different rates within the same day. For instance, Engle, Ito and Lin $(1990,1992)$ report strong evidence of volatility spillovers, or "meteor shower" effects, from the U.S. to the Japanese, to the European, to the U.S. trading areas, but little, or no, evidence of area specific "heat wave" effects.

Set against this backdrop, we now discuss the data used in our work addressing the questions: How do U.S. macroeconomic fundamentals affect foreign exchange rates, domestic and foreign bond and stock prices, and asset return comovements, and do these effects vary across the business cycle?

\section{High-Frequency Return and News Announcement Data}

We explore the impact of twenty-five U.S. macroeconomic news announcements using highfrequency futures returns for foreign exchange, stock and bond markets. We begin by discussing the data sources and salient features of the returns data.

\section{Futures Market Return Data}

We use futures market data for several reasons. First, futures prices are readily available on a tick-by-tick basis. Second, most significant U.S. macroeconomic announcements are released at 8:30 Eastern Standard Time (EST) when the futures markets are open, but the equity markets closed. Third, transaction costs are lower in the futures markets, and the contracts we analyze are very actively traded.

\footnotetext{
${ }^{7}$ Using high-frequency data from 1995 to 2000, Wongswan (2003) also finds evidence of macroeconomic news announcements in Japan and the U.S. affecting the Korean and Thai equity markets.
} 
Indeed, numerous studies find that futures markets tend to lead cash markets in terms of price discovery. ${ }^{8}$ This is truly important as we focus on price adjustments measured over very short time intervals.

Table 1 provides an overview of the specific contracts, the exchanges on which they trade, and their EST trading hours, along with the average number of contracts traded daily. The S\&P500, \$/Pound, $\$ /$ Yen and \$/Euro futures contracts are listed on the Chicago Mercantile Exchange (CME). ${ }^{9}$ Trading in the foreign exchange contracts starts at 8:20 EST, while the regular trading hours for S\&P500 are 9:30 to 16:15 EST. Starting January 2, 1994, however, GLOBEX has offered automated pre-market trading in the S\&P500 futures contract, and we use transactions data from this market to augment the trading day for S\&P500 to 8:20 EST. Our data for the 30-Year U.S. Treasury Bond futures contract comes from the Chicago Board of Trade (CBOT) whose trading hours coincide with those of the CME. The FTSE 100 and the British Long Gilt futures contracts trade on the London International Financial Futures Exchange (LIFFE). The FTSE 100 index is based on the one-hundred largest U.K. companies, while the Long Gilt contract is based on the British 10-Year Treasury note. Trading on LIFFE opens at 8:00 GMT, or 3:00 EST. Our last two contracts, the DJ Euro Stoxx 50 (DJE) and the Euro Bobl futures, both trade on the European Exchange (EUREX). The DJE index is composed of the fifty largest blue-chip market sector leaders in the Euro-zone countries. The Euro Bobl is based on the German 5-Year Treasury note.

We obtained raw tick-by-tick transaction prices for all contracts from Tick Data Inc. The sample for the foreign exchange rates and the U.S. Treasury Bond contracts spans January 2, 1992 through December 31, 2002. Because of the need for pre-market GLOBEX data to augment the trading day, our sample for the S\&P500 starts two years later on January 2, 1994. Data on the four European contracts are only available from July 1, 1998 through December 31, 2002.

All results reported below are based on five-minute local currency continuously compounded returns, $\log \left(p_{t} / p_{t-1}\right)$, where $p_{t}$ denotes the price of the last trade in the $t^{\prime}$ th five-minute interval. ${ }^{10}$ If no trade occurs in a given five-minute interval, we use the price from the previous interval, as long as the previous price was quoted within the last half-hour. We include only the days where there were at least

\footnotetext{
${ }^{8}$ See, for example, Hasbrouck (2003).

${ }^{9}$ The returns for the $\$$ /Euro are based on the $\$ / \mathrm{DM}$ contract prior to June 1, 1999. Both contracts traded actively before and after this date, but the liquidity started to switch from the $\$ / D M$ to the $\$ /$ Euro around that time.

${ }^{10}$ Five-minute returns strike a reasonable balance between confounding market microstructure effects when sampling too frequently and blurring the specific price reactions when disaggregating to coarser time intervals; see e.g., the related discussions in ABDV (2003), Bandi and Russell (2003), Dacorogna et al. (2001), Hansen and Lunde (2004), and Aït-Sahalia, Mykland and Zhang (2005) among others.
} 
one trade every half-hour. We always use the most actively traded nearest-to-maturity contract, switching to the next-maturity contract five days before expiration.

\section{Basic Description of High-Frequency Returns around Macroeconomic News Announcements}

Table 2 reports summary statistics for the five-minute return series around the announcement times. Since our news announcement regressions are based on the period ranging from ten minutes before to one-and-a-half hours after an announcement, we let the sample cover this set of returns only. Moreover, to provide a meaningful benchmark for the subsequent results based on simultaneous estimation across all the markets we further restrict the sample for all contracts to the July 1, 1998 to December 31, 2002, period available for the shortest series, namely the European markets.

The average five-minute returns for each of the nine markets are, as expected, extremely close to zero. However, the (absolute) size of the largest five-minute returns is noteworthy, with the extreme return event being about ten standard deviations or more removed from the sample mean for all markets. For the S\&P500 and the DJE these extreme moves exceed two percent. This immediately suggests that the macroeconomic announcements do move the markets. ${ }^{11}$ The summary statistics confirm the usual rank ordering in terms of volatility, with the stock markets being the most volatile, followed by the foreign exchange rates, and then the fixed income markets. The only exception to this rule is the U.S. TBond market, for which the unconditional return standard deviation actually exceeds the standard deviations for the three exchange rates. This is likely a consequence of the fact that the T-Bond market, as discussed further below, is the market reacting most strongly to macroeconomic announcements.

To provide a sense of the comovements among the asset markets during announcement times, Table 3 reports the unconditional sample correlations. All correlations within each of the three asset classes are positive. For instance, the stock market correlations range from a low of 0.42 between the S\&P500 and the FTSE 100, to a high of 0.54 for the FTSE 100 and the DJE. Similarly, the correlation between the returns for the U.S. T-Bond and the British Long Gilt is 0.53, while the Gilt and German Euro Bobl correlation is 0.61 . The positive cross bond market correlations during U.S. macroeconomic announcement times are directly in line with most theoretical predictions including the implications from the basic Lucas (1982) model discussed in the Appendix. Even if domestic and foreign real activity and monetary shocks are uncorrelated, the frictionless setting produces a highly integrated bond market in that

\footnotetext{
11 This is consistent with Fair (2002), who finds most large moves in high-frequency S\&P500 returns to be readily identified with U.S. macroeconomic news announcements. Similar results for the DM/\$ foreign exchange and U.S. T-Bond markets are reported in Andersen and Bollerslev (1998) and Bollerslev, Cai and Song (2000), respectively.
} 
model. ${ }^{12}$ The positive equity market cross-correlations are also consistent with the model although they are not directly implied by it as three separate influences determine the equity prices: the risk-free interest rate, expected future cash flows and the equity risk premium. Stock market prices around the world would tend to be positively correlated if the discount rate is the dominant effect or if the domestic and foreign real output and/or monetary shocks are positively correlated. ${ }^{13}$

The cross correlations between the different asset types are generally much smaller than the cross correlations within the same asset category across countries. Given our exchange rate convention, all quoted in American terms or \$/Euro, \$/Pound and \$/yen, the negative correlations between the S\&P500 and the exchange rates imply that U.S. macroeconomic news affect the Dollar and the equity market in the same direction. Interestingly, a Dollar appreciation also is associated with stock market increases abroad, even though one may expect the Dollar to depreciate against the Pound (Euro) when the FTSE 100 (DJE) prices are rising. This again suggests that the U.S. macroeconomic fundamentals exert a dominant effect during the announcement period. It also serves as a warning that it may be important to explicitly control for the macroeconomic fundamentals when interpreting the asset market correlations. We attempt to do exactly that within a simultaneous equation setting explored later on.

One primary question of interest is whether the interactions between the asset categories and their responses to macroeconomic fundamentals vary systematically across the business cycle. For a preliminary look at this issue, the bottom panels in Table 3 report the unconditional correlations separately for the expansion period from July 1998 through February 2001 and the recession period from March 2001 through December 2002. ${ }^{14}$ The correlations are generally higher during the recession period. Most notably, however, there is a distinct change in the stock-bond market correlations. During the expansion, the stock-bond correlations are positive albeit small, whereas they are strong and negative

12 The bond market positive correlation is also consistent with the U.S. interest rate effectively serving as the "world interest rate," as assumed in numerous theoretical models; see also Blanchard and Summers (1984) and the more recent discussion in Chinn and Frankel (2003).

13 Although the high positive contemporaneous correlation across countries may be explained by the common bond market response to U.S. macroeconomic news, a number of other influences, including market microstructure, contagion, and cross-market hedging effects, as discussed for example in Fleming, Kirby and Ostdiek (1998), could also account for the high-frequency correlations. It is generally difficult to identify the effects separately, but in the empirical analysis below we attempt to identify the impact of news directly by measuring the surprise components.

14 We define recessions as beginning when there are three consecutive monthly declines in nonfarm payroll employment, and ending when there are three consecutive monthly increases in nonfarm payroll employment. Recessionary periods so-determined match closely those designated by the NBER over the postwar period. The recession dates in our sample, moreover, remain unchanged if we adopt an alternative criterion of three consecutive monthly declines in industrial production. 
during the recession. We cannot claim this as a general pattern, as we only have data for one expansion and one recession. Still, in the context of the stylized framework presented in the Appendix, one possible explanation is that the discount effect dominates in expansions, whereas the cash flow effect dominates during recessions. Hence, stock and bond returns will be negatively correlated during recessions, as the prices respond to news in opposite directions. Similarly, while the correlations between bonds and exchange rates are positive on average, the correlations are much larger for the recession period. This may again be explained by time-variation in the impact of changes in macroeconomic fundamentals across the business cycle. These conjectures are tested more thoroughly in the empirical section below. $\underline{\text { News Announcement Data }}$

We use the International Money Market Services (MMS) real-time data on expected and realized U.S. macroeconomic fundamentals, defining "news" as the difference between the survey expectations and the subsequent realizations, or announcements. The MMS sample covers the period from January 1, 1992 through December 31, 2002. Table 4 provides a basic description of the announcement releases, including the number of observations, the agency reporting the news, and the time of the release. ${ }^{15}$

The units of measurement obviously differ across the announcements. Hence, to allow for meaningful comparisons of the estimated news response coefficients across announcement types and asset classes, we follow ABDV (2003) and Balduzzi, Elton and Green (2001) in the use of "standardized news." Specifically, we divide the surprise by its sample standard deviation, defining the standardized news associated with indicator $k$ at time $t$ as

$$
S_{k t}=\frac{A_{k t}-E_{k t}}{\hat{\sigma}_{k}},
$$

where $A_{k t}$ denotes the announced value of indicator $k, E_{k t}$ refers to the market's expectation of indicator $k$ as distilled in the MMS median forecast, and $\hat{\sigma}_{k}$ is equal to the sample standard deviation of the surprise component, $A_{k t}-E_{k t}$. Because $\hat{\sigma}_{k}$ is constant for any indicator $k$, this standardization affects neither the statistical significance of the estimated response coefficients nor the fit of the regressions compared to the results based on the "raw" surprises.

We now turn to a discussion of our high-frequency estimation results based on the abovedescribed news announcement indicators.

${ }^{15}$ With the exception of the money supply figures, which are released at 16:30 EST after the futures markets have closed, the indicators listed in Table 4 include all regularly-scheduled major U.S. macroeconomic announcements. For a detailed description, including a discussion of the properties of the median expectations, see ABDV (2003). 


\section{Empirical Results}

This section characterizes both the impact and dynamic effects of U.S. macroeconomic announcements for each of the markets in Table 1. In addition to estimating average responses across the full sample, we also investigate the magnitude of the effects and the strength of the cross market linkages separately in expansions and recessions. Finally, we explore the relationships across the markets in a more structural fashion by casting the system in a simultaneous equation setting that explicitly controls for the impact of the macroeconomic announcements, thus allowing for an analysis of the linkages overand-above the impact driven by the news releases.

Impact Effects of News

We initially focus directly on the importance of news at the time of the announcements, so we first estimate the following simple regression model,

$$
R_{t}^{h}=\alpha_{k}^{h}+\beta_{k}^{h} S_{k t}+\epsilon_{t}^{h}
$$

where $R_{t}^{h}=\log \left(p_{t}{ }^{h} / p_{t-1}^{h}\right)$ denotes the five-minute futures return corresponding to asset $h(h=\$ / \mathrm{BP}$, $\$ /$ Yen, $\$$ /Euro, S\&P500, T-Bond, Gilt, Bobl, FTSE, and DJE) from time $t$ to time $t+1, S_{k t}$ refers to the standardized news for announcement $k(k=1, \ldots, 25)$ at time $t$, and the estimates are based on only those observations $\left(R_{t}^{h}, S_{k t}\right)$ where an announcement was made at time $t$. Full-sample regression results are reported in Table 5A, while separate estimates for expansion and recession periods are given in Tables 5B and $5 \mathrm{C}$. Following the discussion in the previous section, we define the expansion period from the beginning of each sample until February 28, 2001, while the recession period extends from March 1, 2001 until the end of our sample, or December 31, 2002. ${ }^{16}$

The results in the first three sets of columns in Table 5A show that many news announcements exert significant influence over the currency futures returns. ${ }^{17}$ The point estimates accord well with the

\footnotetext{
${ }^{16}$ Because high-frequency data for the U.S. markets (\$/Pound, \$/Yen, \$/Euro, T-Bond, and S\&P500) are available over a longer time span, the results and statistical significance of the estimated coefficients for the full and expansion samples are not directly comparable to those for the European markets (Gilt, Bobl, FTSE 100, and DJE).

${ }^{17}$ Even though many of the response coefficients are highly statistically significant, the explained variation for the five-minute returns, as measures by the regression $R^{26} \mathrm{~s}$, remain fairly low, and would obviously be minuscule over daily or longer horizons. This is, of course, not surprising as the regressions reflect the response to publicly available information. In contrast, recent intriguing studies pertaining to the predictive content in non-public order flow information have reported substantially higher $R^{26}$ s over longer horizons; see, e.g., Evans and Lyons (2005).
} 
earlier findings in ABDV (2003) based on spot currency returns over a different sample period. The directional effects are generally consistent with the implications of the standard monetary approach to exchange rate determination as discussed in the Appendix. A comparison of the results in Table 5A to those of Tables 5B and 5C reveals no qualitative difference between the overall response coefficients for the exchange rates and those estimated separately for the expansion and contraction samples.

The next six sets of columns provide results for the domestic and foreign stock and bond markets. Consider first the bond returns. Consistent with the findings in the existing literature, U.S. T-Bond prices respond very significantly to U.S. macroeconomic news. Many of the coefficient estimates for the Gilt and the Bobl are also highly significant and of the same sign as for the T-Bond market. This is again directly in line with the implications from the simple two-country monetary model in the Appendix. Comparing the full-sample estimates across the different markets, the effects of news on bond returns appear noticeably stronger than for any of the other markets. As for currencies, splitting the sample into expansion and recession does not materially affect the estimated response coefficients.

Now consider the results for the stock markets. The full-sample estimates in Table 5A suggest that equity returns are considerably less sensitive to macroeconomic news announcements than bond returns. Equally noteworthy is the direction of the responses. The S\&P500 generally reacts negatively to positive domestic real shocks (employment and new home sales). The significant impact of innovations in foreign trade (net exports) or inflation and interest rates (PPI, CPI, fed funds rate) accords better with standard intuition. The weak stock market reaction to real economic news is, of course, consistent with the presence of opposing effects across the business cycle, to which we have already alluded.

Indeed, separating the data into the expansion and recession periods in Tables $5 \mathrm{~B}$ and $5 \mathrm{C}$ reveals a very different story: for all stock markets, U.S. as well as foreign, the U.S. macroeconomic news releases have statistically significant and economically important effects. However, the impact switches sign with the business cycle. Consequently, news effects look weak when averaged across regimes, even though the within-regime effects are very strong. In particular, "good" news on real activity raises stock prices during recessions, but lowers prices during expansions; that is "good news" is "bad news" for stocks in expansions. Hence, the discount rate effect dominates during economic expansions, as the Federal Reserve is more likely to tighten monetary policy to ward off inflation in response to good news, while the cash flow effect dominates during economic contractions, when the central bank is less concerned about inflation and real output may respond more vigorously to demand shocks as capacity utilization is lower. This interpretation is further supported by the strong and significant negative effect that inflationary shocks (positive PPI and CPI surprises) have on the stock markets during the expansion period, while these same inflationary shocks turn insignificant for the recession sample. This, of course, 
also helps explain why previous studies typically have been unable to detect any strong linkages between the stock market and macroeconomic fundamentals when estimated over long historical samples. ${ }^{18}$

\section{Dynamic Effects of News}

In order to analyze the dynamic news effects in more depth, we also estimate a system of equations using the two five-minute returns directly preceding and the eighteen five-minute returns following each announcement. ${ }^{19}$ This requires data to be available for all markets simultaneously, so these results are based on the shorter common sample from July 1, 1998 through December 31, 2002, with the expansion and recession periods based on the observations before and after February 28, 2001, respectively. ${ }^{20}$ All-in-all, this leaves us with a full sample of $T=15,764=544 \times 20+40 \times 29+98 \times 38$ five-minute return observations, reflecting 544 days with only one macroeconomic announcement released on that day (20 observations per day), 40 days with two announcements, one at 8:30 EST and the other one at 9:15 EST (29 observations per day), and 98 days with two announcements, one at 8:30 EST and the other at 10:00 EST (38 observations per day). The expansion sample is comprised of the first 9,301 observations, while the last 6,463 observations constitute the recession sample.

To allow explicitly for cross-market linkages and dynamic announcement effects, we model the conditional mean of the five-minute return for asset $h, R_{t}{ }^{h}$, as a linear function of $I$ lags of all the returns, together with $J$ lags of each of the $K$ news announcements; that is,

$$
R_{t}^{h}=\beta_{0}^{h}+\sum_{h^{\prime}=1}^{H} \sum_{i=1}^{I} \beta_{h i}^{h^{\prime}} R_{t-i}^{h^{\prime}}+\sum_{k=1}^{K} \sum_{j=0}^{J} \beta_{k j}^{h} S_{k, t-j}+\varepsilon_{t}^{h}, \quad t=1, \ldots, T,
$$

where $H=9$ corresponds to the nine different assets. Because the consumer credit, government budget, and federal funds rate figures are released in the afternoon, when LIFFE and EUREX are closed, we "only" have a total of $K=22$ announcements. Guided by the Schwarz and Akaike information criteria, we uniformly fix the two lag lengths at $I=2$ and $J=3$, resulting in a total of 107 regression coefficients to be

\footnotetext{
18 As mentioned before, McQueen and Roley (1993) is an exception. Our broader coverage of announcements and asset markets as well as the inherently more powerful tests provided by intraday data strengthen their conclusions, add several new findings, and show, contrary to McQueen and Roley (1993), that the announcement effects are highly significant in recessions as well but, of course, with opposite signs relative to the expansion period.

19 Hence the post-announcement window is one and one-half hours. Some preliminary experimentation revealed that our chosen pre- and post-event windows were more than adequate to capture the systematic news responses.

20 As such, the full and expansion sample point estimates for the U.S. markets are not directly comparable to those reported in Tables 5A and 5B.
} 
estimated for each of the nine assets.

Although ordinary least squares (OLS) would be consistent for the parameters in (4.2), the disturbance terms for the five-minute return regressions are clearly heteroskedastic. Thus, to enhance the efficiency of the coefficient estimates, we use a two-step weighted least squares (WLS) procedure. We first estimate the conditional mean model by OLS. We then use the absolute value of the regression residuals, $\left|\hat{\varepsilon}_{t}^{h}\right|$, to estimate a time-varying volatility function, which we then subsequently use to perform weighted least squares estimation of (4.2). We approximate the temporal variation in the five-minute return volatility around the announcement times by the relatively simple regression model,

$$
\left|\hat{\varepsilon}_{t}^{h}\right|=\sum_{i=1}^{I^{\prime}} \beta_{h i}\left|\hat{\varepsilon}_{t-i}^{h}\right|+\sum_{d=1}^{D} \gamma_{d} D_{d}+\sum_{k=1}^{K_{d}} \sum_{j^{\prime}=0}^{J^{\prime}} \gamma_{k j^{\prime}}^{h} D_{k, t-j^{\prime}}+u_{t}^{h}
$$

The $I^{\prime}=9$ own lags of the absolute value of the residuals captures serial correlation, or ARCH effects.

The next term involves $D=38$ dummy variables for each of the five-minute intraday intervals. This term directly accounts for the well-documented intradaily volatility patterns; see, e.g., the discussion and references in Andersen and Bollerslev (1998). The last summation reflects dummy variables for each of the announcement surprises, $D_{k, t}$, up to a lag length of $J^{\prime}=14$. There are only $K_{d}=20$ such dummies as capital utilization and industrial production, and personal consumption expenditures and personal income are announced at the same time. ${ }^{21}$

Because the model in (4.2) contains so many variables and lags, it is counterproductive to report all the parameter estimates. ${ }^{22}$ Instead, in Figures 1A-1C, we present graphically the point estimates for the news response coefficients, $\beta_{k j}^{h}, j=0, \ldots, 3$, for some key indicators at the time of the news releases and fifteen-minutes thereafter (dots), along with corresponding robust ninety-percent confidence bands (dashes). Figure 1A covers the full sample, while the results for the expansion and recession periods appear in Figures 1B and 1C. All figures contain three panels; the first displays the news responses for

\footnotetext{
${ }^{21}$ We also experimented with other lag lengths and alternative volatility specifications, directly including the absolute value of the surprise component, $\left|S_{k, t}\right|$, instead of the news announcement dummies, $D_{k, t}$. However, the fit was generally best for the model in equation (4.3), although the corresponding estimates for the mean parameters in (4.2) were essentially unchanged. This is consistent with the earlier empirical results for the spot foreign exchange market in ABDV (2003) that the mere presence of an announcement, quite apart from the size of the corresponding surprise, tend to boost volatility; see also the discussion in Rich and Tracy (2003).

${ }^{22}$ Details regarding the parameter estimates, including those of equation (4.3), are available upon request.
} 
the domestic and foreign bond markets, the second focuses on the foreign exchange markets, and the last reports the results for the domestic and foreign equity markets.

Consider first the bond market responses. The immediate reactions are qualitatively similar to those discussed earlier for the U.S. T-bond market over the longer eleven-year sample. Regardless of the stage of the business cycle, positive real shocks and inflationary shocks produce lower bond prices, or higher yields. Not surprisingly, the effects are clearly the strongest in the U.S., but many of the U.S. macroeconomic fundamentals also significantly impact the foreign bond markets, and in the same direction. This is, of course, consistent with basic theoretical predictions. It is noteworthy that, almost invariably, only the simultaneous effect is significant, reflecting a very quick price discovery process.

The near instantaneous response holds true for all markets. Any systematic effect is almost exclusively restricted to the five-minute interval following the news release. This helps explain why previous studies relying on daily, or coarser, observations typically have failed to uncover systematic linkages between asset market returns and innovations to macroeconomic fundamentals - the responses occur almost instantaneously and tend to "drown" in the overall day-to-day price movements. Hence, the only way to assess the connection between the news releases and the asset prices with some degree of precision is to focus on the high-frequency returns just around the announcement time.

Turning to the foreign exchange market results, the immediate impact is again directly in line with the point estimates from the simultaneous regressions reported in Table 5A. ${ }^{23}$ News about the U.S. inflation rate do not seem to systematically affect the foreign exchange rates, while positive domestic real shocks lead to an appreciation of the Dollar, particularly during the recent recession regime.

The findings for the equity markets are again striking. The full-sample results in Figure 1A reveal almost no significant responses, but once we split the sample into the expansion and recession periods, we see that positive real economic shocks are met with a negative response in expansions and a positive response in recessions. As discussed previously, this pattern, which is identical for the domestic and foreign markets, is suggestive of positively correlated real economic shocks across the regions along with pronounced business cycle variation in the importance of the discount factor versus cash flow components in the markets' valuation of equities. This is further corroborated by the asymmetric effect of the PPI shocks over the business cycle. The marked negative impact of inflation surprises during expansions suggests the presence of stronger anti-inflationary monetary policies, in turn strengthening the influence of the discount factor component in "good" economic times.

\footnotetext{
${ }^{23}$ The somewhat weaker statistical significance in Figure 1A is due to the shorter sample size. Although a few lagged response coefficients are outside the confidence bands in Figure 1A, the effects do not appear systematic.
} 


\section{$\underline{\text { A Closer Look at Stock-Bond Correlations }}$}

The apparent state dependence in the equity markets news reaction function coupled with the time-invariant reaction of the bond markets naturally translates into state dependent stock-bond market correlations, with price changes being positively correlated during expansions and negatively correlated during recessions. Indeed, the unconditional sample correlations for the expansion and recession periods discussed in Table 3 already point to the existence of time-varying cross-market dependencies. In order to explore this effect in more detail, we display in Figure 2A the daily realized correlations in each country computed from the high-frequency stock-bond market returns for the days containing the arguably most important U.S. macroeconomic announcement, namely the nonfarm payroll employment release. ${ }^{24}$ Figure 2B depicts the corresponding realized correlations over the entire month, which aids assessment of whether the correlation patterns are driven by the macroeconomic news releases or whether they simply indicate the general relationship among the markets. The computations follow the methodology described in Andersen, Bollerslev, Diebold and Labys (2001, 2003). To facilitate cross country comparisons, we restrict the calculations to encompass the common trading hours from 8:20 to 12:30 EST, resulting in a total of 515 -minute intervals per day and approximately $51 \times 22=1,1225$ minute observations per month. Specifically, we define

$$
\operatorname{corr}_{d}^{h, h^{\prime}} \equiv \frac{\sum_{j=1}^{J} R_{d-1+j / J}^{h} R_{d-1+j / J}^{h^{\prime}}}{\left(\sum_{j=1}^{J}\left(R_{d-1+j / J}^{h}\right)^{2} \sum_{j=1}^{J}\left(R_{d-1+j / J}^{h^{\prime}}\right)^{2}\right)^{1 / 2}}
$$

where $J=51(J \approx 1122)$ for the daily (monthly) correlations, and $d$ refers to the corresponding daily (monthly) index. ${ }^{25}$

Turning to the two figures, the time varying stock-bond correlations are remarkably similar across countries, not only for the nonfarm payroll announcement dates (Figure 2A), but also when calculated for the full month (Figure 2B). The correlations are generally higher and mostly positive during the expansion period and smaller and negative during the recession period. Interestingly, there is also an

\footnotetext{
24 The nonfarm payroll is among the most significant of the announcements for all of the markets, and it is often referred to as the "king" of announcements by market participants; see, e.g., Andersen and Bollerslev (1998).

${ }^{25}$ We also tried adjusting for non-synchronous trading effects by including up to three additional leads and lags in a Newey-West calculation of the correlations, and the results were qualitatively identical.
} 
indication that the correlations may evolve smoothly rather and shift somewhat slowly from the values typical of the expansion to the values more representative of the recession. Moreover, there is a noticeable drop just around August and September 0f 1998. This corresponds to the Russian debt default crises and the Long Term Capital Management (LTCM) hedge fund collapse, where the Federal Reserve actively intervened to avoid spill-overs into the global capital markets. This episode is well known to have increased credit spreads on risky securities worldwide. The burst of uncertainty regarding the financial and economic health of the international economy is clearly reflected in our correlation measures as they take on a pattern otherwise only observed during the recession. Our European series are somewhat contaminated by this event as they only are observed from July, 1998, and forward. Ignoring the immediate aftermath of the financial crisis in late 1998, the switch in the sign of the correlations matches almost perfectly the previously exogenously imposed U.S. business cycle regime.

The robustness of these results are, of course, limited to the relatively short calender time span and single U.S. expansion-recession period covered by the high-frequency data. ${ }^{26}$ Nonetheless, it is noteworthy that even though the German and British's business cycles do not necessarily coincide with the U.S. business cycle, ${ }^{27}$ it appears as though the relevant state variable for determining the time-varying impact of the news announcements is the state of the U.S. economy rather than the foreign country. Indeed, the patterns in the time-varying correlations are entirely consistent with our previous assertion that the "discount rate" effect dominates the price movements for each of the three stock markets during U.S. economic expansions, coupled with the U.S. interest rate playing the role of the "world interest rate" and hence dictating the move of the foreign bond markets. ${ }^{28}$

The tentative interpretation of the concurrent stock-bond correlation as a time-varying (continuously evolving) measure of the phase of the business cycle - as reflected in the behavior of the financial markets - rather than a simple bivariate variable taking on a constant within-regime value is purely suggestive given our limited sample period and the presence of only one business cycle.

Nonetheless, it does point to interesting future research directions.

\footnotetext{
${ }^{26}$ Using daily date over a much longer time span, Connolly, Stivers and Sun (2005) find that U.S. stock-bond return correlations are inversely related to the level of aggregate stock market volatility as measured by the VIX index. The VIX may in turn be interpreted as a state variable related to the level of economic uncertainty and the stage of the business cycle in the sense of David and Veronesi (2004) and Ribeiro and Veronesi (2002). See also the recent related empirical result in Guidolin and Timmermann $(2004,2005)$.

27 The U.K. did not experience a recession from March 2001 to December 2002.

28 The dominance of the U.S. interests rate is consistent with the recent empirical evidence reported in Chinn and Frankel (2003).
} 


\section{$\underline{\text { Within-Country and Cross-Country Asset Market Linkages }}$}

We have argued that the movements in asset returns across markets and countries documented above are driven by the common exposure to exogenous U.S. macroeconomic shocks and the U.S.'s business cycle. This contrasts with previous studies that also document important spillover effects and market interdependencies, but little (if any) role for macroeconomic fundamentals in explaining the comovements between markets. Our positive results can be attributed to our focus on synchronous highfrequency data around the time of the announcement - all assets are actively traded during announcement times, so we observe the immediate news reaction of all assets - which mitigates other influences and potentially important omitted variables biases.

To further investigate the extent of the cross-market and cross-country linkages in the highfrequency data over-and-above the direct influence of the macroeconomic news announcement effects, it is informative to consider the simultaneous equation model,

$$
R_{t}^{h}=\beta_{0}^{h}+\sum_{h^{\prime} \neq h} \beta_{h 0}^{h^{\prime}} R_{t}^{h^{\prime}}+\sum_{h^{\prime}=1}^{H} \sum_{i=1}^{I} \beta_{h i}^{h^{\prime}} R_{t-i}^{h^{\prime}}+\sum_{k=1}^{K} \sum_{j=0}^{J} \beta_{k j}^{h} S_{k, t-j}+\eta_{t}^{h}, \quad t=1, \ldots, T .
$$

Except for the inclusion of the contemporaneous asset returns on the right-hand side, the model is identical to the reduced form representation in (4.2). As in equation (4.2), the $\beta_{k 0}^{h}$ coefficients directly capture the U.S. macroeconomic announcement effects, while the $\beta_{h 0}^{h^{\prime}}$ account for any contemporaneous cross-asset linkages and/or spillover effects that are not explained by the news announcements. This could include the reaction to other fundamental information, but also incorporates non-fundamental market microstructure, contagion, and cross-hedging effects. The problem from an econometric perspective, of course, is that without any additional restrictions or modeling assumptions, the contemporaneous coefficients in $\beta_{h 0}^{h^{\prime}}$ are not identified.

To overcome this problem, we follow the approach in the recent series of papers by Rigobon (2003), Rigobon and Sack (2003a,b, 2004), and Sentana and Fiorentini (2001) of using the conditional heteroskedasticity in the high-frequency data to identify the contemporaneous coefficients. The idea is straightforward. Assuming that the "structural" form innovations in (4.4) are conditionally uncorrelated but heteroskedastic - as indicated by our previous estimation results for (4.3) - the conditional covariances of the implied reduced-form innovations in (4.2) will then move in proportion to the conditional heteroskedasticity in the individual structural innovations, with the factors of proportionality 
determined by the elements in $\beta_{h 0}^{h^{\prime}}$. This proportionality in turn, allows for the identification and estimation of the contemporaneous coefficients. ${ }^{29}$

Our approach follows Rigobon and Sack (2003b), in estimating the elements of $\beta_{h 0}^{h^{\prime}}$ by applying Gaussian quasi-maximum likelihood estimation (QMLE) techniques to the multivariate "structural GARCH" model implied by the univariate GARCH models for each of the individual equations in (4.4). ${ }^{30}$ To facilitate the implementation of the multivariate GARCH model, we treat the residuals from the firststage estimation of (4.2) as directly observable. Also, for tractability, we estimate the model for three markets at a time, but the same idea could in principle be applied to any number of assets.

Focusing first on the trivariate domestic system consisting of U.S. T-Bond, S\&P500, and \$/Euro returns, we obtain the following estimates for the contemporaneous linkages among the three markets based on the 9,301 five-minute announcement period returns spanning the July 1, 1998 through February 28, 2001 expansion time period:

$$
\begin{aligned}
& R_{t}^{\text {TBond }}=-0.026 R_{t}^{S \& P}+0.020 R_{t}^{\$ / E u r o}+\beta_{0}^{h}+\sum_{h^{\prime}=1}^{H} \sum_{i=1}^{I} \beta_{h i}^{h^{\prime}} R_{t-i}^{h^{\prime}}+\sum_{k=1}^{K} \sum_{j=0}^{J} \beta_{k j}^{h} S_{k, t-j}+\eta_{t}^{h} \\
& (-9.41) \\
& R_{t}^{S \& P}=0.204 R_{t}^{T B o n d}+0.120 R_{t}^{\$ / \text { Euro }}+\beta_{0}^{h}+\sum_{h^{\prime}=1}^{H} \sum_{i=1}^{I} \beta_{h i}^{h^{\prime}} R_{t-i}^{h^{\prime}}+\sum_{k=1}^{K} \sum_{j=0}^{J} \beta_{k j}^{h} S_{k, t-j}+\eta_{t}^{h}
\end{aligned}
$$

\footnotetext{
${ }^{29}$ Formally, consider the matrix representation of (4.4), $\Psi R_{t}=\Phi X_{t-1}+\eta_{t}$, where the "structural shocks" to each of the equations, $\eta_{t}^{h}$, are assumed to be heteroskedastic, but serially uncorrelated and uncorrelated across equations. The corresponding reduced-form representation, $R_{t}=\Psi^{-1} \Phi X_{t-1}+\Psi^{-1} \eta_{t}$, the uniquely determines the distributional properties of $R_{t}$. Importantly, the non-zero off-diagonal elements of the time-varying conditional covariance matrix for the reduced form shocks, $\varepsilon_{t} \equiv \Psi^{-1} \eta_{t}$, depend directly on $\Psi^{-1}$, thus providing identification of the elements in $\Psi$ through the heteroskedasticity in the data.

30 To economize on the number of parameters, we only include those macroeconomic news announcement dummies that were statistically significant at the five-percent level in the estimation of equation (4.3). We also employ a more parsimonious GARCH(1,1) specification, $E_{t-1}\left[\left(\eta_{t}^{h}\right)^{2}\right] \equiv\left(\sigma_{t}^{h}\right)^{2}=\omega_{h}+\beta_{h}\left(\sigma_{t-1}^{h}\right)^{2}+\lambda_{h}\left(\eta_{t-1}^{h}\right)^{2}+\sum_{k=1}^{K} \gamma_{h, k} D_{k, t}$, as opposed to the $\mathrm{ARCH}(9)$ model implicit in (4.3). Further details of the estimation results are available upon request.
} 


$$
R_{t}^{\$ / \text { Euro }}=0.030 R_{t}^{T B o n d}-0.002 R_{t}^{S \& P}+\beta_{0}^{h}+\sum_{h^{\prime}=1}^{H} \sum_{i=1}^{I} \beta_{h i}^{h^{\prime}} R_{t-i}^{h^{\prime}}+\sum_{k=1}^{K} \sum_{j=0}^{J} \beta_{k j}^{h} S_{k, t-j}+\eta_{t}^{h},
$$

$(-2.39)$

where the numbers in parentheses refer to robust t-statistics. ${ }^{31}$ A number of the coefficients are highly significant and they all have a natural interpretation. For example, an increase in stock prices may be seen as a signal of a positive real activity or inflationary shock and the point estimate for the S\&P500 return coefficient in (4.5) is entirely consistent with the implications of the stylized monetary model. The impact of the exchange rate returns is clearly less important, but the sign is compatible with exchange rate changes on balance reflecting real economic shocks. Equation (4.6) is also directly in line with our aforementioned discussion of the dominance of the "discount" factor component in the evaluation of stock prices during economic expansions, whereby higher bond prices (lower discount rates) are good for the stock market in good times. Similarly, Dollar depreciation (interpreted as a negative real activity or deflationary shock) results in higher stock prices. Notice also that while the unconditional correlation between bond and stock prices for the expansion period reported in Table 3 is positive, the estimation method underlying equations (4.5)-(4.7) allows us to disentangle two opposing effects: bond prices affect stock prices positively, but stock prices affect bond prices negatively. ${ }^{32}$ Finally, interpreting negative bond returns and positive stock returns as indicators of real economic strength the associated appreciation of the Dollar implied by equation (4.7) is as expected.

Estimating the same set of equations for the 6,463 five-minute announcement period returns over the March 1, 2001 through December 31, 2002 recession time period produces the following results:

$$
R_{t}^{\text {TBond }}=-0.033 R_{t}^{S \& P}+0.010 R_{t}^{\$ / E u r o}+\beta_{0}^{h}+\sum_{h^{\prime}=1}^{H} \sum_{i=1}^{I} \beta_{h i}^{h^{\prime}} R_{t-i}^{h^{\prime}}+\sum_{k=1}^{K} \sum_{j=0}^{J} \beta_{k j}^{h} S_{k, t-j}+\eta_{t}^{h}
$$

$(-6.26)$

\footnotetext{
31 The reported t-statistics do not formally account for the first-stage conditional mean parameter estimation error, but this effect is almost surely negligible in the present context.

32 Our results for the high-frequency data in equations (4.5) and (4.6) agree with the findings reported in Rigobon and Sack (2003b) based on daily stock and bond market returns from November 1985 to March 2001. Of course, this is predominantly an expansionary period, so it is not surprising that the directional effects coincide.
} 


$$
\begin{gathered}
R_{t}^{S \& P}=-0.192 R_{t}^{\text {TBond }}-0.090 R_{t}^{\$ / \text { Euro }}+\beta_{0}^{h}+\sum_{h^{\prime}=1}^{H} \sum_{i=1}^{I} \beta_{h i}^{h^{\prime}} R_{t-i}^{h^{\prime}}+\sum_{k=1}^{K} \sum_{j=0}^{J} \beta_{k j}^{h} S_{k, t-j}+\eta_{t}^{h} \\
(-3.88) \quad-1.97) \\
R_{t}^{\$ / \text { Euro }}=0.033 R_{t}^{\text {TBond }}-0.011 R_{t}^{S \& P}+\beta_{0}^{h}+\sum_{h^{\prime}=1}^{H} \sum_{i=1}^{I} \beta_{h i}^{h^{\prime}} R_{t-i}^{h^{\prime}}+\sum_{k=1}^{K} \sum_{j=0}^{J} \beta_{k j}^{h} S_{k, t-j}+\eta_{t}^{h} .
\end{gathered}
$$

The estimates for equations (4.8) and (4.10) are qualitatively as before, although the linkages among the interest rate and the other variables appear to have declined. This is consistent with the interest rates being less sensitive to economic shocks during the recession. In contrast, the difference in the estimates for the S\&P500 returns in equations (4.6) and (4.9) is striking. The contemporaneous linkages between the stock market and the other markets flips sign between the two periods. As before, "good news" during expansions is "bad news" for stocks, but "good news" during recessions is good for the stock market. In summary, the dominant finding is that positive stock returns (positive real or inflationary shocks), ceteris paribus, always raises interest rates, while positive innovations to interest rates (real or inflationary shocks) have a strongly regime-dependent impact on stock returns, once again confirming the differential impacts of the cash-flow and the discount rate effects across the business cycle.

Finally, we use the same "structural GARCH" approach to estimate the interdependence among the national stock markets beyond the linkages explained by the U.S. macroeconomic announcements. As before, dividing the sample in two, we find for the expansion sample:

$$
\begin{gathered}
R_{t}^{S \& P}=0.028 R_{t}^{F T S E}+0.007 R_{t}^{D J E}+\beta_{0}^{h}+\sum_{h^{\prime}=1}^{H} \sum_{i=1}^{I} \beta_{h i}^{h^{\prime}} R_{t-i}^{h^{\prime}}+\sum_{k=1}^{K} \sum_{j=0}^{J} \beta_{k j}^{h} S_{k, t-j}+\eta_{t}^{h} \\
(5.83) \quad 0.00) \\
R_{t}^{F T S E}=014 R_{t}^{S \& P}+0.015 R_{t}^{D J E}+\beta_{0}^{h}+\sum_{h^{\prime}=1}^{H} \sum_{i=1}^{I} \beta_{h i}^{h^{\prime}} R_{t-i}^{h^{\prime}}+\sum_{k=1}^{K} \sum_{j=0}^{J} \beta_{k j}^{h} S_{k, t-j}+\eta_{t}^{h}
\end{gathered}
$$




$$
R_{t}^{D J E}=0.089 R_{t}^{S \& P}+0.001 R_{t}^{F T S E}+\beta_{0}^{h}+\sum_{h^{\prime}=1}^{H} \sum_{i=1}^{I} \beta_{h i}^{h^{\prime}} R_{t-i}^{h^{\prime}}+\sum_{k=1}^{K} \sum_{j=0}^{J} \beta_{k j}^{h} S_{k, t-j}+\eta_{t}^{h} .
$$

Not surprisingly, all estimated coefficients are positive, indicating important cross-country linkages overand-above those explained by the U.S. macroeconomic news releases. Whether these high-frequency international market linkages are due to common reactions to worldwide fundamental news or reflect cross-market hedging or other non-fundamental contagion effects is difficult to ascertain.

Meanwhile, estimating the same relations over the more recent recession period suggests even stronger contemporaneous cross-country linkages,

$$
\begin{aligned}
& R_{t}^{S \& P}=0.447 R_{t}^{F T S E}+0.210 R_{t}^{D J E}+\beta_{0}^{h}+\sum_{h^{\prime}=1}^{H} \sum_{i=1}^{I} \beta_{h i}^{h^{\prime}} R_{t-i}^{h^{\prime}}+\sum_{k=1}^{K} \sum_{j=0}^{J} \beta_{k j}^{h} S_{k, t-j}+\eta_{t}^{h} \\
& R_{t}^{F T S E}=0.074 R_{t}^{S \& P}+0.085 R_{t}^{D J E}+\beta_{0}^{h}+\sum_{h^{\prime}=1}^{H} \sum_{i=1}^{I} \beta_{h i}^{h^{\prime}} R_{t-i}^{h^{\prime}}+\sum_{k=1}^{K} \sum_{j=0}^{J} \beta_{k j}^{h} S_{k, t-j}+\eta_{t}^{h} \\
& R_{t}^{D J E}=0.073 R_{t}^{S \& P}+0.115 R_{t}^{F T S E}+\beta_{0}^{h}+\sum_{h^{\prime}=1}^{H} \sum_{i=1}^{I} \beta_{h i}^{h^{\prime}} R_{t-i}^{h^{\prime}}+\sum_{k=1}^{K} \sum_{j=0}^{J} \beta_{k j}^{h} S_{k, t-j}+\eta_{t}^{h} .
\end{aligned}
$$

These results accord directly with the findings of stronger international stock market cross-correlations in down markets reported in the recent asset pricing literature. ${ }^{33}$ Importantly, however, our results help explain the origins of the linkages, with movements in the DJE and the FTSE both strongly influencing the U.S. market. This contrasts notably with most previous studies, which typically report significant spillover effects from the U.S. equity market to foreign markets, but not the other way around. Again, our use of finely sampled intraday data along with the application of refined statistical procedures are critical

\footnotetext{
33 The theoretical model in Ribeiro and Veronesi (2002), in which news is more informative about the true state of the economy in recessions, resulting in higher cross-market correlations, provides one possible explanation for the findings.
} 
in terms of uncovering such linkages.

\section{Concluding Remarks}

We have characterized the real-time interactions among U.S., German and British stock, bond and foreign exchange markets in the periods surrounding regularly-scheduled U.S. macroeconomic news announcements. We found that announcement surprises produce conditional mean jumps; hence highfrequency stock, bond and exchange rate dynamics are linked to fundamentals. Our results are especially intriguing as regards stock market responses to news, which display distinct state dependence. In particular, bad macroeconomic news has the traditionally-expected negative equity market impact during recessions, but a positive impact during expansions. This explains the small stock market news reaction effect when averaged across expansions and recessions reported in the exiting literature. The asymmetric responses manifest themselves dramatically in very different stock-bond market correlations across the business cycle. We verify that these distinct correlation patterns are not limited to the period around announcements but apply generally for the trading day returns in the expansion vis-a-vis the recession. We conjecture that such real-time correlation measures will be useful for a more refined classification of the phase of the business cycle in future work. Finally, we pursue a "structural GARCH" estimation approach that documents highly significant contemporaneous cross-market and cross-country linkages not directly explained by the macroeconomic announcement effects. These findings generally strengthen and robustify the above conclusions while also pointing toward important direct spill-over effects from foreign to U.S. equity markets that typically are not captured by related existing empirical studies. Our positive results in these dimensions are attributable to the use of synchronous high-frequency futures data, which allow us to observe the immediate reaction and interaction of actively traded financial assets in the period around the announcement times.

Among the many possible directions for future work, we are particularly intrigued by the idea of using high-frequency data to quantify the three separate channels of private information, contagion, and public information that link the markets. Several recent studies have highlighted the role of order flow in the price formation process, including Brandt and Kavajecz (2004), Cao, Lyons and Evans (2004), Evans and Lyons (2003, 2005), Pasquariello and Vega (2004), and Underwood (2003). It would be interesting to exploit the information in order flow and other liquidity measures in concert with the new statistical procedures and rich high-frequency return and news announcement data employed here to further advance our understanding of the price discovery process and cross-market linkages. 


\section{Appendix}

\section{Prices and Fundamentals in Foreign Exchange, Bond and Stock Markets}

The Lucas (1982) two-country general equilibrium model, in which asset prices are directly determined by monetary and real shocks, provides a simple convenient framework for discerning the directional impact of specific macroeconomic news announcements and helps to illuminate the different cross-market linkages that might be in operation. ${ }^{34}$ The model consists of a home and a foreign country, each of which produces a single good. A representative agent in each of the two countries trades in and consumes each of the two goods, with intertemporal substitution taking place via the local stock and bond markets. Trades are facilitated and shocks are propagated across the two countries through the foreign exchange market.

Foreign Exchange

For concreteness, we refer to the home currency as the Dollar and the foreign currency as the Euro. The first order equilibrium condition for the nominal Dollar/Euro exchange rate $S_{t}$ may be expressed as

$$
S_{t}=\frac{u_{y}\left(c_{x t}, c_{y t}\right) M_{t} y_{t}}{u_{x}\left(c_{x t}, c_{y t}\right) N_{t} x_{t}}
$$

where $u_{x}(.,$.$) and u_{y}(.,$.$) refer to the derivatives of the representative domestic consumer's utility$ function with respect to the consumption of the home good, $c_{x t}$, and the foreign good, $c_{y t}$, respectively, $M_{t}\left(N_{t}\right)$ refers to the Dollars (Euros) in circulation, and $x_{t}\left(y_{t}\right)$ denotes domestic (foreign) output.

It follows readily that other things equal, a positive domestic money supply shock, $M_{t+1}-M_{t}>0$, depreciates the Dollar. Similarly, a positive foreign money supply shock, $N_{t+1}-N_{t}>0$, depreciates the Euro. This is also directly in line with the standard monetary approach to exchange rate determination (e.g., Mark, 2001), as well as competing models involving a central bank reaction function that embodies

\footnotetext{
34 Our discussion of the discrete-time Lucas model is adapted from Mark (2001). Our notation slightly differs from Mark's in that $e_{t}\left(e_{t}^{*}\right)$ denotes the nominal rather than the real price of home (foreign) equity. A refined continuous-time version of the model, in which real exchange rates, stock and bond prices are jointly determined has recently been developed by Pavlova and Rigobon (2003). Our paper is not intended as a "test" of the Lucas model per se, however. Instead, we merely use the model to provide us with a rough guide as to the likely directional influences of the different macroeconomic announcements.
} 
a preference for low inflation (e.g., Taylor, 1993).

The effect of real shocks will generally depend upon the exact form of the utility function and the corresponding cross-country substitution effects. To illustrate, suppose that the utility function for the representative domestic consumer takes the form,

$$
u\left(c_{x t}, c_{y t}\right)=\frac{c_{x t}^{1-\gamma_{x}}}{1-\gamma_{x}}+\frac{c_{y t}^{1-\gamma_{y}}}{1-\gamma_{y}}
$$

where $\gamma_{x}>0$ and $\gamma_{y}>0$. Solving for the equilibrium,

$$
S_{t}=2^{\gamma_{y}-\gamma_{x}} \frac{y_{t}^{1-\gamma_{y}}}{x_{t}^{1-\gamma_{x}}} \frac{M_{t}}{N_{t}} .
$$

Hence a positive domestic real shock may appreciate or depreciate the nominal exchange rate depending upon the value of the risk aversion parameter, $\gamma_{x}$. In particular, everything else equal, an increase in domestic output, $x_{t+1}-x_{t}>0$, appreciates the Dollar provided that $\gamma_{x}<1$. Again, this accords directly with the implications of the standard monetary models and central bank reaction function models.

\section{Domestic Bonds}

Following the standard consumption-based approach to asset pricing, the equilibrium nominal price of a one-period domestic bond with a one-Dollar payoff is conveniently expressed as

$$
b_{t}=E_{t}\left(S D_{t+1}\right)
$$

where

$$
S D_{t+1} \equiv \beta \frac{u_{x}\left(c_{x t+1}, c_{y t+1}\right)}{u_{x}\left(c_{x t}, c_{y t}\right)} \frac{P_{t}}{P_{t+1}}
$$

refers to the stochastic discount factor, $P_{t}$ denote the nominal price of domestic output, and $\beta$ is the discount rate. The bond price is, of course, inversely related to the nominal risk free rate, $b_{t}=1 /\left(1+r_{f t}\right)$. Inflationary shocks trivially lower bond prices and raise interest rates. To ascertain the likely impact of a real shock, consider again the representative utility function in equation (A.2), in which case the equilibrium price simplifies to 


$$
b_{t}=\beta E_{t}\left[\left(\frac{x_{t+1}}{x_{t}}\right)^{-\gamma_{x}} \frac{P_{t}}{P_{t+1}}\right] .
$$

Thus, in this situation we would expect positive domestic real shocks, $x_{t+1}-x_{t}>0$, to affect bond prices negatively. ${ }^{35}$

\section{Domestic Stock Market}

The equilibrium nominal price of equity claims solves the standard recursive asset pricing equation,

$$
e_{t}=b_{t} E_{t}\left(P_{t} x_{t}+e_{t+1}\right)+\operatorname{Cov}_{t}\left(S D_{t+1}, e_{t+1}\right)
$$

This highlights the three separate influences determining stock prices: the risk-free interest rate, $b_{t}=1 /\left(1+r_{f t}\right)$, expected future cash flows, $E_{t}\left(P_{t} x_{t}+e_{t+1}\right)$, and the equity risk premium, $\operatorname{Cov}_{t}\left(S D_{t+1}, e_{t+1}\right)$.

As discussed above, a positive real shock, $x_{t+1}-x_{t}>0$, will generally affect bond prices negatively, implying a decrease in the price of equity coming from the first term. This same real shock, however, affects the expected rate of growth positively, and hence implies an increase in stock prices coming from the second term. It is not clear how a positive real shock would affect the covariance, or risk premium, term. As such, this renders the overall effect on equity prices of real domestic shocks elusive. Similarly, the inflation rate, $P_{t+1} / P_{t}$, will affect nominal stock prices in different directions through the three separate channels, leaving the dominant effect of inflationary shocks an empirical question.

There is also the possibility that the relative importance of the different effects, and hence the impact of macroeconomic announcements, changes over the stage of the business cycle. In particular, as argued by Boyd, Jagannathan and $\mathrm{Hu}$ (2005), information about interest rates (i.e., the first term) may be dominant during expansions (i.e., positive real shocks are bad news for stocks during good times), while information about future corporate dividends and/or the equity risk premium (i.e., the second and third term) may be dominant during contractions. We examine this issue in detail in the empirical analysis.

\section{Foreign Bond and Stock Markets}

The foreign exchange market links the equilibrium nominal price of a one-period nominal foreign

\footnotetext{
35 This accords both with the earlier empirical evidence cited in the main text, and with popular financial press explanations of bond market reactions to news. Quoting from Balduzzi, Elton and Green (2001): "The financial press explains the reaction of the bond market to economic news mainly in terms of revisions of inflationary expectations, where, in accord with a Phillips curve view, inflation is perceived to be positively correlated with economic activity. So procyclical variables and inflationary pressures have a negative impact on bond prices."
} 
bond with a one-Euro payoff to the price of a domestic bond with a one-Dollar payoff,

$$
b_{t}^{*}=E_{t}\left[S D_{t+1} \frac{S_{t+1}}{S_{t}}\right] \text {. }
$$

The impact of a shock will therefore again depend upon the form of the utility function and the risk premium implied by the corresponding stochastic discount factor. Assuming that the risk premium stays approximately constant, however, a shock which appreciates (depreciates) the Dollar should lower (increase) the price of the foreign bond, increasing (decreasing) the nominal foreign interest rate, $b_{t}^{*}=1 /\left(1+r_{f t}^{*}\right)$.

By direct analogy to the pricing equation for domestic stocks, the equilibrium nominal foreign equity price satisfies,

$$
e_{t}^{*}=b_{t}^{*} E_{t}\left(P_{t}^{*} y_{t}+e_{t+1}^{*}\right)+\operatorname{Cov}_{t}\left(S D_{t+1}^{*}, e_{t+1}^{*}\right)
$$

where $P_{t}^{*}$ denotes the foreign (Euro) price level, and the foreign nominal stochastic discount factor is defined by

$$
S D_{t+1}^{*} \equiv \beta \frac{u_{y}\left(c_{x t+1}, c_{y t+1}\right)}{u_{y}\left(c_{x t}, c_{y t}\right)} \frac{P_{t}^{*}}{P_{t+1}^{*}}
$$

As discussed above, positive domestic inflationary or real shocks will generally result in lower foreign bond prices, $b_{t}{ }^{*}$. Assuming in addition that domestic and foreign growth are positively correlated, these same shocks will enhance the expected future nominal payoff, $E_{t}\left(P_{t}^{*} y_{t}+e_{t+1}^{*}\right)$. Thus, regardless of the covariance or risk premium term, $\operatorname{Cov}_{t}\left(S D_{t+1}^{*}, e_{t+1}^{*}\right)$, the overall directional impact of a U.S. domestic shock for foreign stock prices remains ambiguous. Moreover, there is again the possibility that the magnitude of the different effects, and hence the impact of the shocks, will vary with the phase of the business cycle. 


\section{References}

Aït-Sahalia, Y., Mykland, P.A. and Zhang, L. (2003), "How Often to Sample a Continuous-Time Process in the Presence of Market Microstructure Noise," Review of Financial Studies, forthcoming.

Almeida, A., Goodhart, C. and Payne, R. (1998), "The Effects of Macroeconomic News on High-Frequency Exchange Rate Behaviour," Journal of Financial and Quantitative Analysis, 33, 383-408.

Andersen, T.G. and Bollerslev, T. (1998), "Deutsche Mark-Dollar Volatility: Intraday Activity Patterns, Macroeconomic Announcements, and Longer Run Dependencies," Journal of Finance, 53, 219-265.

Andersen, T.G., Bollerslev, T., Diebold, F.X. and Labys, P. (2001), "The Distribution of Realized Exchange Rate Volatility," Journal of the American Statistical Association, 96, 42-55.

Andersen, T.G., Bollerslev, T., Diebold, F.X. and Labys, P. (2003), "Modeling and Forecasting Realized Volatility," Econometrica, 71, 579-626.

Andersen, T.G., Bollerslev, T., Diebold, F.X. and Vega, C. (2003), "Micro Effects of Macro Announcements: Real-Time Price Discovery in Foreign Exchange," American Economic Review, 93, 38-62.

Barsky, R.B. (1989), "Why Don't the Prices of Stocks and Bonds Move Together?," American Economic Review, 79, 1132-1145.

Balduzzi, P., Elton, E.J. and Green, T.C. (2001), "Economic News and Bond Prices: Evidence From the U.S. Treasury Market," Journal of Financial and Quantitative Analysis, 36, 523-543.

Bandi, F. and Russell, J.R. (2003), "Microstructure Noise, Realized Volatility, and Optimal Sampling," Manuscript, University of Chicago.

Blanchard, O.J. and Summers, L.H. (1984), "Perspectives on High World Real Interest Rates," Brookings Papers on Economic Activity, 2, 273-324.

Becker, K. G., Finnerty, J. E. and Friedman, J. (1995) "Economic News and Equity Market Linkages between the U.S. and U.K.," Journal of Banking and Finance, 19, 1191-1210.

Bessembinder, H. (1994), "Bid-Ask Spreads in the Interbank Foreign Exchange Market," Journal of Financial Economics, 35, 317-348.

Bernanke, B. S., and Kuttner, K. N. (2005), "What Explains the Stock Market's Reaction to Federal Reserve Policy," Journal of Finance, forthcoming.

Bollerslev, T., Cai, J. and Song, F.M. (2000), "Intraday Periodicity, Long Memory Volatility, and Macroeconomic Announcement Effects in the U.S. Treasury Bond Market," Journal of Empirical Finance, 7, 37-55.

Bomfim, A.N. (2003), "Pre-Announcement Effects, News Effects, and Volatility: Monetary Policy and the Stock Market," Journal of Banking and Finance, 27, 133-151.

Boyd, J. H., Jagannathan, R. and Hu, J. (2005), “The Stock Market's Reaction to Unemployment News: Why Bad News Is Usually Good For Stocks," Journal of Finance, forthcoming. 
Brandt, M.W. and Kavajecz, K.A. (2004), "Price Discovery in the U.S. Treasury Market: The Impact of Order Flow and Liquidity on the Yield Curve," Journal of Finance, 59, 2623-2654.

Campbell, J.Y. and Ammer, J. (1993), "What Moves the Stock and Bond Markets? A Variance Decomposition for Long-Term Asset Returns," Journal of Finance, 48, 3-37.

Campbell, J.Y. and Mei, J. (1993), "Where Do Betas Come From? Asset Pricing Dynamics and the Sources of Systematic Risk," Review of Financial Studies, 6, 567-592.

Cao, H.H., Lyons, R. and Evans, M.D.D. (2004), "Inventory Information,” Journal of Business, forthcoming.

Chaboud, A.P., Chernonko, S.V., Howorka, E., Iyer, R.S.K., Liu, D. and Wright, J.H. (2004), "The HighFrequency Effects of U.S. Macroeconomic Data Releases on Prices and Trading Activity in the Global Interdealer Foreign Exchange Market,” Manuscript, Board of Governors of the Federal Reserve System, Washington D.C.

Chinn, M. and Frankel, J. (2003), "The Euro Area and World Interest Rates,” Working Paper 1016, Department of Economics, University of California, Santa Cruz.

Christie-David, R., Chaudhry, M. and Khan, M. (2002), "News Releases, Market Integration, and Market Leadership," Journal of Financial Research, 25, 223-245.

Connolly, R., Stivers, C. and Sun, L. (2005), "Stock Market Uncertainty and the Stock-Bond Return Relation," Journal of Financial and Quantitative Analysis, forthcoming.

Connolly, R. and Wang, A. F. (2003), "International Equity Market Comovements: Economic Fundamentals or Contagion?" Pacific-Basin Finance Journal, 11, 23-43.

Cornell, B. (1983), “The Money Supply Announcement Puzzle: Review and Interpretation,” American Economic Review, 73, 644- 657.

Cutler, D. M., Poterba, J.M. and Summers, L.H. (1989), “What Moves Stock Prices?” Journal of Portfolio Management, 4-12.

David, A. and Veronesi, P. (2004), "Inflation and Earnings Uncertainty and Volatility Forecasts,” Manuscript, University of Chicago.

Ehrmann, M and Fratzscher, M. (2003), "Interdependence between the Euro Area and the U.S.: What Role for EMU," Manuscript, European Central Bank, Frankfurt.

Engle, R.F. (2002), "Dynamic Conditional Correlation: A Simple Class of Multivariate Generalized Autoregressive Conditional Heteroskedasticity Models," Journal of Business and Economic Statistics, 20,339-350.

Engel, C and Frankel, J.A. (1984), "Why Interest Rates React to Money Announcements: An Explanation from the Foreign Exchange Market," Journal of Monetary Economics, 13, 31-39.

Engle, R.F., Ito, T. and Lin, W.L. (1990), "Meteor-Showers or Heat Waves - Heteroskedastic Intradaily Volatility in the Foreign Exchange Market,"Econometrica, 55, 391-407. 
Engle, R.F., Ito, T. and Lin, W.L. (1992), "Where Does the Meteor Shower Come From? The Role of Stochastic Policy and Coordination,"Journal of International Economics, 32, 221-240.

Evans, M.D.D. and Lyons, R. (2003), "How Is Macro News Transmitted to Exchange Rates?” NBER Working Paper No.9433, Cambridge, Mass.

Evans, M.D.D. and R.K. Lyons (2005), "Meese-Rogoff Redux: Micro-Based Exchange Rate Forecasting,"American Economic Review, forthcoming.

Fair, R. (2002), "Events that Shook the Market," Journal of Business, 75, 713-732.

Fair, R. (2003), "Shock Effects on Stocks, Bonds and Exchange Rates," Journal of International Money and Finance, 21, 307-341.

Faust, J., Rogers, J.H., Wand, S.Y.B. and Wright, J.H. (2003), "The High-Frequency Response of Exchange Rates and Interest Rates to Macroeconomic Announcements," Manuscript, Board of Governors of the Federal Reserve System, Washington D.C.

Flannery, M. J. and Protopapadakis, A. (2002), "Macroeconomic Factors do Influence Aggregate Stock Returns,” Review of Financial Studies, 15, 751-782.

Fleming, M.J. and Remolona, E.M. (1997), "What Moves the Bond Market,” Economic Policy Review, Federal Reserve Bank of New York, 3 (December), 31-50.

Fleming, M.J. and Remolona, E.M. (1999), "Price Formation and Liquidity in the U.S. Treasury Market: The Response to Public Information," Journal of Finance, 54, 1901-1915.

Fleming, J., Kirby, C. and Ostdiek, B. (1998), "Information and Volatility Linkages in the Stock, Bond and Money Market," Journal of Financial Economics, 49, 111-137.

Forbes, K.J. and Rigobon, R. (2002), "No Contagion, Only Interdependence: Measuring Stock Market CoMovements," Journal of Finance, 57, 2223-2261.

Frankel, J. A. and Hardouvelis, G. (1985), "Commodity Prices, Money Surprises, and Fed Credibility," Journal of Money, Credit and Banking, 17, 427-438.

Frankel, J. A. and Rose, A.K. (1995), "A Survey of Empirical Research on Nominal Exchange Rates," in G. Grossman and K. Rogoff (eds.), Handbook of International Economics. Amsterdam: North-Holland.

Galati, G. and Ho, C. (2003), "Macroeconomic News and the Euro/Dollar Exchange Rate," Economic Notes, 32, 371-398.

Goldberg, L. and Leonard, D. (2003), "What Moves Sovereign Bond Markets? The Effects of Economic News on U.S. and German Yields," Current Issues in Economics and Finance, Federal Reserve Bank of New York, 9, 1-7.

Goto, S. and Valkanov, R (2002), “The Fed's Effect on Excess Returns and Inflation is Bigger Than you Think," Manuscript, UCLA.

Green, C.T. (2004), "Economic News and the Impact of Trading on Bond Prices," Journal of Finance, 59, $1201-1233$. 
Grossman, J. (1981), "The Rationality of Money Supply Expectations and the Short-Run Response of Interest Rates to Monetary Surprises," Journal of Money, Credit and Banking, 13, 409-424.

Guidolin, M. and Timmermann, A. (2004), "Strategic Asset Allocation under Multivariate Regime Switching," Manuscript, University of California San Diego.

Guidolin, M. and Timmermann, A. (2005), “An Econometric Model of Nonlinear Dynamics in the Joint Distribution of Stock and Bond Returns," Journal of Applied Econometrics, forthcoming.

Hamao, Y., Masulis, R.W. and Ng, V. (1990), "Correlations in Price Changes and Volatility Across International Stock Markets,” Review of Financial Studies, 3, 281-307.

Hansen, P.R. and Lunde, A. (2004), “An Unbiased Measure of Realized Variance,” Manuscript, Brown University.

Hardouvelis, G. A. (1987), "Macroeconomic Information and Stock Prices," Journal of Economics and Business, 39, 131-140.

Hardouvelis, G. A. (1988), “Economic News, Exchange Rates and Interest Rates,” Journal of International Money and Finance, 7, 23-35.

Harvey, C.R. and Huang, R.D. (2002), "The Impact of the Federal Reserve Bank's Open Market Operations," Journal of Financial Markets, 5, 223-257.

Hasbrouck, J. (1999), "Security Bid/Ask Dynamics with Discreteness and Clustering: Simple Strategies for Modeling and Estimation," Journal of Financial Markets, 2, 1-28.

Hasbrouck, J. (2003), “Intraday Price Formation in U.S. Equity Index Markets," Journal of Finance, 58, 23752400 .

Hautsch, N. and Hess, D. (2002), "The Processing of Non-Anticipated Information in Financial Markets: Analyzing the Impact of the Surprises in the Employment Report," European Finance Review, 6, 133161.

Ito, T. and Roley, V. (1987), "News from the U.S. and Japan: Which Moves the Yen/Dollar Exchange Rate," Journal of Monetary Economics, 19, 255-277.

King, M.A. and Wadhwani, S. (1990), "Transmission of Volatility between Stock Markets," Review of Financial Studies, 3, 5-33.

Kuttner, K.N. (2001), "Monetary Policy Surprises and Interest Rates: Evidence from the Fed Funds Futures Market," Journal of Monetary Economics, 47, 523-544.

Li, L. (2002), "The Correlation of Stock and Bond Returns," Yale University, ICF Working Paper No. 02-46.

Li, L. and Engle, R.F. (1998), "Macroeconomic Announcements and Volatility of Treasury Futures," Manuscript, University of California, San Diego.

Lucas, R. (1982), "Interest Rates and Currency Prices in a Two-Country World," Journal of Monetary Economics, 10, 335-359. 
Mark, N.C. (2001). International Macroeconomics and Finance: Theory and Empirical Methods. Blackwell Publishers, Oxford, U.K..

McQueen, G. and Roley, V.V. (1993), "Stock Prices, News, and Business Conditions," Review of Financial Studies, 6, 683-707.

Orphanides, A. (1992), "When Good News is Bad News: Macroeconomic News and the Stock Market," Working Paper, Board of Governors of the Federal Reserve System.

Pasquariello, P. and Vega, C. (2004), "Informed and Strategic Order Flow in the Bond Markets," Manuscript, University of Michigan and University of Rochester.

Pavlova, A. and Rigobon, R. (2003), “Asset Prices and Exchange Rates,” Manuscript, Massachusetts Institute of Technology.

Pearce, D. and Roley, V.V. (1985), "Stock Prices and Economic News," Journal of Business, 58, 49-67.

Roley, V. V. and Walsh, C.E. (1985), "Monetary Policy Regimes, Expected Inflation and the Response of Interest Rates to Money Announcements," Quarterly Journal of Economics, 100, 1011-1039.

Ribeiro, R. and Veronesi, P. (2002), "Excess Comovement of International Stock Markets in Bad Times: A Rational Expectations Equilibrium Model," Manuscript, University of Chicago.

Rich, R. and Tracy, J. (2003), "Modeling Uncertainty: Predictive Accuracy as a Proxy for Predictive Confidence," Federal Reserve Bank of New York, Staff Reports No.161.

Rigobon, R. (2003), “Identification Through Heteroskedasticity," Review of Economics and Statistics, 85, 777-792.

Rigobon, R. and Sack, B. (2004), “The Impact of Monetary Policy on Asset Prices," Journal of Monetary Economics, 51, 1553-1573.

Rigobon, R. and Sack, B. (2003a), "Measuring the Reaction of Monetary Policy to the Stock Market," Quarterly Journal of Economics, 118, 639-669.

Rigobon, R. and Sack, B. (2003b), “Spillovers Across U.S. Financial Markets,” NBER Working Paper No. 9640, Cambridge, Mass.

Rudebusch, G.D. (1998), “Do Measures of Monetary Policy in a VAR Make Sense?," International Economic Review, 39, 907-931.

Sentana, E., and Fiorentini, G. (2001), "Identification, Estimation and Testing of Conditional Heteroskedastic Factor Models," Journal of Econometrics, 102, 143-164.

Shiller, R. J. and Beltratti, A.E. (1992), "Stock Prices and Bond Yields," Journal of Monetary Economics, 30, 25-46.

Schwert, G.W. (1981), "The Adjustment of Stock Prices to Information About Inflation," Journal of Finance, $36,15-29$. 
Scruggs, J. T. and Glabadanidis, P. (2003), "Risk Premia and the Dynamic Covariance Between Stock and Bond Returns," Journal of Financial and Quantitative Analysis, 38, 295-316.

Tandon, K. and Urich, T. (1987), "International Market Response to Announcements of U.S. Macroeconomic Data," Journal of International Money and Finance, 6, 71-83.

Taylor, J.B. (1993), "Discretion Versus Policy Rules in Practice," Carnegie-Rochester Conference Series on Public Policy, 39, 195-214.

Underwood, S. (2003), “Cross-Market Informational Effects of Stock and Bond Order Flow,” Manuscript, University of Pennsylvania.

Urich, T. and Wachtel, P. (1981), "Market Response to the Weekly Money Supply Announcements in the 1970s," Journal of Finance, 36, 1063-1072.

Wongswan, J. (2003), “Transmission of Information Across International Equity Markets,” International Finance Discussion Paper 759, Federal Reserve Board.

Zarnowitz, V. and Lambros, L.A. (1987), "Consensus and Uncertainty in Economic Prediction," Journal of Political Economy, 95, 591-621. 
Table 1

Futures Contracts

\begin{tabular}{llccc}
\hline \multicolumn{1}{c}{ Futures Contract } & \multicolumn{1}{c}{ Exchange $^{2}$} & $\begin{array}{c}\text { Trading } \\
\text { Hours }^{3}\end{array}$ & Sample $^{4}$ & Liquidity $^{5}$ \\
\hline \$/Pound & CME & $8: 20-15: 00$ & $01 / 92-12 / 02$ & 160.73 \\
\$/Yen & CME & $8: 20-15: 00$ & $01 / 92-12 / 02$ & 202.26 \\
\$/Euro & \\
S\&P 500 & CME & $8: 20-15: 00$ & $01 / 92-12 / 02$ & 216.01 \\
30-Year U.S. Treasury Bond & CBOT & $8: 20-16: 15^{7}$ & $01 / 94-12 / 02$ & 231.10 \\
British Long Gilt & & $8: 20-15: 00$ & $01 / 92-12 / 02$ & 228.27 \\
Euro Bobl & LIFFE & $3: 00-13: 00$ & $07 / 98-12 / 02$ & 200.59 \\
FTSE 100 & EUREX & $2: 00-13: 00$ & $07 / 98-12 / 02$ & 234.97 \\
DJ Euro Stoxx 50 & LIFFE & $3: 00-12: 30$ & $07 / 98-12 / 02$ & 235.65 \\
& EUREX & $3: 00-14: 00^{12}$ & $07 / 98-12 / 02$ & 169.20 \\
\hline
\end{tabular}

Footnotes to Table 1:

1. The delivery months for all of the contracts are March, June, September and December. We always use the contract closest to expiration - which is generally the most actively traded - switching to the next-maturity contract five days before expiration.

2. Chicago Mercantile Exchange (CME), Chicago Board of Trade (CBOT), London International Financial Futures Exchange (LIFFE), European Exchange (EUREX).

3. Open auction regular trading hours, Eastern Standard Time.

4. Starting and ending dates of our data sample.

5. Average number of daily transactions in the common sample $07 / 98$ to $12 / 02,8: 20$ to $12: 30$ EST.

6. Prior to June 1,1999 , we use $\$ / D M$ futures.

7. The S\&P500 data from 8:20 to 9:30 comes from GLOBEX.

8. The British Long Gilt contract is based on the British 10-Year Treasury Note.

9. The Euro Bobl contract is based on the German 5-Year Treasury Note.

10. The FTSE 100 index is constructed from the 100 largest U.K. companies.

11. The DJ Euro Stoxx 50 index is composed of the 50 largest blue-chip market sector leaders in continental Europe. In July 2003 the index was composed of one Belgian, twelve German, five Spanish, one Finish, seventeen French, seven Italian and seven Dutch companies.

12. EUREX extended the DJ Euro Stoxx 50 trading hours from 4:00-11:00 EST to 3:00-11:00 EST on October 18, 1999, again from 3:00-11:00 EST to 3:00-11:30 EST on January 24, 2000, and yet again from 3:00-11:30 EST to 3:00-14:00 EST on January 2, 2002. 
Table 2

Summary Statistics for Five-Minute Stock, Bond and Forex Returns

\begin{tabular}{lcccccc}
\hline & Mean & Maximum & Minimum & Std. Dev. & Skewness & Kurtosis \\
\hline \$/Pound & 0.00063 & 0.535 & -0.460 & 0.048 & 0.025 & 7.499 \\
\$/Yen & 0.00022 & 0.615 & -1.111 & 0.067 & -0.464 & 19.443 \\
\$/Euro & -0.00043 & 0.824 & -0.587 & 0.066 & -0.055 & 11.018 \\
S\&P 500 & -0.00131 & 2.103 & -2.437 & 0.171 & -0.183 & 26.115 \\
FTSE 100 & -0.00187 & 1.785 & -1.516 & 0.138 & 0.284 & 25.745 \\
DJ Euro Stoxx 50 & -0.00118 & 2.203 & -2.037 & 0.175 & -0.081 & 17.507 \\
30-Year Treasury Bond & 0.00063 & 1.319 & -0.917 & 0.081 & 0.141 & 15.583 \\
British Long Gilt & 0.00005 & 0.470 & -0.366 & 0.040 & 0.087 & 11.217 \\
German Euro Bobl & 0.00010 & 0.261 & -0.257 & 0.023 & -0.168 & 13.258 \\
\hline
\end{tabular}

Notes to Table 2: See the footnotes to Table 1 for a description of the different contracts. The summary statistics for each of the different contracts are based on the 15,764 five-minute returns ten minutes before and one-and-a-half hours after the release of each of the U.S. macroeconomic announcements described in Table 4. The full common sample for all of the contracts used in the calculations spans July 1, 1998 through December 31, 2002. 
Table 3

Unconditional Correlation Matrix for Five-Minute Stock, Bond and Forex Returns

\begin{tabular}{|c|c|c|c|c|c|c|c|c|c|}
\hline & \$/Pound & $\$ /$ Yen & $\$ /$ Euro & S\&P 500 & FTSE 100 & $\begin{array}{l}\text { DJ Euro } \\
\text { Stoxx } 50 \\
\end{array}$ & $\begin{array}{c}30-\text { Year } \\
\text { Treasury Bond }\end{array}$ & $\begin{array}{c}\text { British Long } \\
\text { Gilt }\end{array}$ & $\begin{array}{c}\text { German Euro } \\
\text { Bobl }\end{array}$ \\
\hline \multicolumn{10}{|c|}{ Full Sample } \\
\hline \$/Pound & 1.000 & 0.267 & 0.582 & -0.152 & -0.166 & -0.181 & 0.101 & 0.087 & 0.135 \\
\hline$\$ /$ Yen & & 1.000 & 0.367 & -0.123 & -0.124 & -0.149 & 0.052 & 0.040 & 0.061 \\
\hline$\$ /$ Euro & & & 1.000 & -0.227 & -0.215 & -0.253 & 0.127 & 0.114 & 0.187 \\
\hline S\&P 500 & & & & 1.000 & 0.420 & 0.502 & -0.129 & -0.119 & -0.178 \\
\hline FTSE 100 & & & & & 1.000 & 0.544 & -0.123 & -0.127 & -0.182 \\
\hline DJ Euro Stoxx 50 & & & & & & 1.000 & -0.174 & -0.169 & -0.250 \\
\hline 30-Year Treasury Bond & & & & & & & 1.000 & 0.526 & 0.583 \\
\hline British Long Gilt & & & & & & & & 1.000 & 0.614 \\
\hline German Euro Bobl & & & & & & & & & 1.000 \\
\hline \multicolumn{10}{|c|}{ Expansion Sample } \\
\hline \$/Pound & 1.000 & 0.230 & 0.547 & -0.124 & -0.107 & -0.118 & 0.024 & 0.021 & 0.049 \\
\hline$\$ /$ Yen & & 1.000 & 0.326 & -0.101 & -0.077 & -0.114 & -0.014 & -0.009 & -0.011 \\
\hline$\$ /$ Euro & & & 1.000 & -0.218 & -0.151 & -0.182 & 0.020 & 0.029 & 0.085 \\
\hline S\&P 500 & & & & 1.000 & 0.439 & 0.518 & 0.071 & 0.023 & 0.003 \\
\hline FTSE 100 & & & & & 1.000 & 0.407 & 0.056 & 0.015 & 0.004 \\
\hline DJ Euro Stoxx 50 & & & & & & 1.000 & 0.063 & 0.022 & 0.019 \\
\hline 30-Year Treasury Bond & & & & & & & 1.000 & 0.505 & 0.555 \\
\hline British Long Gilt & & & & & & & & 1.000 & 0.575 \\
\hline German Euro Bobl & & & & & & & & & 1.000 \\
\hline \multicolumn{10}{|c|}{ Recession Sample } \\
\hline \$/Pound & 1.000 & 0.345 & 0.637 & -0.184 & -0.249 & -0.251 & 0.196 & 0.204 & 0.237 \\
\hline$\$ /$ Yen & & 1.000 & 0.453 & -0.166 & -0.214 & -0.212 & 0.161 & 0.154 & 0.175 \\
\hline \$/Euro & & & 1.000 & -0.248 & -0.313 & -0.342 & 0.272 & 0.277 & 0.319 \\
\hline S\&P 500 & & & & 1.000 & 0.417 & 0.492 & -0.300 & -0.303 & -0.324 \\
\hline FTSE 100 & & & & & 1.000 & 0.698 & -0.345 & -0.379 & -0.399 \\
\hline DJ Euro Stoxx 50 & & & & & & 1.000 & -0.393 & -0.431 & -0.483 \\
\hline 30-Year Treasury Bond & & & & & & & 1.000 & 0.578 & 0.612 \\
\hline British Long Gilt & & & & & & & & 1.000 & 0.703 \\
\hline German Euro Bobl & & & & & & & & & 1.000 \\
\hline
\end{tabular}

Notes to Table 3: See the footnotes to Table 1 for a description of the different contracts. The unconditional cross correlations are based on the 15,764 five-minute returns ten minutes before and one-and-a-half hours after the release of each of the U.S. macroeconomic announcements described in Table 4. The full common sample spans July 1, 1998 through December 31, 2002. The expansion covers July 1, 1998 through February 28, 2001, for a total of 9,301 five-minute returns. The recession period spans March 1, 2001 to December 31, 2002, for a total of 6,463 five-minute returns. 
Table 4

\section{U.S. News Announcements}

\begin{tabular}{|c|c|c|c|c|}
\hline Announcement & Obs. $^{1}$ & Source $^{2}$ & Dates $^{3}$ & Announcement Time ${ }^{4}$ \\
\hline \multicolumn{5}{|c|}{ Quarterly Announcements } \\
\hline 1- GDP Advance & 51 & BEA & $01 / 92-12 / 02$ & $8: 30$ \\
\hline 2- GDP Preliminary & 50 & BEA & $01 / 92-12 / 02$ & $8: 30$ \\
\hline 3- GDP Final & 51 & BEA & $01 / 92-12 / 02$ & $8: 30$ \\
\hline \multicolumn{5}{|c|}{ Monthly Announcements } \\
\hline \multicolumn{5}{|l|}{ Real Activity } \\
\hline 4- Nonfarm Payroll Employment & 194 & BLS & $01 / 92-12 / 02^{5}$ & $8: 30$ \\
\hline 5- Retail Sales & 193 & $\mathrm{BC}$ & $01 / 92-12 / 02$ & $8: 30$ \\
\hline 6- Industrial Production & 193 & FRB & $01 / 92-12 / 02$ & $9: 15$ \\
\hline 7- Capacity Utilization & 177 & FRB & $01 / 92-12 / 02$ & $9: 15$ \\
\hline 8- Personal Income & 192 & BEA & $01 / 92-12 / 02^{6}$ & $10: 00 / 8: 30^{7}$ \\
\hline 9- Consumer Credit & 178 & FRB & $01 / 92-12 / 02$ & $15: 00^{8}$ \\
\hline \multicolumn{5}{|l|}{ Consumption } \\
\hline 10- New Home Sales & 167 & $\mathrm{BC}$ & $01 / 92-12 / 02$ & $10: 00$ \\
\hline $\begin{array}{l}\text { 11- Personal Consumption Expenditures } \\
\text { Investment }\end{array}$ & 192 & BEA & $01 / 92-12 / 02^{9}$ & $10: 00 / 8: 30^{10}$ \\
\hline 12- Durable Goods Orders & 237 & $\mathrm{BC}$ & $01 / 92-12 / 02^{11}$ & $8: 30 / 9: 00 / 10: 00^{12}$ \\
\hline 13- Factory Orders & 178 & $\mathrm{BC}$ & $01 / 92-12 / 02^{13}$ & $10: 00$ \\
\hline 14- Construction Spending & 177 & $\mathrm{BC}$ & $01 / 92-12 / 02^{14}$ & $10: 00$ \\
\hline 15- Business Inventories & 177 & $\mathrm{BC}$ & $01 / 92-12 / 02$ & $10: 00 / 8: 30^{15}$ \\
\hline \multicolumn{5}{|l|}{ Government Purchases } \\
\hline $\begin{array}{l}\text { 16- Government Budget } \\
\text { Net Exports }\end{array}$ & 175 & FMS & $01 / 92-12 / 02^{16}$ & $14: 00$ \\
\hline \multicolumn{5}{|l|}{ Prices } \\
\hline 18- Producer Price Index & 193 & BLS & $01 / 92-12 / 02$ & $8: 30$ \\
\hline $\begin{array}{l}\text { 19- Consumer Price Index } \\
\text { Forward-Looking }\end{array}$ & 275 & BLS & $01 / 92-12 / 02$ & $8: 30$ \\
\hline 20- Consumer Confidence Index & 138 & $\mathrm{CB}$ & $01 / 92-12 / 02$ & 10:00 \\
\hline 21- NAPM Index & 156 & NAPM & $01 / 92-12 / 02$ & $10: 00$ \\
\hline 22- Housing Starts & 269 & $\mathrm{BC}$ & $01 / 92-12 / 02$ & $8: 30$ \\
\hline 23- Index of Leading Indicators & 275 & $\mathrm{CB}$ & $01 / 92-12 / 02$ & $8: 30$ \\
\hline \multicolumn{5}{|c|}{ Six-Week Announcements } \\
\hline \multicolumn{5}{|l|}{ FOMC } \\
\hline 24- Target Federal Funds Rate & 175 & FRB & 01/92-12/02 & $14: 15^{17}$ \\
\hline \multicolumn{5}{|c|}{ Weekly Announcements } \\
\hline 25- Initial Unemployment Claims & 600 & ETA & $01 / 92-12 / 02$ & $8: 30$ \\
\hline
\end{tabular}


Notes to Table 4: We partition the U.S. monthly news announcements into seven groups: real activity, GDP constituents (consumption, investment, government purchases and net exports), prices, and forward-looking. Within each group, we list U.S. news announcements in chronological order of their release.

Footnotes to Table 4:

1. Total number of observations in our announcements and expectations data sample.

2. Bureau of Labor Statistics (BLS), Bureau of the Census (BC), Bureau of Economic Analysis (BEA), Federal Reserve

Board (FRB), National Association of Purchasing Managers (NAPM), Conference Board (CB), Financial

Management Office (FMO), Employment and Training Administration (ETA).

3. Starting and ending dates of our announcements and expectations data sample.

4. Eastern Standard Time. Daylight savings time starts on the first Sunday of April and ends on the last Sunday of October.

5. $10 / 98$ is a missing observation.

6. $11 / 95,2 / 96$ and $03 / 97$ are missing observations.

7. In 01/94, the personal income announcement time moved from 10:00 EST to 8:30 EST.

8. Beginning in 01/96, consumer credit was released regularly at 15:00 EST. Prior to this date the release times varied.

9. $11 / 95$ and $2 / 96$ are missing observations.

10. In 12/93, the personal consumption expenditures announcement time moved from 10:00 EST to 8:30 EST.

11. $03 / 96$ is a missing observation.

12. Whenever GDP is released on the same day as durable goods orders, the durable goods orders announcement is moved to 10:00 EST. On 07/96 the durable goods orders announcement was released at 9:00 EST.

13. $10 / 98$ is a missing observation.

14. $01 / 96$ is a missing observation.

15. In 01/97, the business inventory announcement was moved from 10:00 EST to 8:30 EST.

16. $05 / 88,06 / 88,11 / 98,12 / 89$ and $01 / 96$ are missing observations.

17. Beginning in $3 / 28 / 94$, the fed funds rate was released regularly at 14:15 EST. Prior to this date the release times varied. 
Table 5A

Contemporaneous News Response Coefficients U.S. Markets, Full Sample

\begin{tabular}{|c|c|c|c|c|c|c|c|c|c|c|}
\hline \multirow[b]{2}{*}{ Announcement } & \multicolumn{2}{|c|}{ \$/Pound } & \multicolumn{2}{|c|}{$\$ /$ Yen } & \multicolumn{2}{|c|}{$\$ /$ Euro } & \multicolumn{2}{|c|}{ S\&P 500} & \multicolumn{2}{|c|}{$\begin{array}{c}\text { 30-Year Treasury } \\
\text { Bond } \\
\end{array}$} \\
\hline & $\overline{\beta_{k}}$ & $R^{2}$ & $\overline{\beta_{k}}$ & $R^{2}$ & $\overline{\beta_{k}}$ & $R^{2}$ & $\overline{\beta_{k}}$ & $R^{2}$ & $\overline{\beta_{k}}$ & $R^{2}$ \\
\hline \multicolumn{11}{|c|}{ Quarterly Announcements } \\
\hline 1- GDP Advance & $-0.054 * *$ & 0.220 & $-0.048 * *$ & 0.154 & $-0.119 * *$ & 0.418 & 0.118 & 0.063 & $-0.095 * *$ & 0.097 \\
\hline 2- GDP Preliminary & -0.022 & 0.035 & $-0.026^{*}$ & 0.074 & $-0.050 * *$ & 0.118 & -0.029 & 0.024 & -0.030 & 0.030 \\
\hline 3- GDP Final & -0.011 & 0.018 & -0.014 & 0.034 & -0.010 & 0.012 & 0.005 & 0.002 & -0.017 & 0.031 \\
\hline \multicolumn{11}{|c|}{ Monthly Announcements } \\
\hline \multicolumn{11}{|l|}{ Real Activity } \\
\hline 4- Nonfarm Payroll Employment & $-0.098 * *$ & 0.160 & $-0.078 * *$ & 0.177 & $-0.153 * *$ & 0.218 & $-0.151 * *$ & 0.075 & $-0.325 * *$ & 0.360 \\
\hline 5- Retail Sales & $-0.042 * *$ & 0.152 & $-0.026 * *$ & 0.086 & $-0.056 * *$ & 0.134 & 0.004 & 0.000 & $-0.097 * *$ & 0.110 \\
\hline 6- Industrial Production & $-0.022 * *$ & 0.060 & $-0.016^{* *}$ & 0.045 & $-0.032 * *$ & 0.094 & -0.002 & 0.001 & $-0.062 * *$ & 0.194 \\
\hline 7- Capacity Utilization & -0.014 & 0.024 & -0.011 & 0.020 & $-0.025 * *$ & 0.058 & 0.006 & 0.004 & $-0.076^{* *}$ & 0.281 \\
\hline 8- Personal Income & $-0.016 * *$ & 0.053 & -0.005 & 0.005 & -0.014 & 0.024 & 0.000 & 0.000 & -0.017 & 0.013 \\
\hline 9- Consumer Credit & 0.000 & 0.000 & 0.000 & 0.001 & 0.001 & 0.011 & 0.018 & 0.025 & -0.002 & 0.009 \\
\hline \multicolumn{11}{|l|}{ Consumption } \\
\hline 10- New Home Sales & -0.011 & 0.022 & $-0.015^{* *}$ & 0.038 & -0.014 & 0.018 & $-0.031^{*}$ & 0.027 & $-0.077 * *$ & 0.244 \\
\hline $\begin{array}{l}\text { 11- Personal Consumption Expend. } \\
\text { Investment }\end{array}$ & -0.002 & 0.001 & -0.003 & 0.002 & -0.009 & 0.009 & -0.031 & 0.040 & -0.009 & 0.004 \\
\hline 12- Durable Goods Orders & $-0.038 * *$ & 0.167 & $-0.028 * *$ & 0.099 & $-0.070 * *$ & 0.264 & -0.019 & 0.007 & $-0.098 * *$ & 0.210 \\
\hline 13- Factory Orders & $-0.018^{* *}$ & 0.056 & $-0.014 * *$ & 0.029 & $-0.028^{* *}$ & 0.053 & 0.023 & 0.009 & -0.015 & 0.005 \\
\hline 14- Construction Spending & $-0.015^{*}$ & 0.043 & -0.002 & 0.001 & -0.016 & 0.024 & 0.013 & 0.005 & $-0.029 * *$ & 0.061 \\
\hline 15- Business Inventories & 0.006 & 0.007 & -0.002 & 0.001 & -0.004 & 0.002 & -0.020 & 0.007 & 0.022 & 0.013 \\
\hline \multicolumn{11}{|l|}{ Government Purchases } \\
\hline $\begin{array}{l}\text { 16- Government Budget } \\
\text { Trade Balance }\end{array}$ & $-0.006^{* *}$ & 0.032 & -0.005 & 0.021 & $-0.009 * *$ & 0.064 & 0.010 & 0.010 & 0.006 & 0.011 \\
\hline 17- Net Exports & $-0.049 * *$ & 0.164 & $-0.059 * *$ & 0.111 & $-0.078 * *$ & 0.196 & $0.040^{* *}$ & 0.099 & $0.018 *$ & 0.026 \\
\hline \multicolumn{11}{|l|}{ Prices } \\
\hline 18- Producer Price Index & 0.002 & 0.000 & 0.012 & 0.017 & 0.004 & 0.001 & $-0.094 * *$ & 0.100 & $-0.115 * *$ & 0.154 \\
\hline 19- Consumer Price Index & -0.014 & 0.031 & 0.003 & 0.002 & $-0.017 *$ & 0.025 & $-0.110^{* *}$ & 0.139 & $-0.110 * *$ & 0.166 \\
\hline \multicolumn{11}{|l|}{ Forward Looking } \\
\hline 20- Consumer Confidence Index & $-0.044 * *$ & 0.189 & $-0.036^{* *}$ & 0.203 & $-0.077 * *$ & 0.277 & 0.034 & 0.020 & $-0.088 * *$ & 0.361 \\
\hline 21- NAPM Index & $-0.035 * *$ & 0.201 & $-0.017 * *$ & 0.045 & $-0.049 * *$ & 0.140 & -0.011 & 0.002 & $-0.153 * *$ & 0.388 \\
\hline 22- Housing Starts & -0.011 & 0.020 & $-0.009 *$ & 0.020 & $-0.015^{*}$ & 0.023 & -0.014 & 0.011 & $-0.064 * *$ & 0.193 \\
\hline 23- Index of Leading Indicators & -0.004 & 0.002 & 0.003 & 0.001 & -0.006 & 0.003 & -0.006 & 0.006 & -0.005 & 0.001 \\
\hline \multicolumn{11}{|c|}{ Six-Week Announcements } \\
\hline 24- Target Federal Funds Rate & $-0.033^{*}$ & 0.116 & $-0.019^{*}$ & 0.024 & $-0.026^{*}$ & 0.037 & $-0.174 *$ & 0.131 & $-0.025^{*}$ & 0.048 \\
\hline \multicolumn{11}{|c|}{ Weekly Announcements } \\
\hline 25- Initial Unemployment Claims & $0.017 * *$ & 0.036 & $0.013 * *$ & 0.021 & $0.026 * *$ & 0.047 & 0.002 & 0.000 & $0.048 * *$ & 0.074 \\
\hline
\end{tabular}


Table 5A (continued)

Contemporaneous News Response Coefficients European Markets, Full Sample

\begin{tabular}{|c|c|c|c|c|c|c|c|c|}
\hline Announcement & \multicolumn{2}{|c|}{ British Long Gilt } & \multicolumn{2}{|c|}{ Euro Bobl } & \multicolumn{2}{|c|}{$\overline{\text { FTSE } 100}$} & \multicolumn{2}{|c|}{ DJ Euro Stoxx 50} \\
\hline & \multicolumn{6}{|c|}{ Quarterly Announcements } & & \\
\hline 2- GDP Preliminary & $-0.031 * *$ & 0.262 & -0.017 & 0.196 & -0.034 & 0.033 & 0.091 & 0.042 \\
\hline 3- GDP Final & -0.024 & 0.171 & -0.007 & 0.068 & 0.018 & 0.033 & -0.015 & 0.007 \\
\hline 4- Nonfarm Payroll Employment & $-0.071 * *$ & 0.142 & $-0.032 * *$ & 0.138 & $-0.117 * *$ & 0.086 & -0.030 & 0.001 \\
\hline 5- Retail Sales & $-0.029 * *$ & 0.165 & $-0.032 * *$ & 0.346 & -0.007 & 0.001 & $0.087 * *$ & 0.100 \\
\hline 6- Industrial Production & $-0.021 * *$ & 0.293 & $-0.018 * *$ & 0.390 & 0.051 & 0.035 & 0.063 & 0.086 \\
\hline 7- Capacity Utilization & $-0.023 * *$ & 0.247 & $-0.019 * *$ & 0.370 & 0.007 & 0.001 & 0.063 & 0.056 \\
\hline $\begin{array}{l}\text { 8- Personal Income } \\
\text { Consumption }\end{array}$ & -0.006 & 0.019 & -0.002 & 0.005 & 0.005 & 0.001 & -0.027 & 0.027 \\
\hline 12- Durable Goods Orders & $-0.029 * *$ & 0.323 & $-0.021 * *$ & 0.285 & 0.015 & 0.007 & 0.091 & 0.084 \\
\hline 13- Construction Spending & -0.010 & 0.011 & -0.007 & 0.017 & 0.023 & 0.013 & $0.096^{*}$ & 0.057 \\
\hline 14- Factory Orders & $-0.016^{* *}$ & 0.074 & $-0.007 * *$ & 0.049 & 0.008 & 0.001 & $0.070 * *$ & 0.051 \\
\hline 15- Business Inventories & 0.008 & 0.013 & 0.002 & 0.001 & -0.026 & 0.017 & -0.012 & 0.001 \\
\hline \multicolumn{9}{|l|}{ Trade Balance } \\
\hline 17- Net Exports & 0.001 & 0.000 & 0.003 & 0.015 & $0.037 * *$ & 0.087 & 0.045 & 0.075 \\
\hline \multicolumn{9}{|l|}{ Prices } \\
\hline 18- Producer Price Index & $-0.028 * *$ & 0.160 & $-0.017 * *$ & 0.148 & $-0.092 * *$ & 0.135 & -0.034 & 0.013 \\
\hline 19- Consumer Price Index & $-0.029 *$ & 0.111 & $-0.010 *$ & 0.060 & $-0.084 * *$ & 0.185 & $-0.139 * *$ & 0.223 \\
\hline 25- Initial Unemployment Claims & $0.010 * *$ & 0.037 & $0.008 * *$ & 0.060 & 0.003 & 0.000 & $-0.032 * *$ & 0.018 \\
\hline
\end{tabular}

Notes to Table 5A: We report $\hat{\beta}_{k}$ and $R^{2}$ from the contemporaneous news response regression, $R_{t}^{h}=\alpha_{k}^{h}+\beta_{k}^{h} S_{k t}+\epsilon_{t}^{h}$, where $R_{t}^{h}$ denotes the five-minute return from $t$ to $t+1$, and $S_{k t}$ refers to the standardized news announcement, for nine asset returns, $h$, and twenty-five news announcements, $k$. The model is estimated using only those observations $\left(R_{t}^{h}, S_{k t}\right)$ such that an announcement was made at time $t$. Two asterisks denote statistical significance at the five-percent level, and one asterisk denotes statistical significance at the ten-percent level, where we assess significance with asymptotic tstatistics constructed using heteroskedasticity and autocorrelation consistent standard errors. The sample for the exchange rates and the U.S. Treasury bond goes from January 2, 1992 through December 31, 2002. The results for the S\&P500 are based on the slightly shorter sample starting January 2, 1994. Data for the European stock and bond contracts are only available from July 1, 1998 through December 31, 2002. We do not estimate the consumer credit, government budget and federal funds rate responses (announcements 9,16 and 24) for the European markets, because LIFFE and EUREX are not open after 14:00 EST when the announcements are made. 
Table 5B

Contemporaneous News Response Coefficients

U.S. Markets, Expansion Sample

\begin{tabular}{|c|c|c|c|c|c|c|c|c|c|c|}
\hline \multirow[b]{2}{*}{ Announcement } & \multicolumn{2}{|c|}{ \$/Pound } & \multicolumn{2}{|c|}{$\$ /$ Yen } & \multicolumn{2}{|c|}{$\$ /$ Euro } & \multicolumn{2}{|c|}{ S\&P 500} & \multicolumn{2}{|c|}{$\begin{array}{c}\text { 30-Year } \\
\text { Treasury Bond }\end{array}$} \\
\hline & $\overline{\beta_{k}}$ & $R^{2}$ & $\beta_{k}$ & $R^{2}$ & $\beta_{k}$ & $R^{2}$ & $\beta_{k}$ & $R^{2}$ & $\beta_{k}$ & $R^{2}$ \\
\hline \multicolumn{11}{|c|}{$\overline{\text { Quarterly Announcements }}$} \\
\hline 1- GDP Advance & $-0.054 * *$ & 0.217 & $-0.048 * *$ & 0.142 & $-0.118 * *$ & 0.405 & 0.049 & 0.010 & $-0.089 * *$ & 0.072 \\
\hline 2- GDP Preliminary & -0.017 & 0.019 & $-0.026^{*}$ & 0.074 & $-0.050 *$ & 0.112 & $-0.064 * *$ & 0.166 & -0.017 & 0.009 \\
\hline 3- GDP Final & -0.017 & 0.048 & -0.017 & 0.046 & -0.013 & 0.021 & -0.009 & 0.011 & -0.010 & 0.013 \\
\hline \multicolumn{11}{|c|}{ Monthly Announcements } \\
\hline \multicolumn{11}{|l|}{ Real Activity } \\
\hline 4- Nonfarm Payr & $-0.098 * *$ & 0.162 & $-0.077 * *$ & 0.180 & $-0.148 * *$ & 0.220 & $-0.220 * *$ & 0.200 & $-0.330 * *$ & 0.372 \\
\hline 5- Retail Sales & $-0.076^{* *}$ & 0.188 & -0.023 & 0.029 & $-0.089 * *$ & 0.135 & $-0.131 * *$ & 0.069 & $-0.213 * *$ & 0.218 \\
\hline 6- Industrial Production & $-0.025 * *$ & 0.062 & $-0.022 * *$ & 0.067 & $-0.034 * *$ & 0.087 & -0.001 & 0.000 & $-0.068 * *$ & 0.187 \\
\hline 7- Capacity Utilization & -0.016 & 0.026 & -0.014 & 0.028 & $-0.027 * *$ & 0.060 & 0.009 & 0.005 & $-0.083 * *$ & 0.297 \\
\hline 8- Personal Income & $-0.020 * *$ & 0.085 & -0.007 & 0.014 & -0.018 & 0.038 & 0.000 & 0.000 & -0.018 & 0.014 \\
\hline \multicolumn{11}{|l|}{ Consumption } \\
\hline 10- New Home Sales & -0.010 & 0.020 & -0.011 & 0.031 & -0.013 & 0.016 & $-0.042 * *$ & 0.055 & $-0.082 * *$ & 0.263 \\
\hline $\begin{array}{l}\text { 11- Personal Consumption Expend. } \\
\text { Investment }\end{array}$ & -0.006 & 0.006 & -0.006 & 0.009 & -0.013 & 0.015 & -0.033 & 0.033 & -0.024 & 0.017 \\
\hline 12- Durable Goods Orders & $-0.047 * *$ & 0.201 & $-0.028 * *$ & 0.085 & $-0.077 * *$ & 0.261 & $-0.090 * *$ & 0.181 & $-0.117 * *$ & 0.237 \\
\hline 13- Factor & $-0.016 * *$ & 0.051 & $-0.012 * *$ & 0.029 & $-0.029 * *$ & 0.063 & -0.001 & 0.000 & -0.009 & 0.002 \\
\hline 14- Const & $-0.015^{*}$ & 0.044 & 0.000 & 0.000 & -0.016 & 0.030 & -0.011 & 0.004 & $-0.026^{*}$ & 0.047 \\
\hline 15- Business Inventories & 0.005 & 0.003 & -0.001 & 0.000 & -0.006 & 0.003 & -0.020 & 0.006 & 0.009 & 0.002 \\
\hline \multicolumn{11}{|l|}{ Government Purchases } \\
\hline $\begin{array}{l}\text { 16- Government Budget } \\
\text { Trade Balance }\end{array}$ & $-0.007 * *$ & 0.034 & -0.006 & 0.018 & -0.005 & 0.019 & 0.004 & 0.001 & 0.004 & 0.005 \\
\hline $\begin{array}{l}\text { 17- Net Exports } \\
\text { Prices }\end{array}$ & $-0.063 * *$ & 0.210 & $-0.076^{*}$ & 0.142 & $-0.100 * *$ & 0.246 & $0.033^{*}$ & 0.046 & 0.019 & 0.025 \\
\hline 18- Produce & 0.000 & 0.000 & 0.016 & 0.022 & 0.004 & 0.000 & $-0.165^{* *}$ & 0.204 & $-0.174 * *$ & 0.234 \\
\hline \multicolumn{11}{|l|}{ Forward Looking } \\
\hline 20- Consumer Cor & $-0.043 * *$ & 0.160 & $-0.029 * *$ & 0.129 & $-0.066^{* *}$ & 0.219 & $-0.035 * *$ & 0.047 & $-0.076^{* *}$ & 0.301 \\
\hline 21- NAPM Index & $-0.030 * *$ & 0.160 & $-0.014 *$ & 0.033 & $-0.040 * *$ & 0.104 & $-0.076^{* *}$ & 0.097 & $-0.159 * *$ & 0.405 \\
\hline 22- Housing Starts & -0.010 & 0.014 & -0.010 & 0.019 & -0.016 & 0.022 & $-0.027 * *$ & 0.040 & $-0.072 * *$ & 0.216 \\
\hline 23- Index of Leading Indicators & -0.007 & 0.004 & 0.001 & 0.000 & -0.019 & 0.013 & -0.010 & 0.012 & -0.011 & 0.003 \\
\hline \multicolumn{11}{|c|}{ Six-Week Announcements } \\
\hline 24- Target Federal Funds Rate & $-0.075 * *$ & 0.245 & $-0.083 *$ & 0.168 & $-0.078 * *$ & 0.148 & $-0.130 *$ & 0.054 & $-0.080 * *$ & 0.189 \\
\hline \multicolumn{11}{|c|}{ Weekly Announcements } \\
\hline 25- Initial Unemployment Claims & $0.018^{* *}$ & 0.034 & $0.014 * *$ & 0.018 & $0.027 * *$ & 0.041 & $0.018^{*}$ & 0.008 & $0.054 * *$ & 0.072 \\
\hline
\end{tabular}


Table 5B (continued)

Contemporaneous News Response Coefficients

European Markets, Expansion Sample

\begin{tabular}{|c|c|c|c|c|c|c|c|c|}
\hline \multirow{2}{*}{ Announcement } & \multicolumn{2}{|c|}{ British Long Gilt } & \multicolumn{2}{|c|}{ Euro Bobl } & \multicolumn{2}{|c|}{ FTSE 100} & \multicolumn{2}{|c|}{ DJ Euro Stoxx 50} \\
\hline & $\beta_{k}$ & $R^{2}$ & $\overline{\beta_{k}}$ & $R^{2}$ & $\overline{\beta_{k}}$ & $R^{2}$ & $\beta_{k}$ & $R^{2}$ \\
\hline & \multicolumn{6}{|c|}{ Quarterly Announcements } & & \\
\hline 1- GDP Advance & -0.017 & 0.026 & -0.012 & 0.058 & 0.029 & 0.009 & $0.173 *$ & 0.156 \\
\hline 2- GDP Preliminary & -0.040 & 0.280 & -0.004 & 0.018 & $-0.050 * *$ & 0.116 & $-0.141 * *$ & 0.161 \\
\hline \multirow[t]{2}{*}{ 3- GDP Final } & -0.022 & 0.088 & -0.008 & 0.082 & 0.002 & 0.000 & $-0.09 *$ & 0.261 \\
\hline & \multicolumn{6}{|c|}{ Monthly Announcements } & & \\
\hline \multicolumn{9}{|l|}{ Real Activity } \\
\hline 4- Nonfarm Payroll Employment & $-0.060 * *$ & 0.122 & $-0.028 * *$ & 0.180 & $-0.156^{* *}$ & 0.174 & -0.178 & 0.052 \\
\hline 5- Retail Sales & $-0.078 * *$ & 0.179 & $-0.038 * *$ & 0.169 & $-0.095 * *$ & 0.095 & $-0.215^{*}$ & 0.176 \\
\hline 6- Industrial Production & $-0.017 * *$ & 0.214 & $-0.013 * *$ & 0.337 & 0.028 & 0.009 & $-0.034 *$ & 0.070 \\
\hline 7- Capacity Utilization & $-0.025 * *$ & 0.246 & $-0.015^{* *}$ & 0.404 & -0.019 & 0.005 & $-0.086 * *$ & 0.244 \\
\hline 8- Personal Income & -0.007 & 0.033 & -0.004 & 0.032 & 0.007 & 0.004 & $-0.039 * *$ & 0.070 \\
\hline \multicolumn{9}{|l|}{ Consumption } \\
\hline 10- New Home Sales & -0.010 & 0.072 & $-0.008 * *$ & 0.097 & $-0.028 * *$ & 0.049 & $-0.052 * *$ & 0.117 \\
\hline 11- Personal Consumption Expend. & -0.003 & 0.004 & -0.001 & 0.002 & -0.014 & 0.011 & $-0.085^{* *}$ & 0.171 \\
\hline \multicolumn{9}{|l|}{ Investment } \\
\hline 12- Durable Goods Orders & $-0.036^{* *}$ & 0.470 & $-0.020 * *$ & 0.317 & $-0.045^{* *}$ & 0.098 & $-0.073 * *$ & 0.250 \\
\hline 13- Construction Spending & -0.007 & 0.005 & -0.004 & 0.008 & 0.006 & 0.001 & 0.034 & 0.019 \\
\hline 14- Factory Orders & $-0.020 * *$ & 0.087 & -0.006 & 0.042 & -0.023 & 0.015 & 0.008 & 0.002 \\
\hline 15- Business Inventories & 0.001 & 0.000 & -0.007 & 0.015 & -0.027 & 0.015 & -0.006 & 0.000 \\
\hline \multicolumn{9}{|l|}{ Trade Balance } \\
\hline 17- Net Exports & -0.002 & 0.003 & 0.001 & 0.003 & $0.040 *$ & 0.084 & $0.099 * *$ & 0.154 \\
\hline \multicolumn{9}{|l|}{ Prices } \\
\hline 18- Producer Price Index & $-0.057 * *$ & 0.285 & $-0.028 * *$ & 0.256 & $-0.155^{* *}$ & 0.280 & $-0.191 * *$ & 0.253 \\
\hline 19- Consumer Price Index & $-0.048 *$ & 0.213 & -0.013 & 0.088 & $-0.098 * *$ & 0.224 & $-0.208^{* *}$ & 0.346 \\
\hline \multicolumn{9}{|l|}{ Forward Looking } \\
\hline 20- Consumer Confidence Index & $-0.025 * *$ & 0.254 & $-0.013 * *$ & 0.270 & $-0.024 * *$ & 0.035 & -0.044 & 0.021 \\
\hline 21- NAPM Index & $-0.081 * *$ & 0.444 & $-0.041 * *$ & 0.457 & $-0.076^{* *}$ & 0.142 & $-0.131 * *$ & 0.163 \\
\hline 22- Housing Starts & 0.002 & 0.000 & -0.006 & 0.033 & $-0.033 * *$ & 0.079 & -0.015 & 0.004 \\
\hline 23- Index of Leading Indicators & 0.001 & 0.001 & -0.003 & 0.030 & 0.014 & 0.020 & -0.006 & 0.003 \\
\hline \multicolumn{9}{|c|}{ Weekly Announcements } \\
\hline 25- Initial Unemployment Claims & 0.007 & 0.011 & $0.007 * *$ & 0.039 & $0.016 * *$ & 0.008 & -0.011 & 0.002 \\
\hline
\end{tabular}

Notes to Table 5B: See the notes to Table 5A. The expansion sample for the U.S. markets covers January 2, 1992 through February 28, 2001, except for the S\&P500 results which are based on the slightly shorter sample starting January 2, 1994. The expansion data for the European markets spans July 1, 1998 through February 28, 2001. 
Table 5C

Contemporaneous News Response Coefficients U.S. Markets, Recession Sample

\begin{tabular}{|c|c|c|c|c|c|c|c|c|c|c|}
\hline \multirow[b]{2}{*}{ Announcement } & \multicolumn{2}{|c|}{ \$/Pound } & \multicolumn{2}{|c|}{ \$/Yen } & \multicolumn{2}{|c|}{$\$ /$ Euro } & \multicolumn{2}{|c|}{ S\&P 500} & \multicolumn{2}{|c|}{$\begin{array}{c}30-\text { Year } \\
\text { Treasury Bond }\end{array}$} \\
\hline & $\overline{\beta_{k}}$ & $R^{2}$ & $\beta_{k}$ & $R^{2}$ & $\beta_{k}$ & $R^{2}$ & $\beta_{k}$ & $R^{2}$ & $\beta_{k}$ & $R^{2}$ \\
\hline \multicolumn{11}{|c|}{$\overline{\text { Quarterly Announcements }}$} \\
\hline 1- GDP Advance & $-0.060 * *$ & 0.325 & -0.046 & 0.269 & $-0.128 * *$ & 0.584 & $0.388 * *$ & 0.814 & $-0.131 * *$ & 0.850 \\
\hline 2- GDP Preliminary & -0.044 & 0.309 & -0.020 & 0.068 & -0.052 & 0.174 & 0.088 & 0.142 & $-0.084^{*}$ & 0.296 \\
\hline 3- GDP Final & 0.041 & 0.232 & 0.013 & 0.058 & 0.025 & 0.102 & 0.080 & 0.162 & -0.059 & 0.169 \\
\hline \multicolumn{11}{|c|}{ Monthly Announcements } \\
\hline Real Activity & & & & & & & & & & \\
\hline 4- Nonfarm Payroll Emp & $-0.107 * *$ & 0.136 & $-0.072 * *$ & 0.099 & $-0.209 * *$ & 0.202 & $0.415^{* *}$ & 0.180 & $-0.298 * *$ & 0.247 \\
\hline 5- Retail Sales & $-0.023 * *$ & 0.323 & $-0.027 * *$ & 0.322 & $-0.038 * *$ & 0.275 & $0.056^{*}$ & 0.134 & -0.031 & 0.046 \\
\hline 6- Industrial Production & -0.014 & 0.091 & -0.008 & 0.035 & $-0.028 * *$ & 0.186 & -0.010 & 0.015 & $-0.044 * *$ & 0.242 \\
\hline 7- Capacity Utilization & -0.007 & 0.018 & -0.004 & 0.006 & -0.017 & 0.058 & 0.013 & 0.028 & $-0.044 * *$ & 0.216 \\
\hline 8- Personal Income & $0.033^{*}$ & 0.161 & 0.020 & 0.026 & 0.029 & 0.059 & 0.006 & 0.001 & -0.006 & 0.002 \\
\hline 9- Consumer Credit & 0.000 & 0.000 & 0.000 & 0.000 & 0.000 & 0.000 & $0.063 * *$ & 0.441 & 0.000 & 0.000 \\
\hline \multicolumn{11}{|l|}{ Consumption } \\
\hline 10- New Home Sales & -0.020 & 0.052 & $-0.051 * *$ & 0.126 & -0.024 & 0.040 & 0.038 & 0.025 & -0.042 & 0.112 \\
\hline $\begin{array}{l}\text { 11- Personal Consumption Expend. } \\
\text { Investment }\end{array}$ & 0.004 & 0.014 & 0.004 & 0.005 & 0.001 & 0.000 & $-0.028 *$ & 0.127 & 0.020 & 0.076 \\
\hline 12- Durable Goods Orders & .015 & 0.088 & -0.027 & 0.152 & $-0.052 *$ & 0.328 & $0.116^{*}$ & 0.197 & -0.053 & 0.163 \\
\hline 13- Factor & $-0.030 *$ & 0.093 & -0.022 & 0.034 & -0.020 & 0.016 & $0.199 * *$ & 0.213 & $-0.062 *$ & 0.047 \\
\hline 14- Construction Spending & -0.022 & 0.070 & -0.008 & 0.018 & -0.023 & 0.040 & $0.106^{* *}$ & 0.152 & $-0.042 *$ & 0.131 \\
\hline 15- Business Inventories & 0.008 & 0.088 & -0.006 & 0.017 & -0.001 & 0.001 & -0.024 & 0.076 & 0.056 & 0.217 \\
\hline \multicolumn{11}{|l|}{ Government Purchases } \\
\hline $\begin{array}{l}\text { 16- Government Budget } \\
\text { Trade Balance }\end{array}$ & -0.002 & 0.007 & -0.004 & 0.022 & $-0.015^{* *}$ & 0.218 & $0.018 * *$ & 0.050 & 0.011 & 0.053 \\
\hline $\begin{array}{l}\text { 17- Net Exports } \\
\text { Prices }\end{array}$ & -0.013 & 0.050 & -0.011 & 0.029 & -0.018 & 0.057 & $0.052 * *$ & 0.358 & 0.010 & 0.021 \\
\hline$\overline{18-\text { Prod }}$ & 0.003 & 0.005 & 0.006 & 0.014 & 0.004 & 0.004 & -0.020 & 0.024 & -0.022 & 0.030 \\
\hline 19- Consumer Price Index & -0.001 & 0.001 & -0.006 & 0.030 & $-0.026^{* *}$ & 0.270 & -0.022 & 0.046 & -0.004 & 0.001 \\
\hline \multicolumn{11}{|l|}{ Forward Looking } \\
\hline 20- Consumer Co & $-0.046^{* *}$ & 0.286 & $-0.059 * *$ & 0.492 & $-0.107 * *$ & 0.435 & $0.208 * *$ & 0.322 & $-0.121 * *$ & 0.509 \\
\hline 21- NAPM Index & $-0.048 * *$ & 0.350 & $-0.025^{*}$ & 0.071 & $-0.071 * *$ & 0.276 & $0.248 * *$ & 0.471 & $-0.131 * *$ & 0.317 \\
\hline 22- Housing Starts & $-0.016^{*}$ & 0.126 & -0.010 & 0.034 & -0.015 & 0.056 & 0.034 & 0.096 & -0.030 & 0.094 \\
\hline 23- Index of Leading & 0.001 & 0.002 & 0.005 & 0.016 & 0.009 & 0.038 & -0.006 & 0.006 & -0.002 & 0.001 \\
\hline \multicolumn{11}{|c|}{ Six-Week Announcements } \\
\hline 24- Target Federal Funds Rate & -0.011 & 0.039 & 0.009 & 0.036 & -0.006 & 0.004 & -0.203 & 0.183 & -0.008 & 0.009 \\
\hline \multicolumn{11}{|c|}{ Weekly Announcements } \\
\hline 25- Initial Unemployment Claims & $0.012 * *$ & 0.066 & $0.011 * *$ & 0.049 & $0.022 * *$ & 0.105 & -0.023 & 0.023 & $0.036^{* *}$ & 0.110 \\
\hline
\end{tabular}


Table 5C (continued)

Contemporaneous News Response Coefficients

European Markets, Recession Sample

\begin{tabular}{|c|c|c|c|c|c|c|c|c|}
\hline \multirow[b]{2}{*}{ Announcement } & \multicolumn{2}{|c|}{ British Long Gilt } & \multicolumn{2}{|c|}{ Euro Bobl } & \multicolumn{2}{|c|}{ FTSE 100} & \multicolumn{2}{|c|}{ DJ Euro Stoxx 50} \\
\hline & $\beta_{k}$ & $R^{2}$ & $\beta_{k}$ & $R^{2}$ & $\beta_{k}$ & $R^{2}$ & $\beta_{k}$ & $R^{2}$ \\
\hline & \multicolumn{6}{|c|}{ Quarterly Announcements } & & \\
\hline 1- GDP Advance & $-0.095 * *$ & 0.763 & $-0.099 * *$ & 0.881 & $0.278 * *$ & 0.839 & $0.683 * *$ & 0.683 \\
\hline 2- GDP Preliminary & -0.025 & 0.258 & $-0.030 * *$ & 0.485 & 0.222 & 0.206 & $0.238^{*}$ & 0.237 \\
\hline \multirow[t]{2}{*}{ 3- GDP Final } & $-0.027 * *$ & 0.537 & -0.004 & 0.023 & $0.114 * *$ & 0.513 & 0.068 & 0.184 \\
\hline & \multicolumn{6}{|c|}{ Monthly Announcements } & & \\
\hline \multicolumn{9}{|l|}{ Real Activity } \\
\hline 4- Nonfarm Payroll Employment & $-0.121 * *$ & 0.261 & $-0.068 * *$ & 0.170 & $0.274 * *$ & 0.181 & $0.386 * *$ & 0.102 \\
\hline 5- Retail Sales & $-0.024 * *$ & 0.239 & $-0.031 * *$ & 0.442 & 0.040 & 0.116 & $0.115^{*}$ & 0.234 \\
\hline 6- Industrial Production & $-0.026^{* *}$ & 0.417 & $-0.028 * *$ & 0.527 & $0.146^{* *}$ & 0.455 & $0.222 * *$ & 0.502 \\
\hline 7- Capacity Utilization & $-0.022 * *$ & 0.248 & $-0.025 * *$ & 0.386 & $0.111^{* *}$ & 0.233 & $0.212 * *$ & 0.406 \\
\hline $\begin{array}{l}\text { 8- Personal Income } \\
\text { Consumption }\end{array}$ & 0.002 & 0.001 & 0.005 & 0.023 & -0.009 & 0.002 & 0.016 & 0.005 \\
\hline 10- New Home Sales & -0.016 & 0.105 & $-0.021 * *$ & 0.265 & $0.047 * *$ & 0.056 & 0.055 & 0.038 \\
\hline 11- Personal Consumption Expend. & 0.001 & 0.001 & -0.002 & 0.014 & -0.018 & 0.037 & 0.005 & 0.003 \\
\hline \multicolumn{9}{|l|}{ Investment } \\
\hline 12- Durable Goods Orders & -0.022 & 0.190 & -0.021 & 0.250 & $0.159 *$ & 0.441 & $0.281 * *$ & 0.424 \\
\hline 13- Construction Spending & -0.020 & 0.039 & $-0.018 * *$ & 0.047 & $0.147 *$ & 0.198 & $0.271 * *$ & 0.180 \\
\hline 14- Factory Orders & $-0.012 *$ & 0.065 & $-0.012 *$ & 0.093 & $0.122 * *$ & 0.199 & $0.152 * *$ & 0.142 \\
\hline 15- Business Inventories & 0.014 & 0.158 & 0.011 & 0.121 & $-0.026^{*}$ & 0.138 & -0.019 & 0.024 \\
\hline \multicolumn{9}{|l|}{ Trade Balance } \\
\hline 17- Net Exports & 0.002 & 0.019 & 0.002 & 0.019 & $0.029 *$ & 0.159 & 0.020 & 0.035 \\
\hline \multicolumn{9}{|l|}{ Prices } \\
\hline 18- Producer Price Index & -0.008 & 0.050 & -0.004 & 0.019 & 0.003 & 0.001 & 0.031 & 0.016 \\
\hline 19- Consumer Price Index & 0.000 & 0.000 & -0.005 & 0.019 & -0.028 & 0.059 & -0.035 & 0.054 \\
\hline \multicolumn{9}{|l|}{ Forward Looking } \\
\hline 20- Consumer Confidence Index & $-0.035 * *$ & 0.253 & $-0.038 * *$ & 0.344 & $0.190 * *$ & 0.259 & $0.286^{* *}$ & 0.213 \\
\hline 21- NAPM Index & $-0.060 * *$ & 0.464 & $-0.046^{* *}$ & 0.420 & $0.174 * *$ & 0.399 & $0.380 * *$ & 0.498 \\
\hline 22- Housing Starts & $-0.01 *$ & 0.100 & $-0.013 * *$ & 0.262 & $0.057 * *$ & 0.230 & 0.048 & 0.074 \\
\hline 23- Index of Leading Indicators & 0.000 & 0.000 & 0.002 & 0.015 & -0.007 & 0.008 & -0.015 & 0.015 \\
\hline \multicolumn{9}{|c|}{ Weekly Announcements } \\
\hline 25- Initial Unemployment Claims & $0.011 * *$ & 0.082 & $0.008 * *$ & 0.086 & $-0.023^{*}$ & 0.029 & $-0.043 * *$ & 0.038 \\
\hline
\end{tabular}

Notes to Table 5C: See the notes to Table 5A. The recession sample for all of the markets goes from March 1, 2001 through December 31, 2002. 
Figure 1A

\section{Bond Market News Announcement Responses, Full Sample}
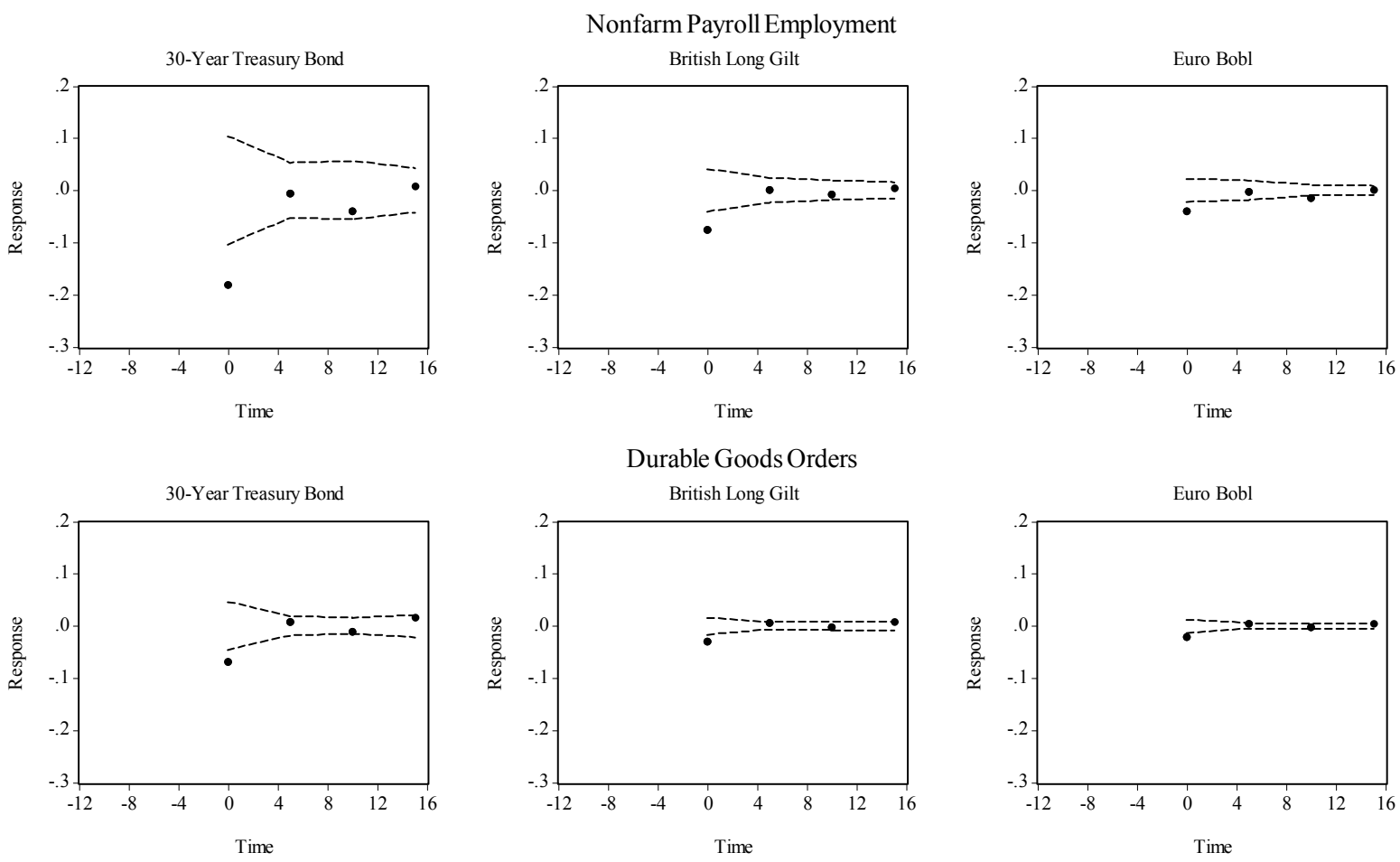

Durable Goods Orders
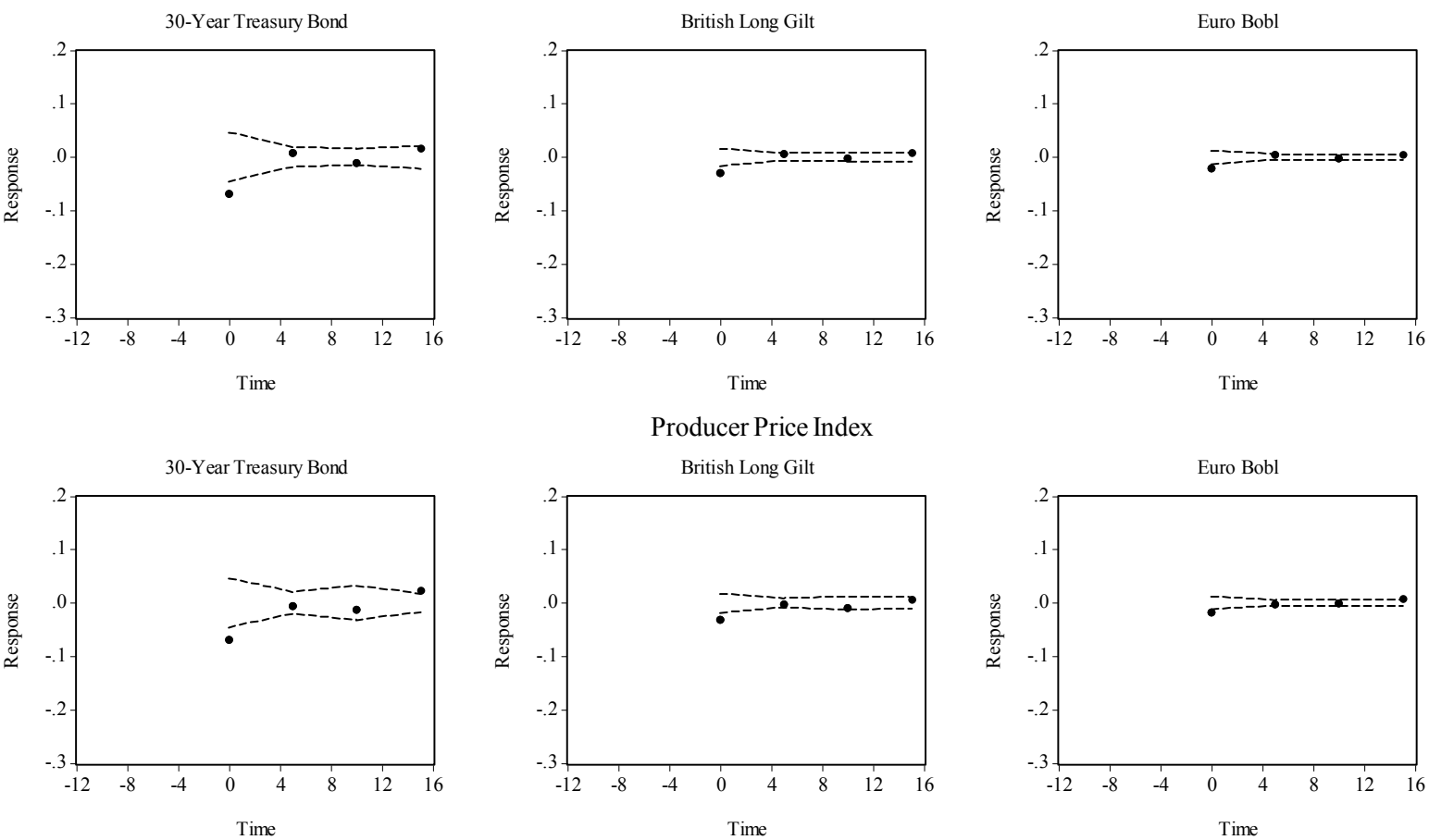

Producer Price Index
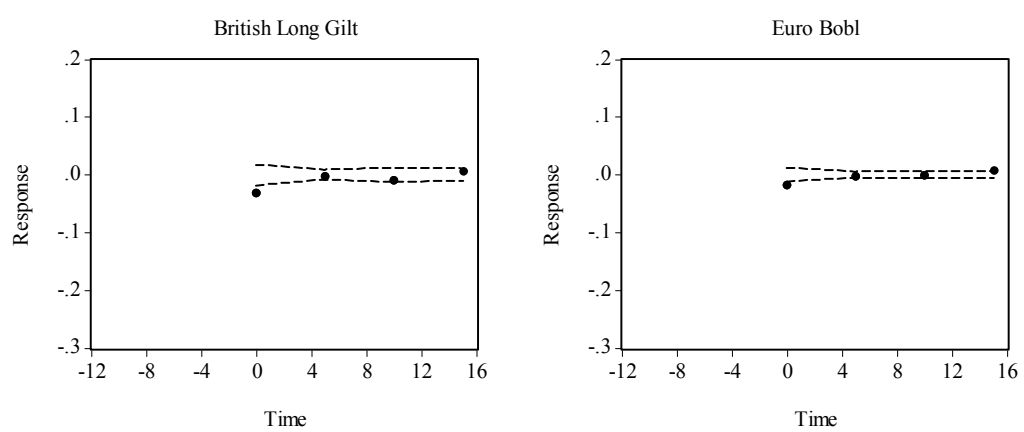

Initial Unemployment Claims
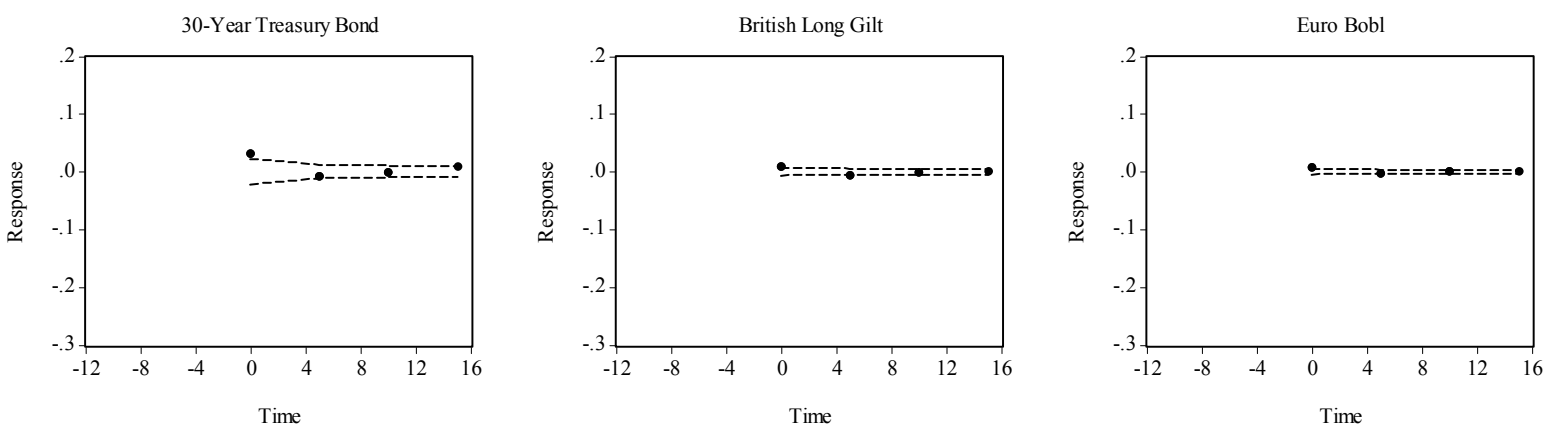
Figure 1A (continued)

Foreign Exchange Market News Announcement Responses, Full Sample
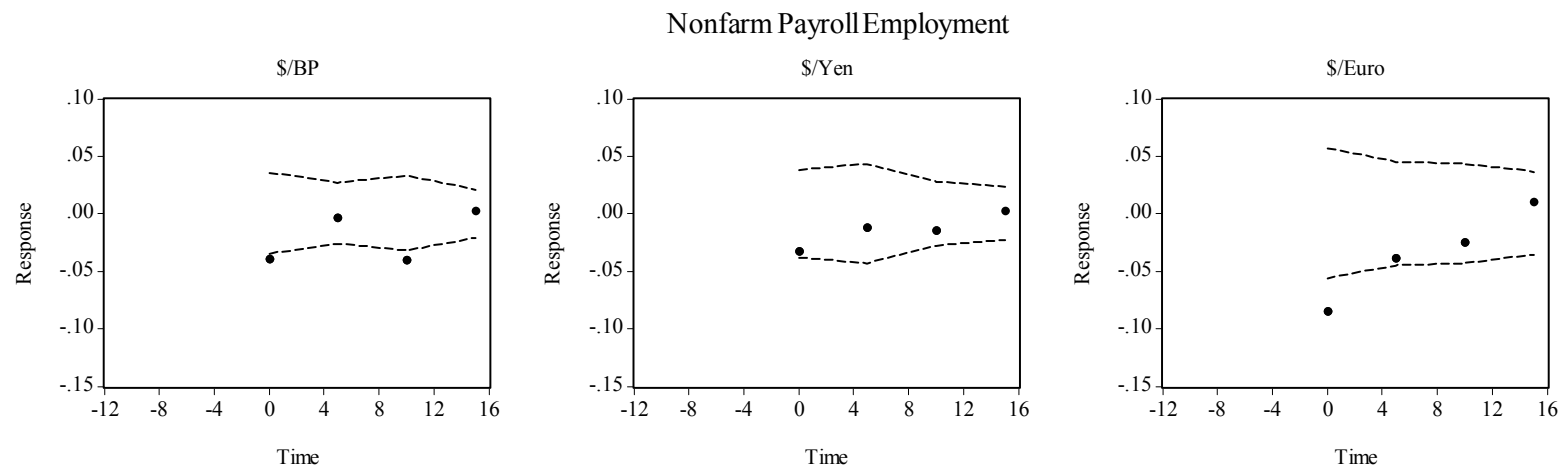

Durable Goods Orders
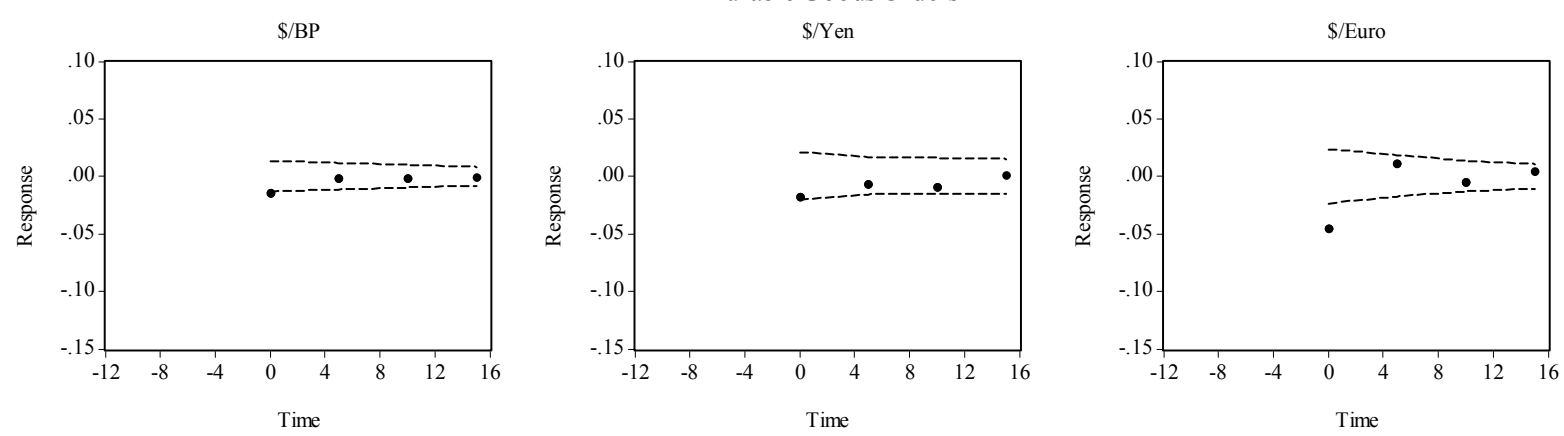

Producer Price Index
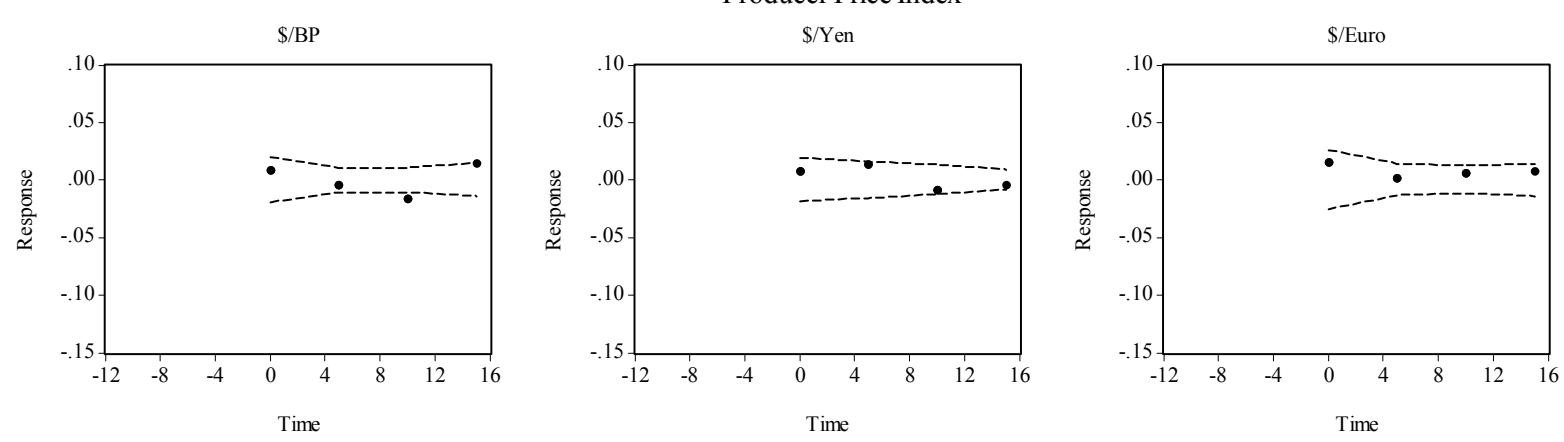

Initial Unemployment Claims
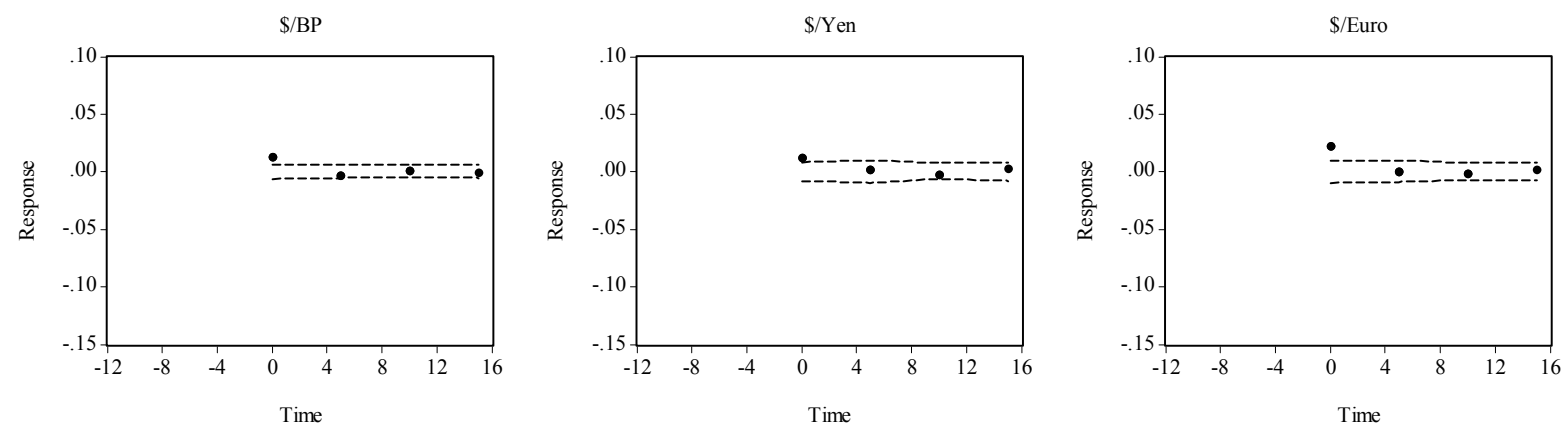
Figure 1A (continued)

Stock Market News Announcement Responses, Full Sample
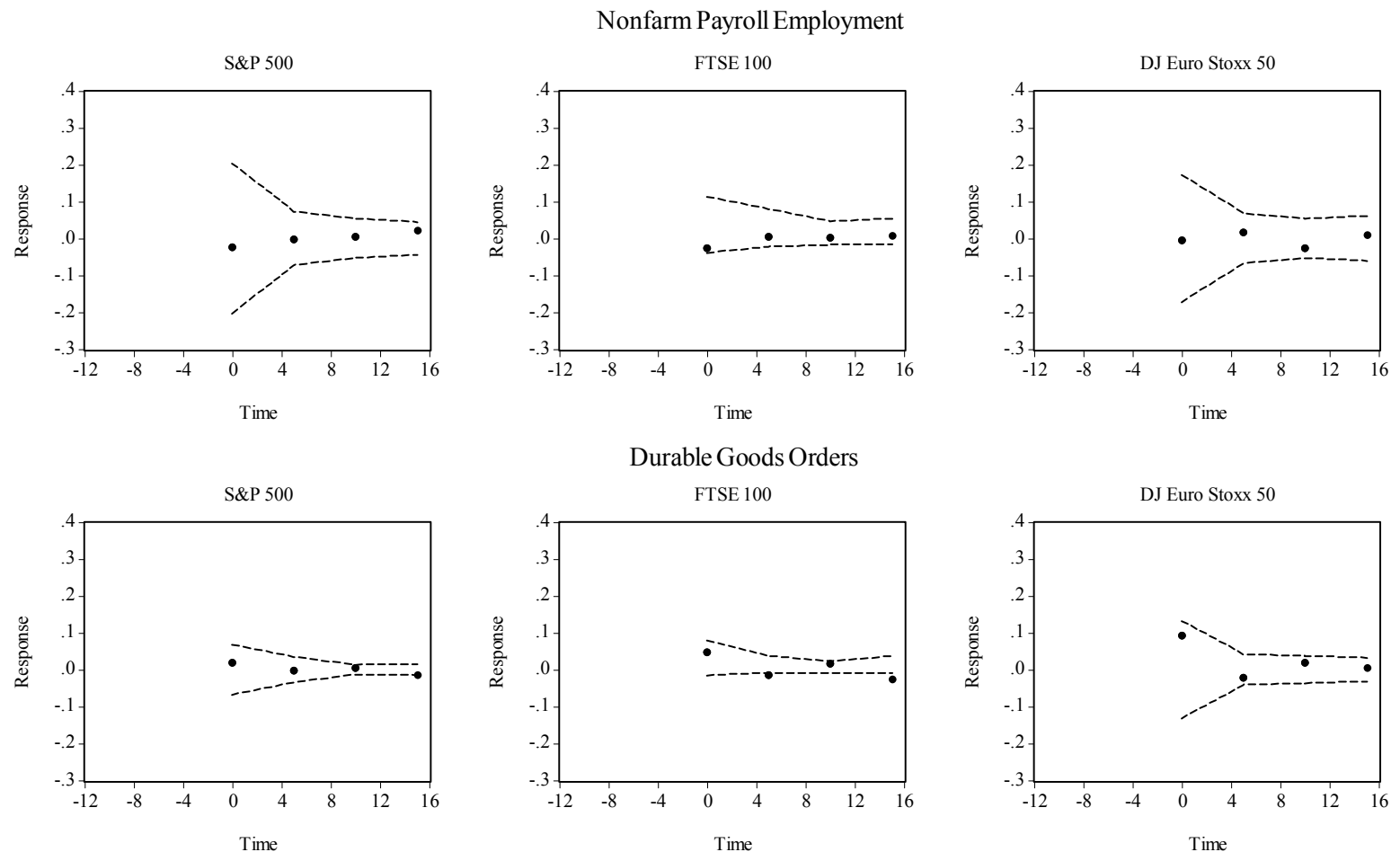

Durable Goods Orders
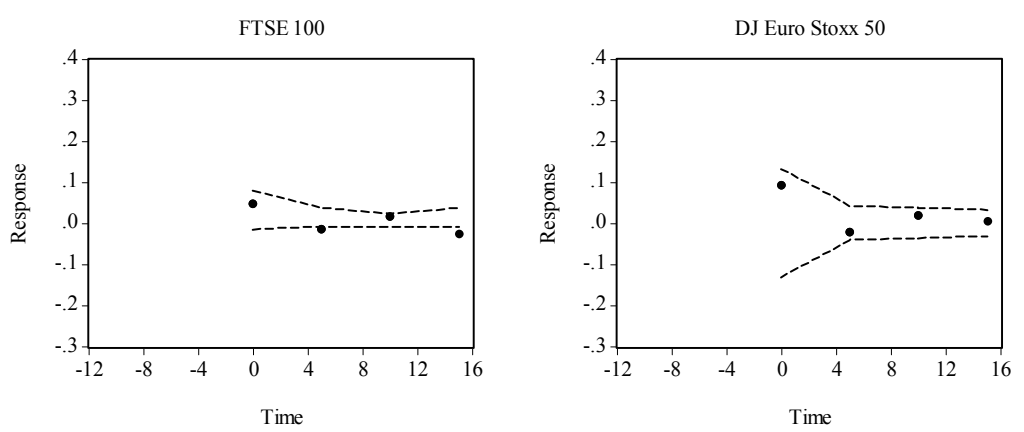

Producer Price Index

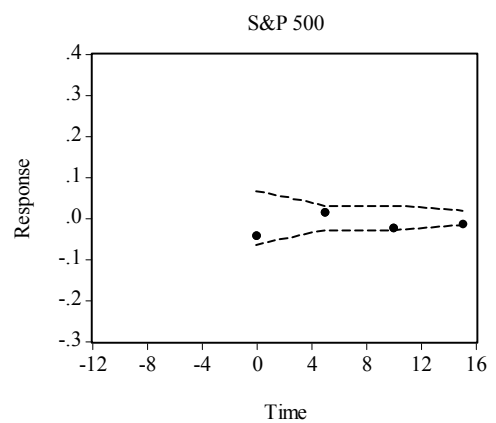

FTSE 100

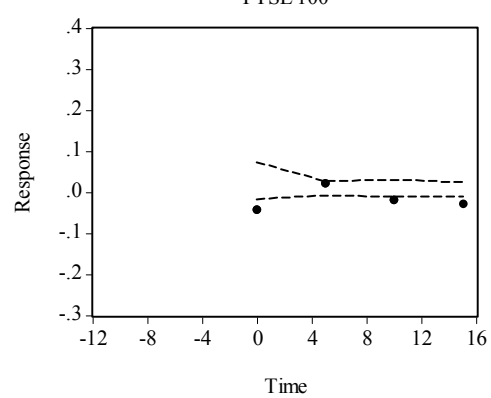

DJ Euro Stoxx 50

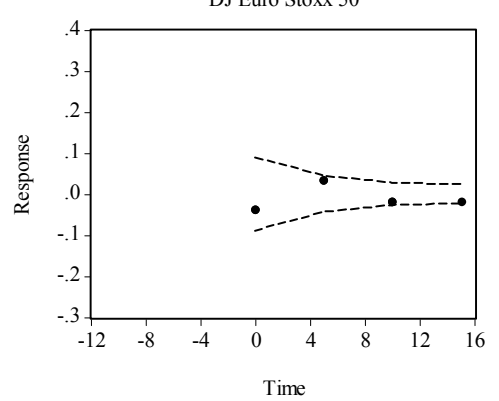

Initial Unemployment Claims
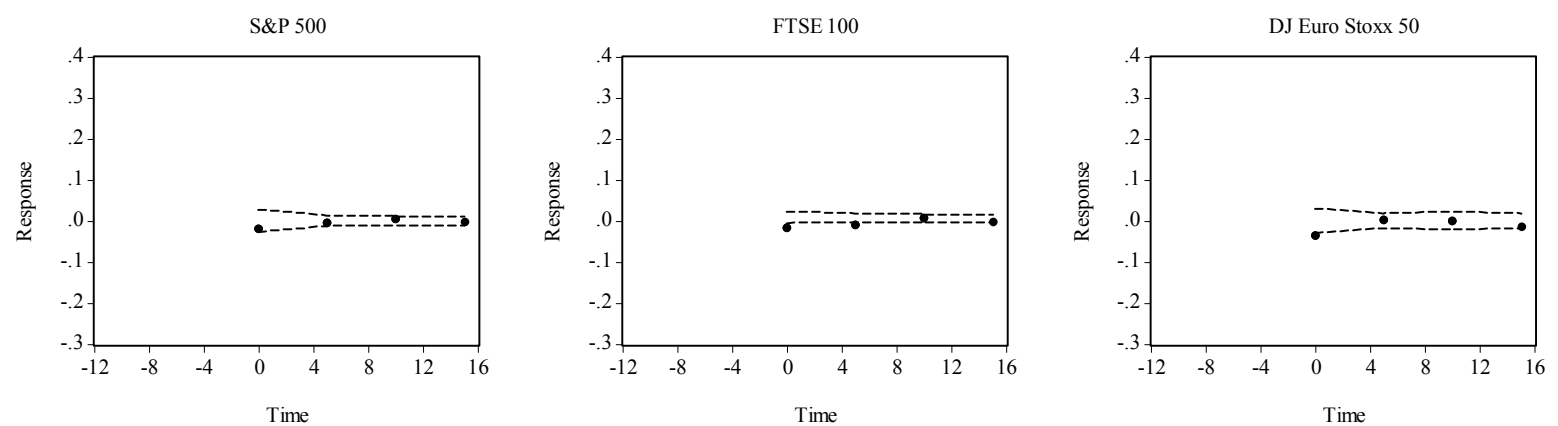
Figure 1B

\section{Bond Market News Announcement Responses, Expansion Sample}
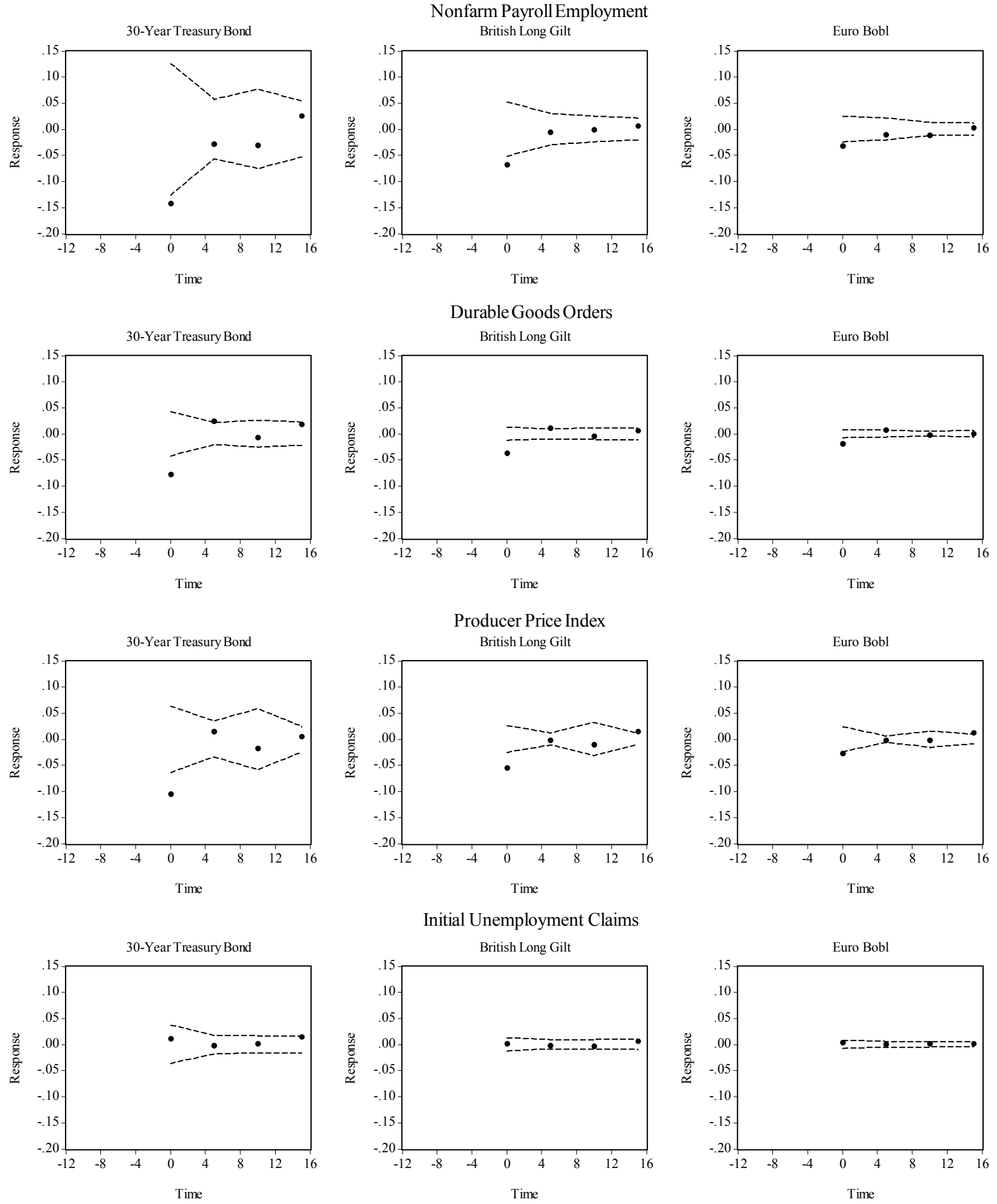
Figure 1B (continued)

Foreign Exchange Market News Announcement Responses, Expansion Sample
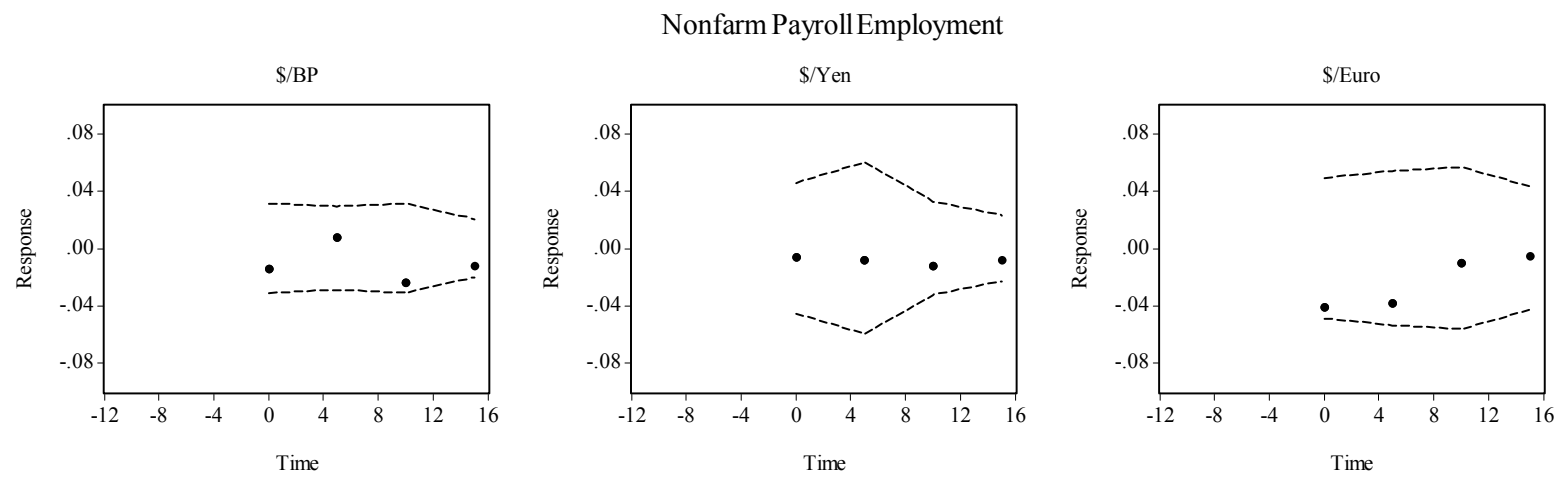

Durable Goods Orders

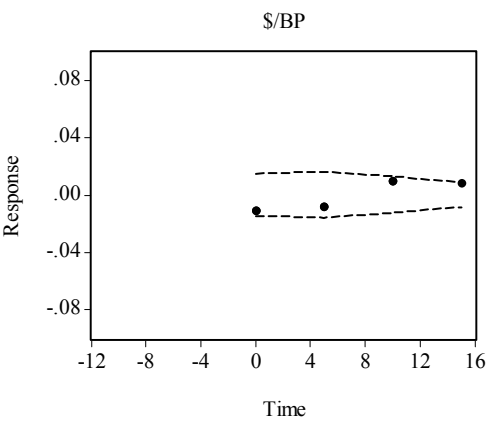

\$YYen
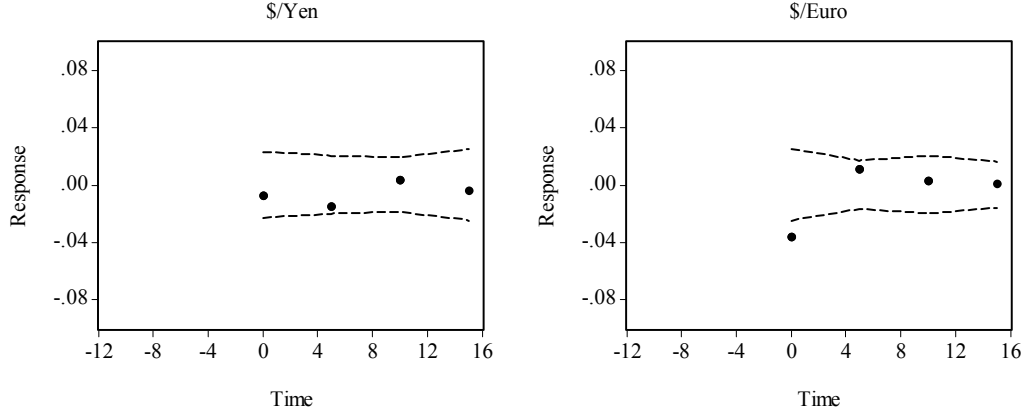

Producer Price Index

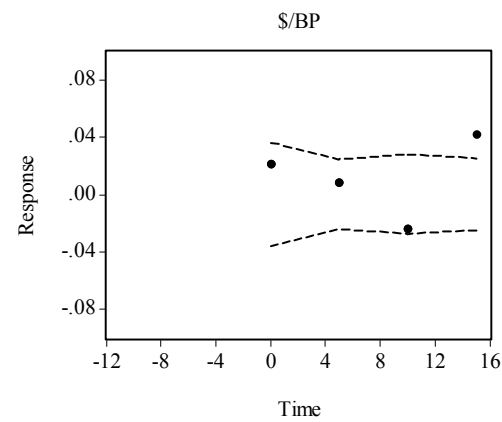

$\$ /$ Yen
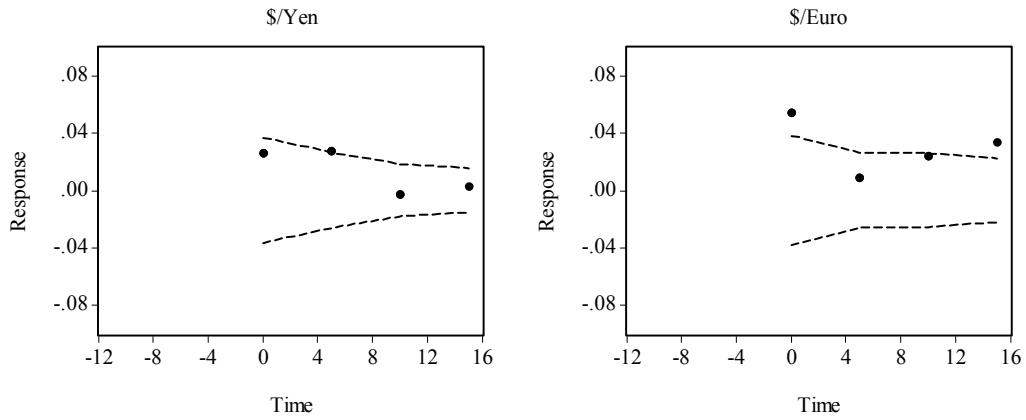

Initial Unemployment Claims
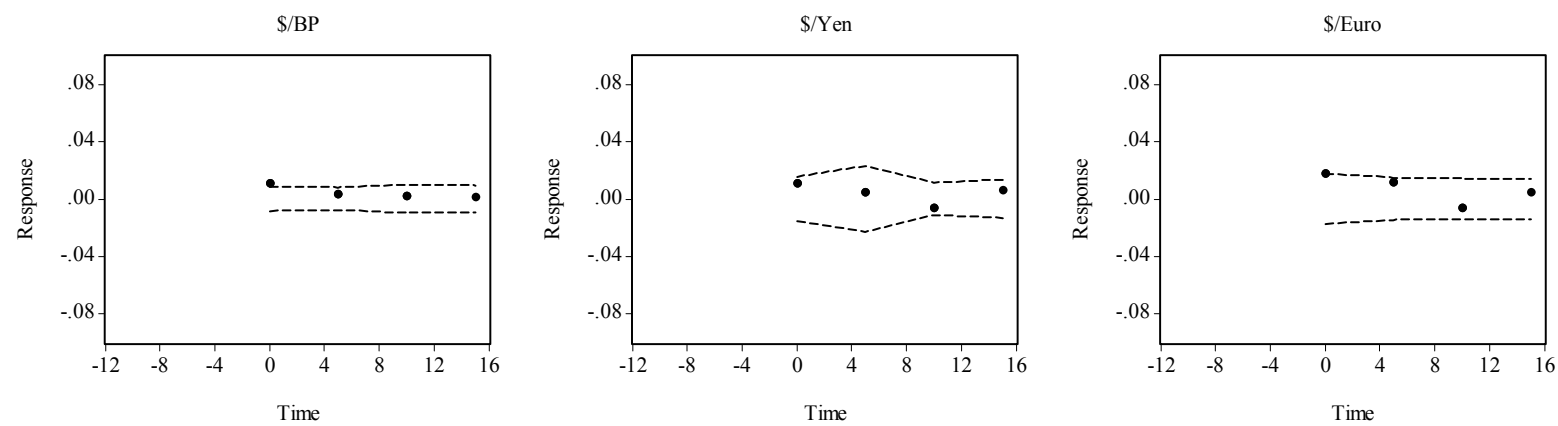
Figure 1B (continued)

Stock Market News Announcement Responses, Expansion Sample
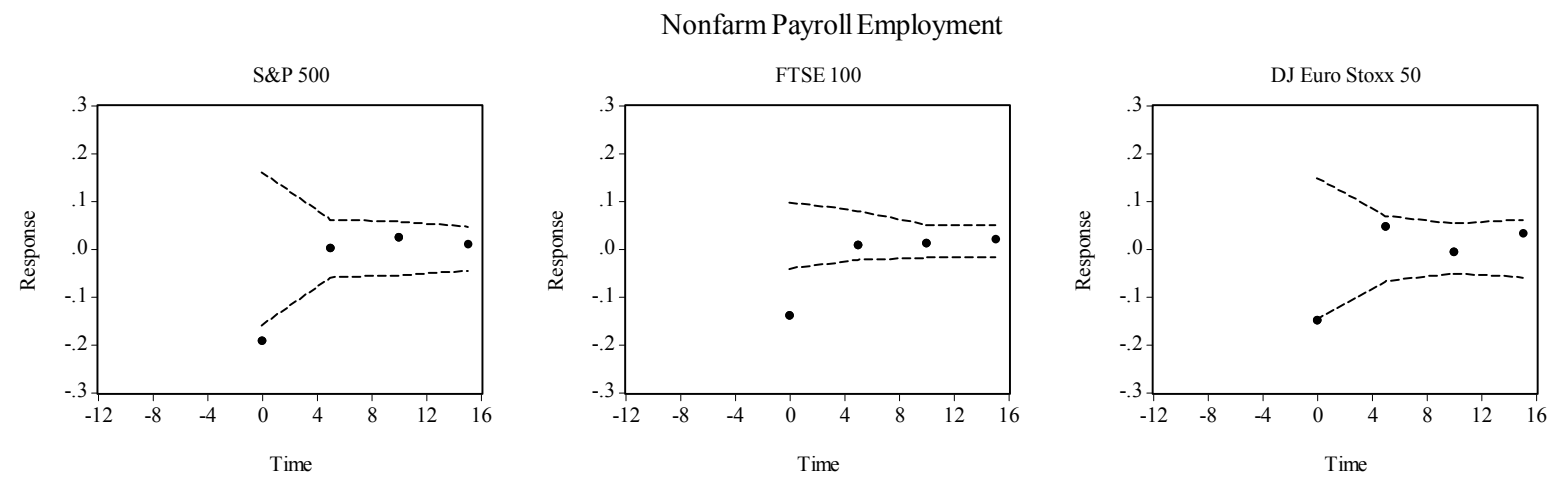

Durable Goods Orders
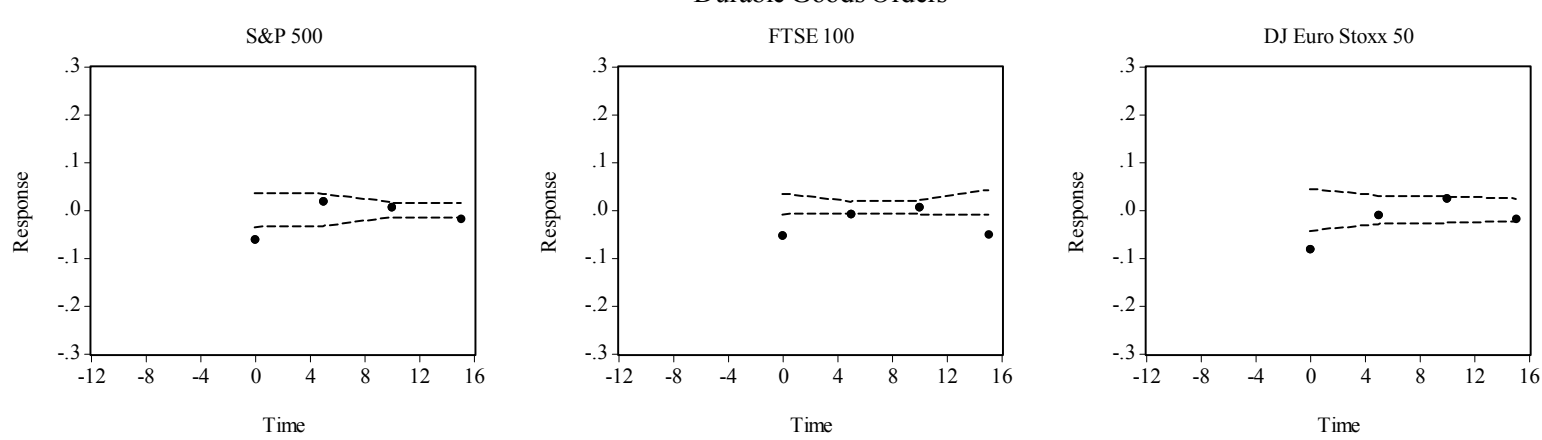

Producer Price Index
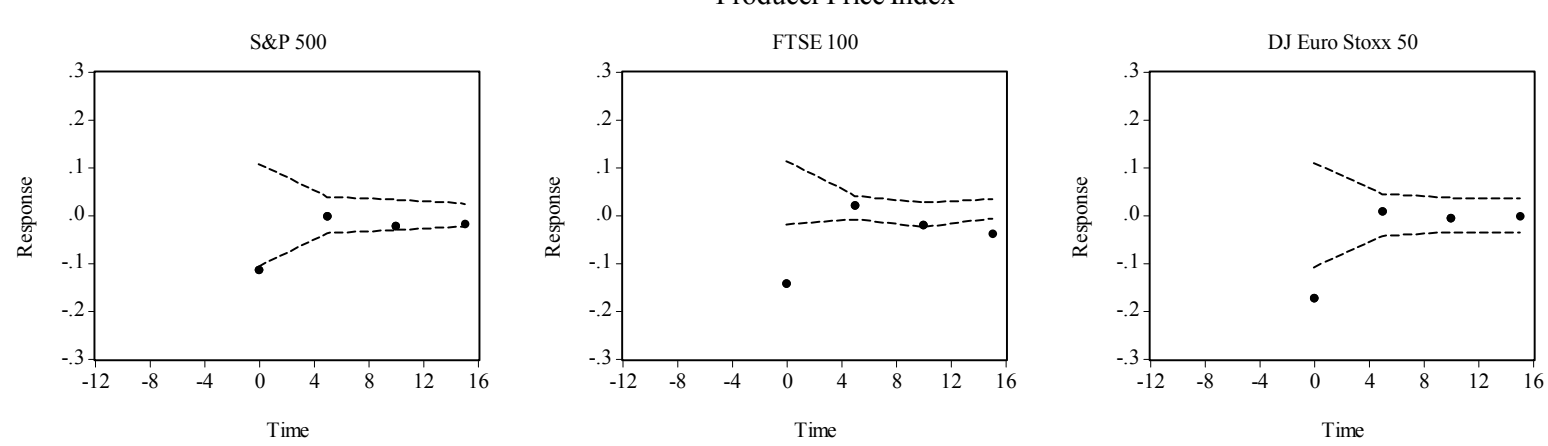

Initial Unemployment Claims
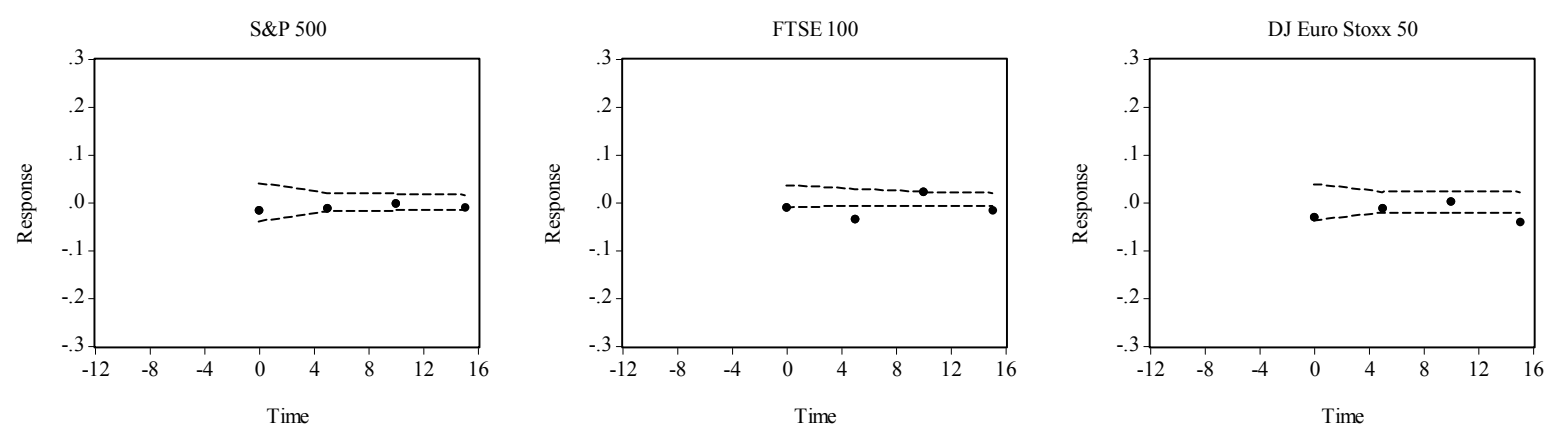
Figure 1C

Bond Market News Announcement Responses, Recession Sample
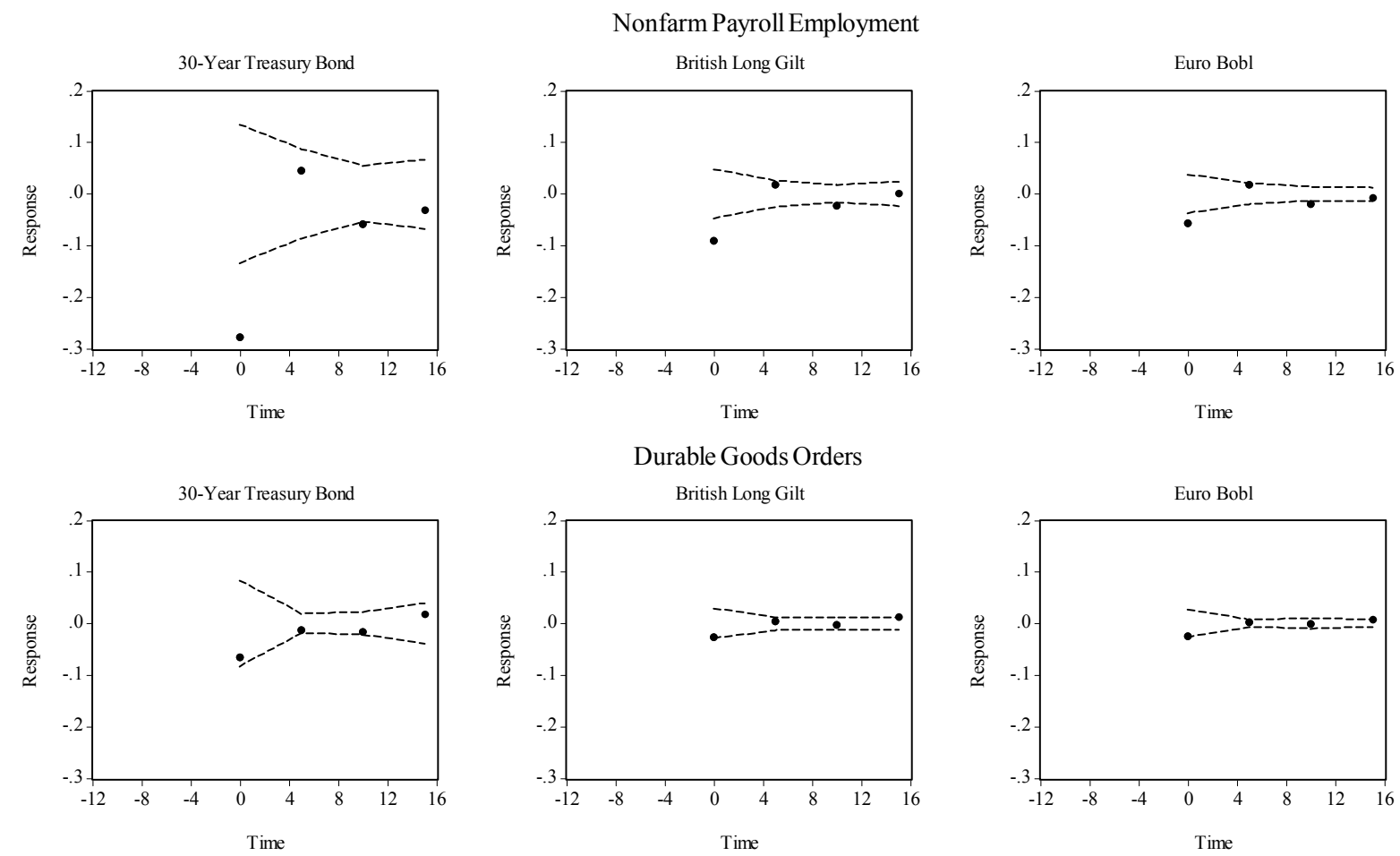

Durable Goods Orders
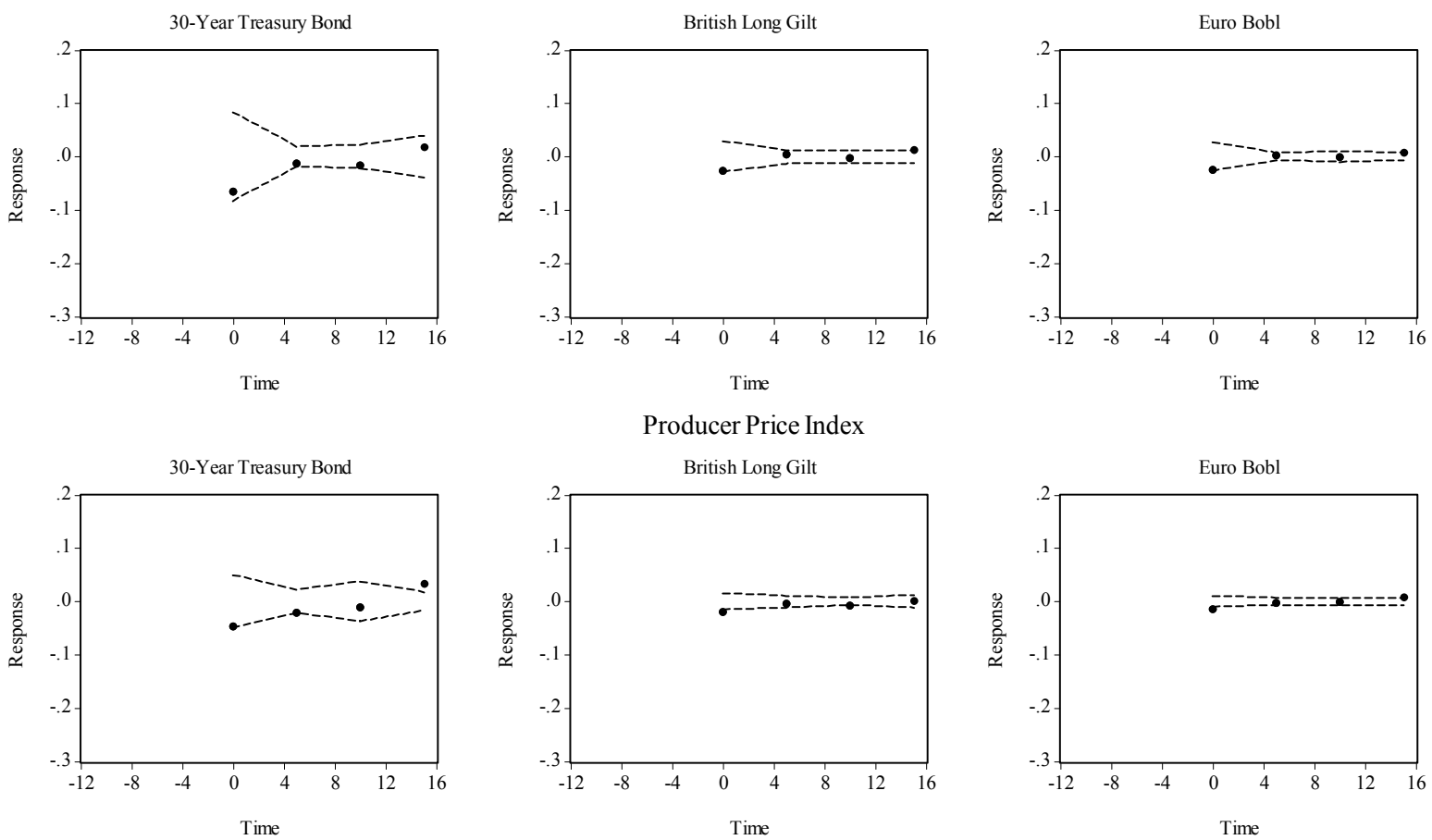

Producer Price Index
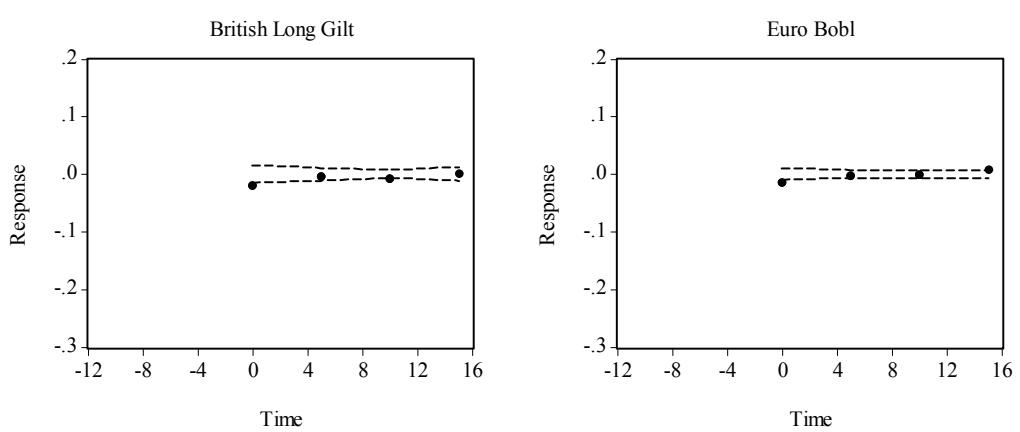

Initial Unemployment Claims
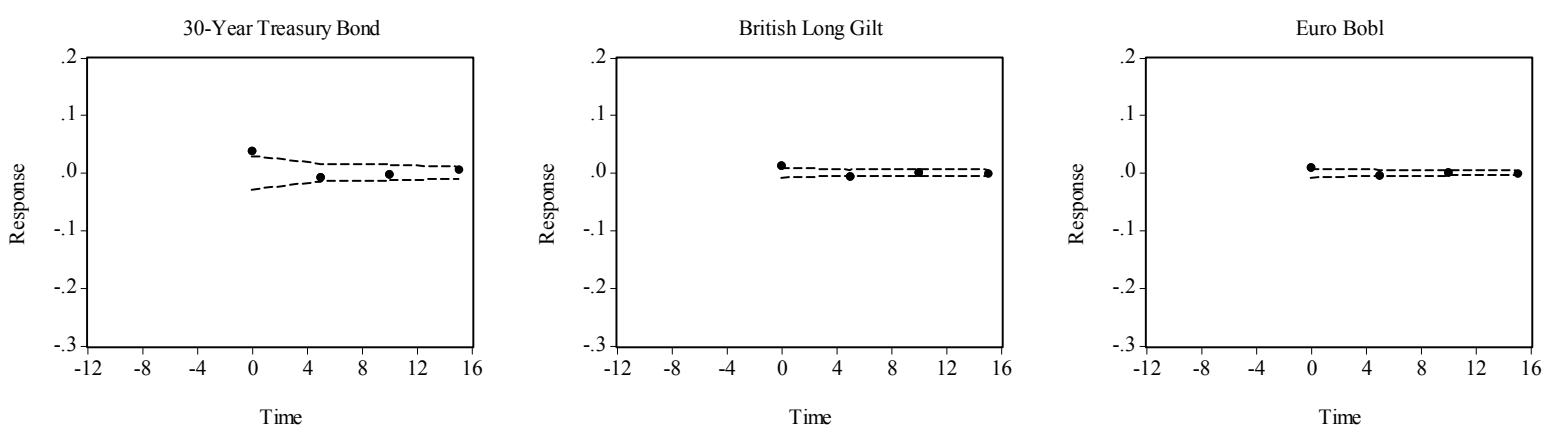
Figure 1C (continued)

Foreign Exchange Market News Announcement Responses, Recession Sample
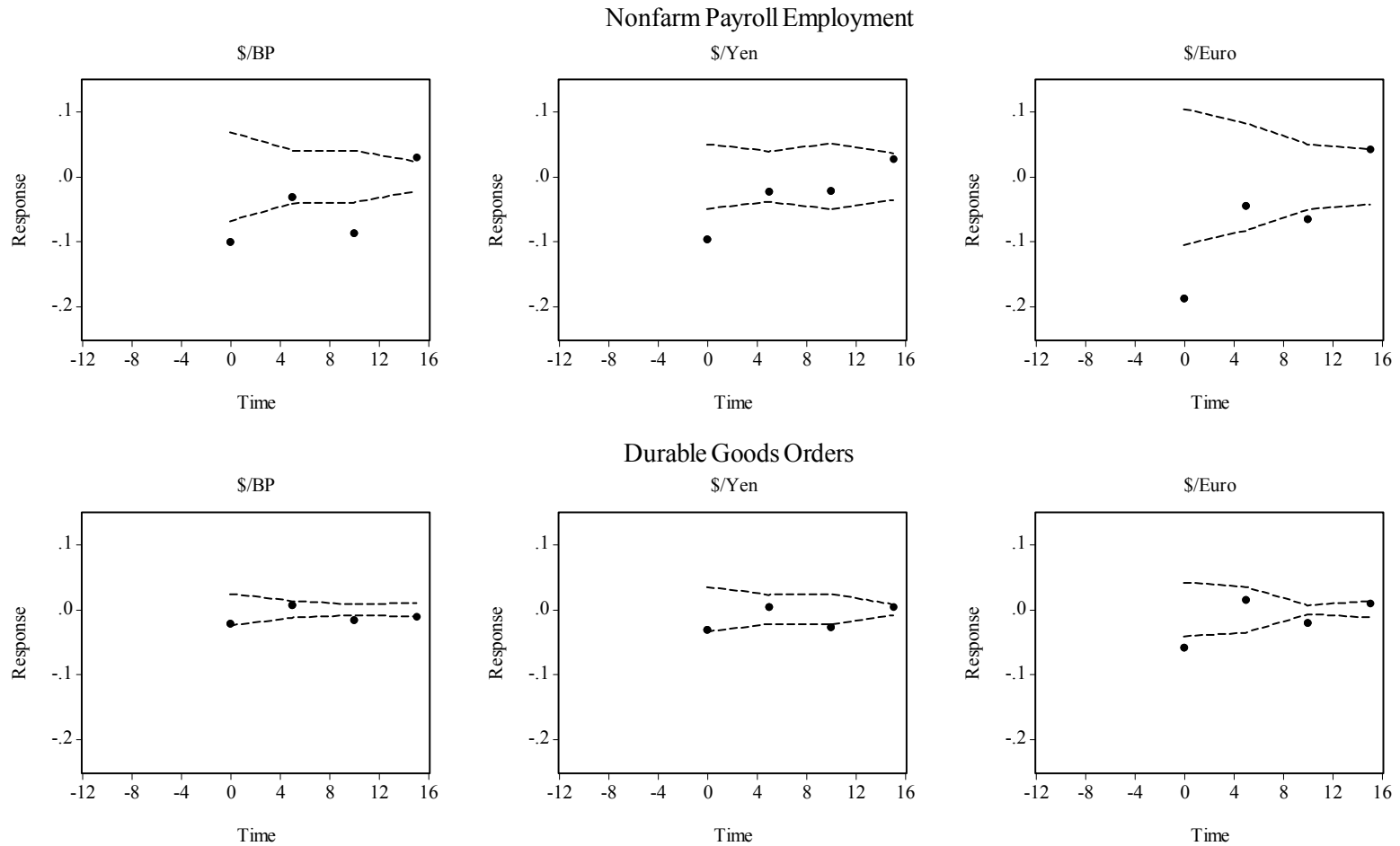

Durable Goods Orders
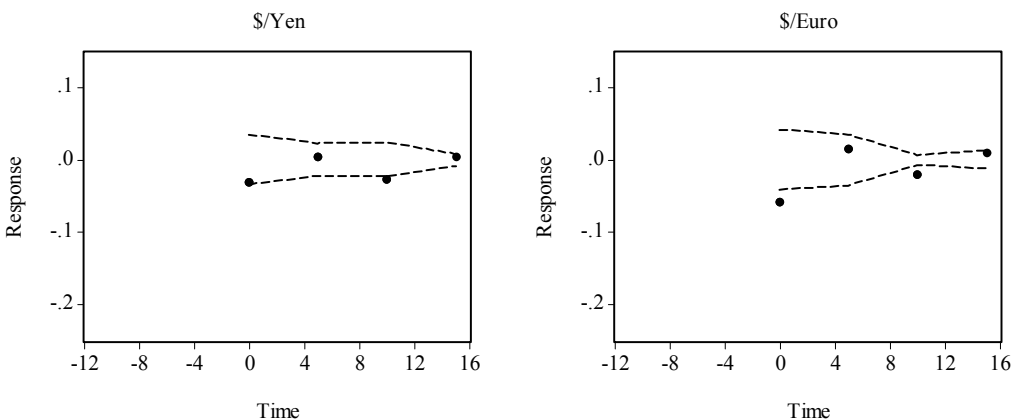

Producer Price Index
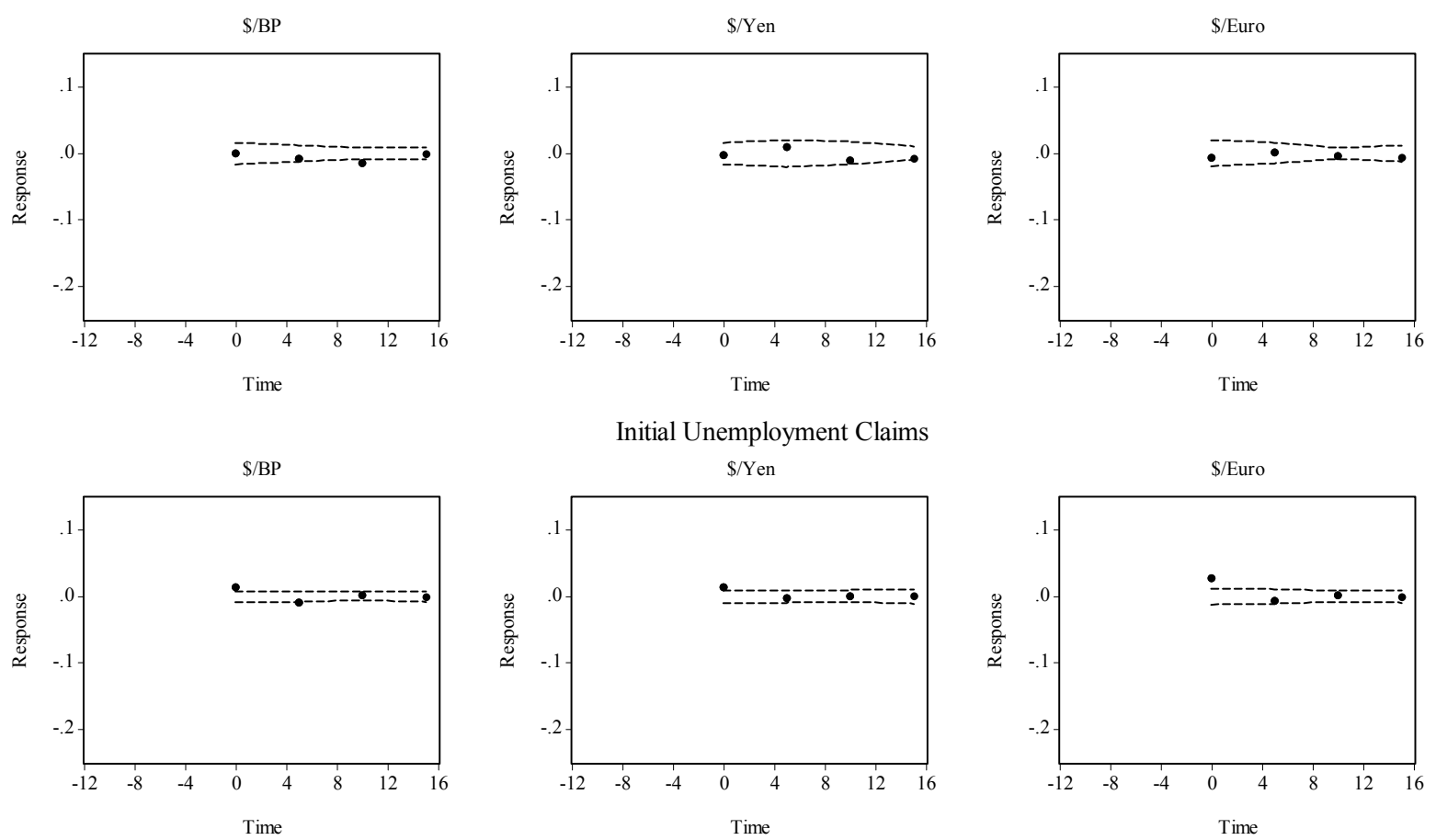

Initial Unemployment Claims
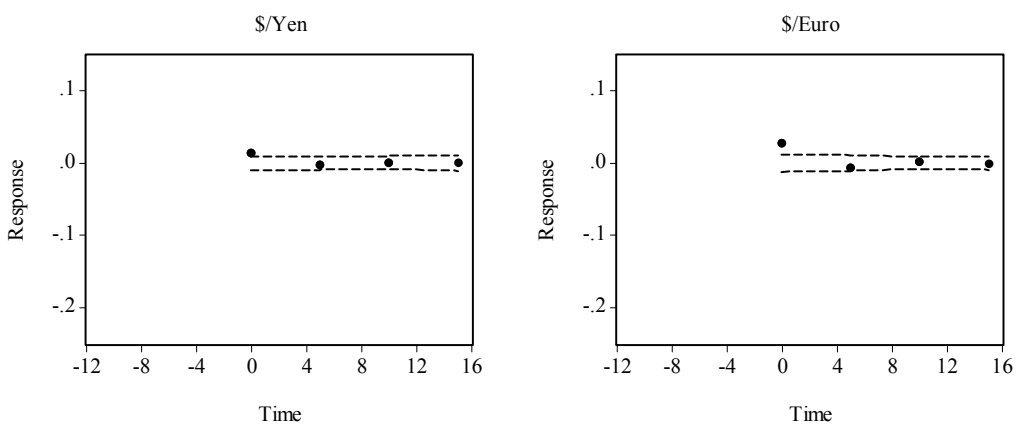
Figure 1C (continued)

Stock Market News Announcement Responses, Recession Sample
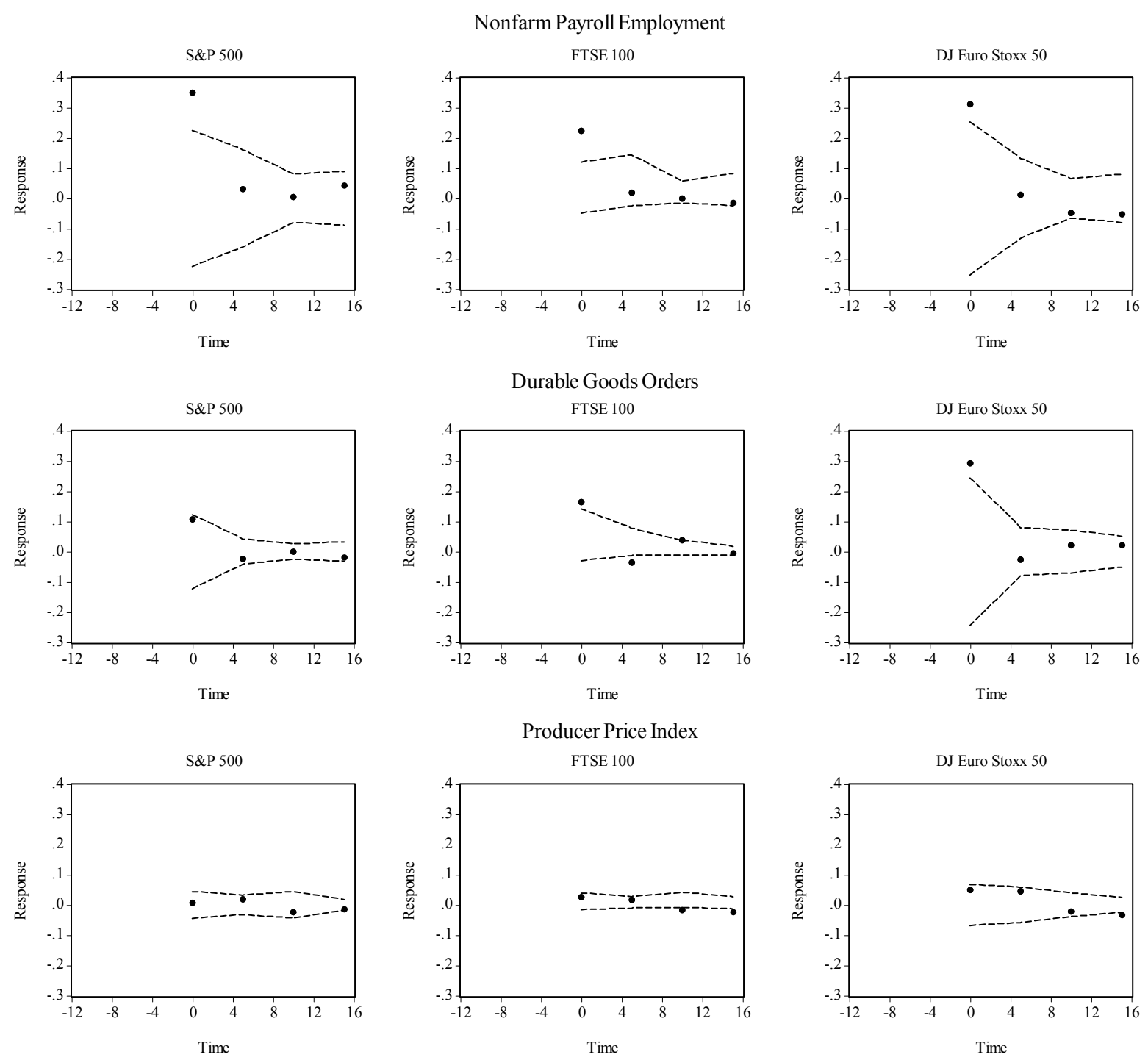

Initial Unemployment Claims
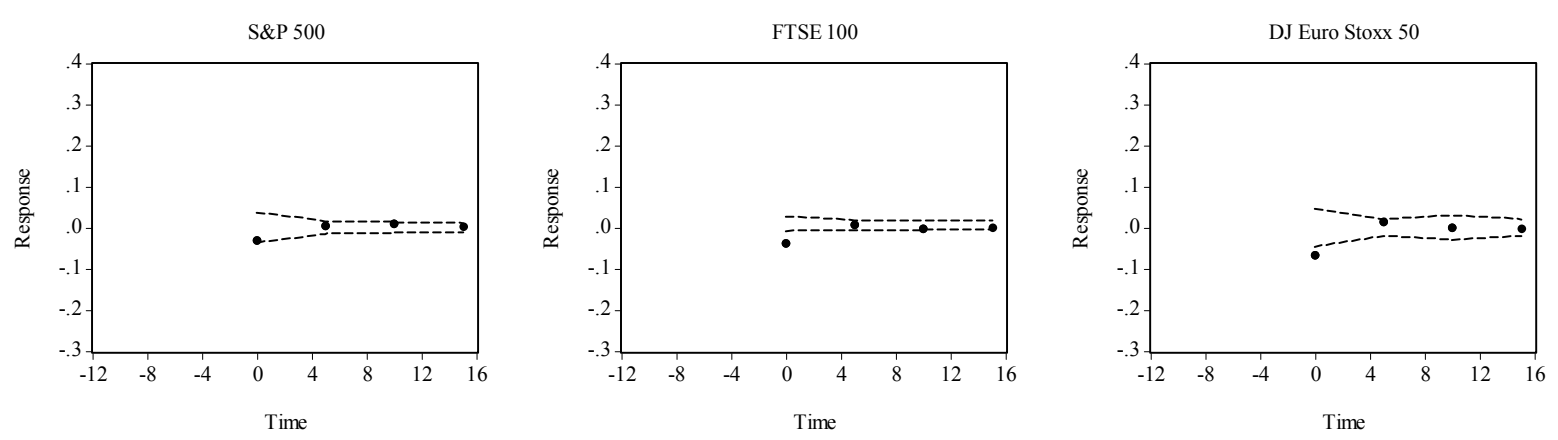

Notes to Figures 1A, 1B and 1C: We graph the news announcement response coefficients from the weighted least squares estimation of equation (4.2), corresponding to the responses at the announcement time, and five-, ten-, and fifteen-minutes after the announcement. We also show two heteroskedasticity consistent standard error bands under the null hypothesis of a zero response. The common full sample goes from July 1, 1998 through December 31, 2002. The expansion sample spans July 1, 1998 to February 28, 2001. The recession sample covers the period from March 1, 2001 to December 31, 2002. 
Figure 2A

Daily Realized Correlations

on Nonfarm Payroll Announcement Days

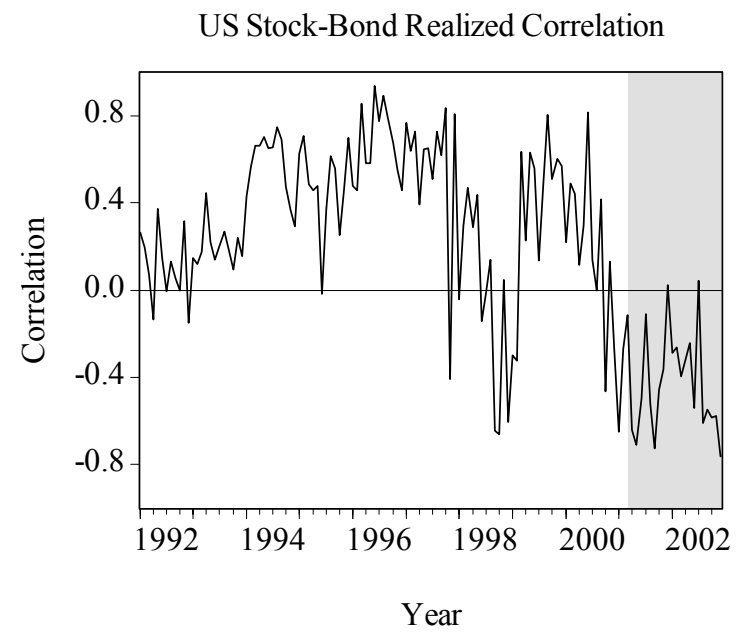

British Stock-Bond Realized Correlation

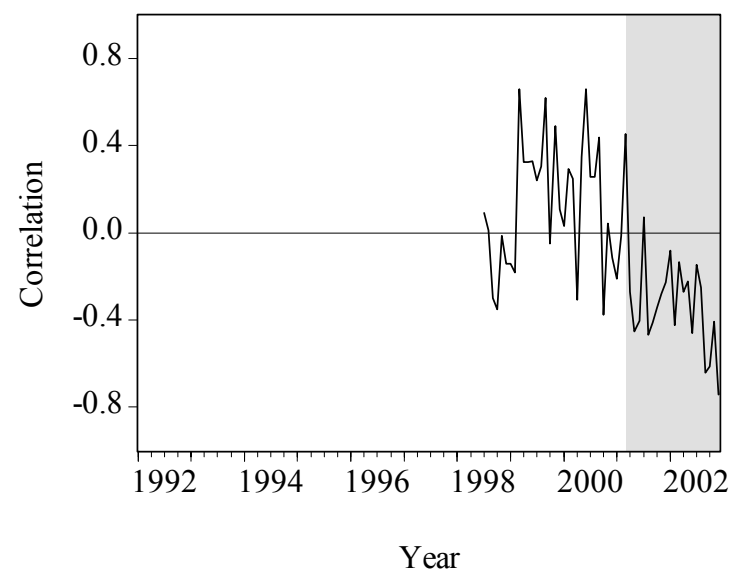

German Stock-Bond Realized Correlation

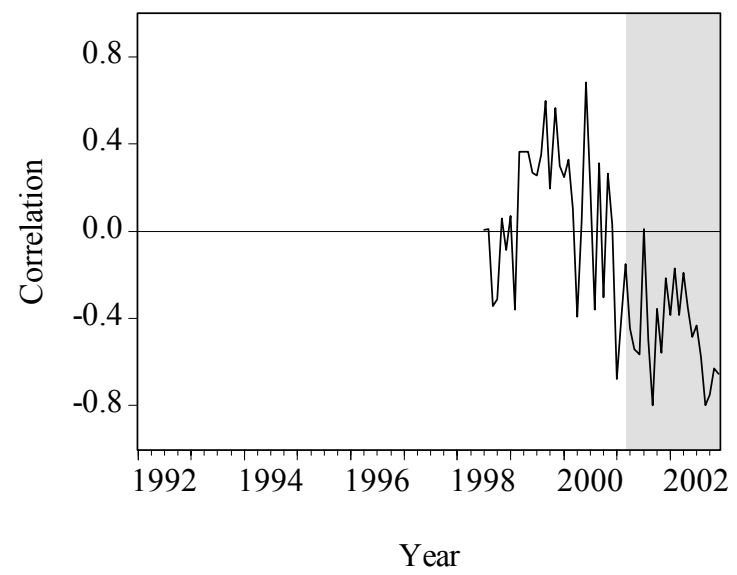

Notes to Figure 2A: We graph the daily U.S., British and German stock-bond realized correlations, as detailed in the main text, for Nonfarm Payroll announcement days from January 1, 1992 through December 31, 2002. The shaded area corresponds to the U.S. recession sample from March 1, 2001 to December 31, 2002. 


\section{Figure 2B \\ Monthly Realized Correlations}
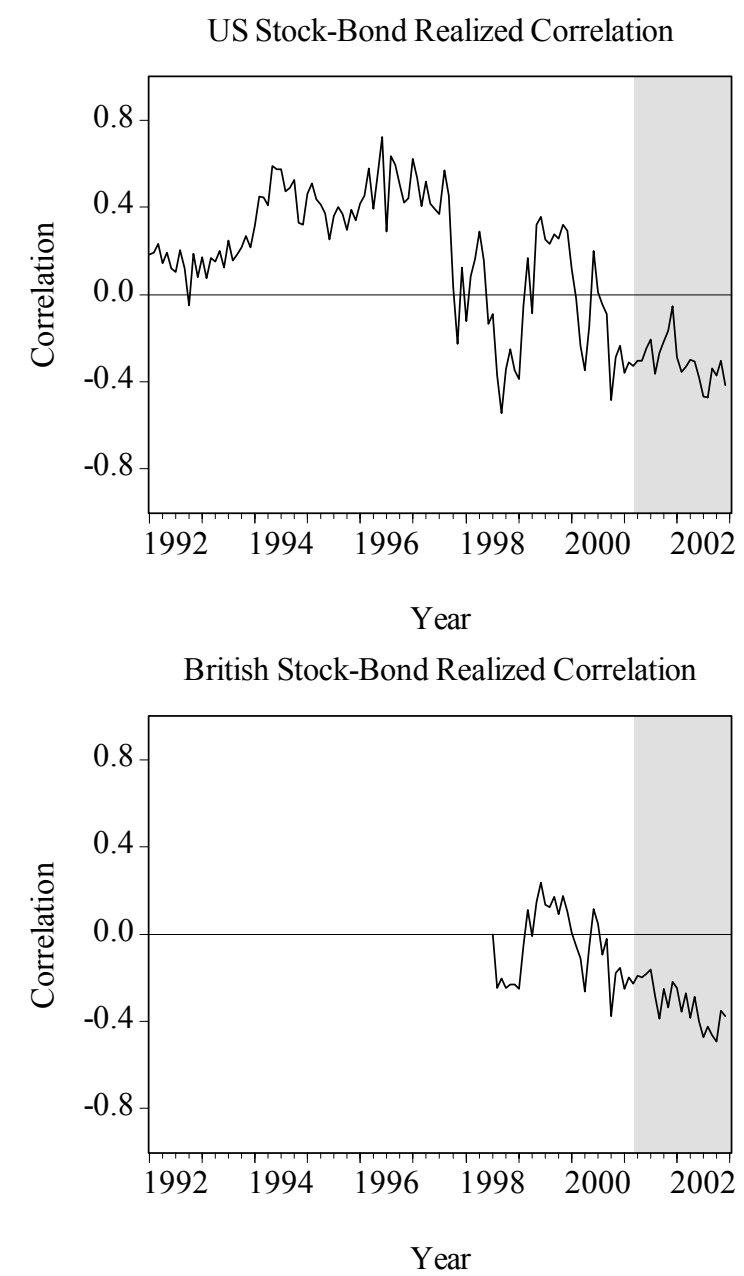

German Stock-Bond Realized Correlation

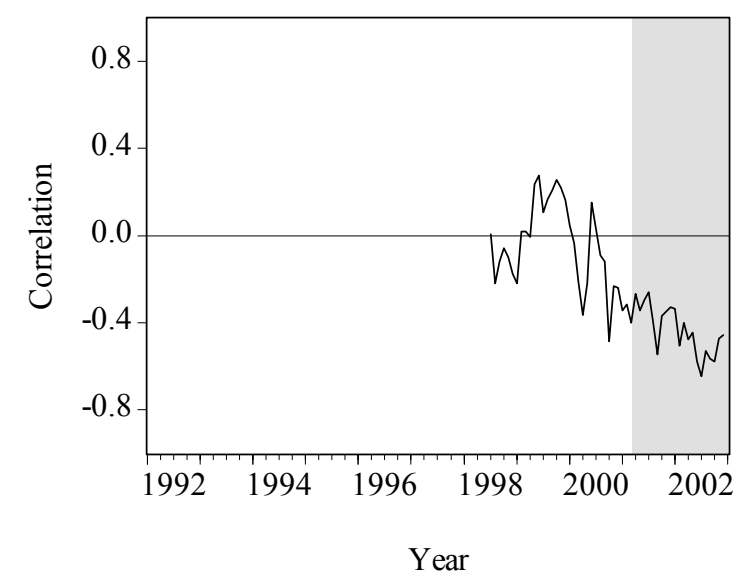

Notes to Figure 2B: We graph the monthly U.S., British and German stock-bond realized correlations, as detailed in the main text, from January 1, 1992 through December 31, 2002. The shaded area corresponds to the U.S. recession sample from March 1, 2001 to December 31, 2002. 